\title{
Participation in place-making: \\ Enhancing the wellbeing of marginalised communities in Aotearoa/New Zealand
}

\author{
Andrea Ricketts
}

A thesis

submitted to Victoria University of Wellington in fulfilment of the requirements for the degree of Masters of Architecture

Victoria University of Wellington

Te Whare Wānanga o te Ūpoko o te Ika a Māui

Aotearoa New Zealand 


\section{Abstract}

This research examines the relationship between community participation in public space decisions and the wellbeing of marginalised communities. A cross-disciplinary literature review and four New Zealand case studies investigate if community participation in public space design enhances the wellbeing of marginalised communities, and if so, how this is best done.

The findings from the literature review, case study interviews and surveys show strong evidence that participation in place-making does enhance the wellbeing of marginalised communities in New Zealand. Furthermore, four aspects of community wellbeing stand out as being most significantly enhanced by participatory processes. These are an increased empowerment, enhanced vision-making and advocacy capabilities, an increased collective action and an enhanced sense of pride, belonging and connectedness to community. The findings also identify a comprehensive range of processes that are critical to effective participatory projects. The range includes community-led support initiatives, community involvement in social analysis, celebration events, engagement processes for visioning and decision-making, work-group collaboration, involvement in implementing, partnerships with stakeholders and post-project involvements. Two actions that are critical to gaining authentic engagement in these processes is participant involvement in the initial preparation processes and the appointment of a community advocate to plan and facilitate the participatory process.

This research is distinguished by identifying effective participatory processes that are typically under-utilised or not considered in conventional public consultation work. Furthermore, it provides strong evidence that these participatory processes enhance the wellbeing of marginalised communities. 


\section{Acknowledgements}

This research has been inspired by my friends who are committed to building communities that are centred on justice and hope.

Debbie and Ngahau Davis, thank you for sharing your community's story and your passion for the people of Moerewa. To my Stillwaters and Urban Vision whānau, I have been significantly shaped by knowing you all for many years, the approaches to this research have largely come from the lessons I have learnt from working alongside you. To Steve, my friends and family, thank you for all the encouragement and practical support you have given to me throughout this research. Me te aroha nui e hoa ma, mā Te Atua e manaaki.

To my supervisor Graeme McIndoe, I have greatly appreciated the encouragement and wisdom you have brought to guiding my work which has kept me on track and made the process very enjoyable and rewarding. Thank you.

Thank you to the interview and survey participants associated with Ngai Tupoto ki Motukaraka marae, YFC and the former S.A.S club at Alfred Cox skatepark, He Iwi Kotahi Tātou trust and the Moerewa community, Kōkiri Te Rahuitanga trust and Kura Piripono, you have all been so generous with your time. All the best with your current and future community endeavours.

To Rau Hoskins, Kay Saville-Smith, David Thorns, John Gray and Gordon Holden, thank you for sharing your experience and advice earlier on in this research.

To the team at Centre for Housing Research Aotearoa New Zealand (CHRANZ), thank you for your research and financial support.

Me te mihi nui mō ā koutou manaakitanga. 


\section{Contents}

Abstract 2

Acknowledgements $\quad 3$

Table of contents 4

List of illustrations \& interviewees $\quad 5$

\section{Introduction}

I.I Context \& purpose 6

I.2 Research question \& aim 7

I.3 Methodology 9

\section{Literature Review}

2.I Community participation in place-making 13

$\begin{array}{ll}\text { Definition, politics and values } & 13\end{array}$

$\begin{array}{ll}\text { Conventional public space design without public participation } & 14\end{array}$

$\begin{array}{ll}\text { Practices of participation } & 19\end{array}$

Benefits of participation 28

2.2 Marginalised communities \& community wellbeing 31

Defining marginalised communities in Aotearoa/New Zealand 31

The impacts of mono-functional \& socially homogenous urban development 32

Defining community wellbeing 33

Links between local participation \& community wellbeing 34

Public space developments that enhance community wellbeing 35

2.3 Literature review summary findings 36

\section{Measuring Community Wellbeing}

3.I Community wellbeing indicators 38

3.2 Creating a case study indicator framework 45

\section{Case Studies}

4.I Case study methodology 5 I

4.2 Description \& findings $\quad 59$

Gisborne: Skateboarding park youth centre $\quad 59$

Moerewa: Township \& economic initiative developments $\quad 77$

Motukaraka: Marae \& housing developments 95

Otara: Urban papakāinga complex 110

$\begin{array}{ll}\text { 4.3 General case study trends \& findings } & 127\end{array}$

4.4 Case study summary findings 13 I

5 Discussion \& Conclusions

5.1 Overarching conclusions $\quad 135$

$\begin{array}{ll}5.2 \text { Significance of conclusions } & 146\end{array}$

6 References 147

7 Appendices 153 


\section{List of Illustrations}

Table I

Table 2

Table 3

Table 4

Table 5

Table 6

Table 7

Table 8

Form I

Form 2

Form 3

Figure I

Figure 2

Figure 3
Literature review summary findings

Case study overarching themes \& dimensions derived from five theories

Case study indicators derived from five theories

Case study framework and survey questions

Survey findings

Case study summary findings (condensed version)

Case study summary findings

Integrated findings: four predominant community wellbeing

enhancements

p. 136

Appendices

Appendices

Appendices

p. 22

p. 45

Framework structure and terms

Participatory process summary

p. 127

\section{List of Interviewees}

Breckell, Graham. (August 2006). Transcribed interview. Recorded in Gisborne.

Davis, Ngahau. (August 2006). Transcribed interview. Recorded in Moerewa.

Henwood, Wendy. (November 2006). Telephone interview.

Hoskins, Rau. (August 2006). Transcribed interview. Recorded in Auckland.

Kingsbeer, Shane. (August 2006). Transcribed interview. Recorded in Gisborne.

McMillan, Terry. (August 2006). Transcribed interview. Recorded in Gisborne.

Tamanui, Zena. (December 2006). Transcribed interview. Recorded in Otara.

Tims, Dave. (August 2006). Transcribed interview. Recorded in Gisborne.

White, Paul. (November 2006). Transcribed interview. Recorded in Hokianga. 


\section{Introduction}

\section{I.I Context and purpose}

The design of public space involves social decisions. Public spaces can be powerful mediums for expressing society's values through built forms that determine the living patterns of communities. These observations raise questions for the ongoing practice of architecture, urban design and related disciplines. Are the designers of public spaces representing the interests of the entire public or only the sectors that have the power to decide and the ability to reap the advantages? Who represents the public in the planning of neighbourhoods, town centres and mass housing complexes? Traditionally, de Carlo claims, architects and related disciplines have limited their relations to the public that is represented by the elite: the client developers and power brokers rather than the users and bearers of architecture. Both de Carlo and Hawkes suggest that too often decisions about public environments are delegated and limited to those who are deemed 'professional experts'.' And at the same time, questions arise about why various spaces become dilapidated and why the inhabitants feel no responsibility to defend the environment. These types of observations suggest there is a need to integrate the public more authentically into decision-making about public environments.

Community design [public space design] is based on a recognition that professional technical knowledge is often inadequate in the resolution of societal problems, and it represents the addition of a moral and political content to professional practice. ${ }^{2}$ The designer's job is no longer to produce finished and unalterable solutions but to extract solutions from a continuous confrontation with those who will use his/her work. $^{3}$

Community and public space planning practices in relation to enhancing community wellbeing are developing in specific policy areas of the New Zealand government. In 2002 the New Zealand government created an Urban Affairs portfolio, intending to strengthen the Ministry for the Environment's existing public space design work. Cheyne stresses that within public space planning guidance, "the potential exists for a focus on social dimensions" and that "the challenge will be to move beyond the physical and environmental aspects of urban design." 4 This evaluation identifies the need to create community planning processes that develop and enhance the community wellbeing of citizens. Furthermore, participatory measures are promoted in the Local Government Act 2002: Section 93, requiring local authorities to create a 'long term council community plan' (LTCCP), which, amongst other

\footnotetext{
I de Carlo, 1992, 2005. p. 8; Hawkes, 2003. p. 16

2 Comerio, 1984. pp. 21-22

3 Sanoff, 1990. p. 7

4 Cheyne, 2006. p. 32
} 
points, specifies the provision of "opportunity for public participation in decision-making processes on activities to be undertaken by the local authority." 5

The principles of participatory design draw attention to the political nature of public space design as it affects community life; it raises awareness of who controls the design decisions and who is implicated by the decisions. This research is concerned with how the public exercises responsibility for the physical environments they live, work and play in.

Conventional roles of the professional 'expert' and the forced passivity of 'users' are critiqued and proposals made that reframe each as contributing their particular expertise to the process. Various development models and methodologies are explored that facilitate the outworking of community aspirations through the vehicle of participatory decision-making about physical environments.

The inspiration for this research came from the discovery of an effective model of local involvement in transforming the social, environmental and economic circumstances of a community. Moerewa, in the Far North district of New Zealand, is a small town that embarked upon a process of community mobilization and township redevelopment in response to the historical and continuing negative pressures they were experiencing. The most significant finding was that the community's involvement in the participatory process empowered the community to take responsibility for addressing the social needs and creating the physical environment changes.

\section{I.2 Research question and aim}

The aim of the research is to investigate the method and benefits of a community participating in decision-making processes about their public spaces. The scope of the investigation is focused on groups within New Zealand communities who are marginalised by less access to social, economic, environmental resources and a lack of involvement in public decision-making. The premise for this scope is the democratic responsibility of ensuring all of society has equal access to decision-making and resources.

Participation might be seen as direct public involvement in decision-making processes: citizens share in social decisions that determine the quality and direction of their lives. ${ }^{6}$

The need for this ongoing commitment is illustrated by numerous research and statistics that implore society to address the disempowerment experienced by some communities in New Zealand. In policy work undertaken by Christchurch City Council NZ, poverty for those who experience it is broadly defined as "an inability to influence outcomes in a regular and

\footnotetext{
5 Cheyne, 2006. p. 34

6 Sanoff, 1990. p. 6
} 
meaningful way" 7 caused by the lack of participation and disconnection in societal affairs, in addition to the typically defined lack of financial income.

By exploring research and working models that provide examples of initiatives seeking to enhance public participation, we can better understand how the participatory process has the capacity to assist people who experience disempowerment to be reconnected with decision-making processes. Beyond the fulfilment of equal opportunities for people, this thesis tests the notion that participatory place-making can also enhance the wellbeing of communities that have traditionally had public spaces designed 'for' them.

From this context the research question was formed - Does community participation in place-making lead to the enhanced community wellbeing of marginalised communities, and if so, how?

To provide an initial overview of the definitions contained in this question, community participation is defined as the act of engaging community members in collaborative processes that lead to decision-making and implementing the decisions.

Place-making uses these types of participatory processes to plan and create public places for the local community. These public places are typically important to the social life, economy and environmental aspects of the community.

The term community is defined as both a group of people who belong to the same geographical area and those who identify as a group through their similar values and circumstances.

Community wellbeing is usually defined as communities who experience healthy levels of social, environmental, governmental, economic \& cultural welfare. In this research, the scope is narrowed to dimensions of community wellbeing that are impacted by the inter-relational nature of participation; hence the dimension of economic growth is excluded from the research scope.

The definition of marginalised communities has been discussed above and can be summarised as communities of people who experience a continuous lack of positive welfare. This has resulted from negative pressures upon their lives and these pressures make them less able to participate fully in society.

${ }^{7}$ Christchurch City Council N.Z., Retrieved I I.04.06. 


\section{I.3 Methodology}

\section{Multiple method rationale}

Three methods of investigation have been chosen to explore the thesis question. The literature review provides contemporary and classic theory and practice evidence of the link between participatory place-making and community wellbeing. The case study research uses the two methods of surveying and interviewing for gaining both the quantitative and qualitative data required to measure the extent of enhanced community wellbeing and how it has been enhanced.

The sample population for measuring the enhancement of community wellbeing is exclusive to the participants of the place-making projects. Despite the seemingly small total sample number of twenty people, the survey response rate from the contactable respondents for each case study ranged from $63 \%$ up to $86 \%$. The small sample size is limited by the size of the project participant group.

Nine interviews in total were conducted across the four case study communities, primarily with people that had a key role in each place-making project.

\section{Verification \& validation of the interpretation of information}

To ensure the internal validity of the findings, five strategies will be utilised.

Triangulation of information: The triangulation of data mentioned above; collecting data from the literature review, surveys and interviews, aims to converge findings across the qualitative and quantitative methods.

Member checking: The method of 'member checking' requires the key contacts (interviewees) of each case study community to check the interpretations of the data during the analysis stage to ensure the account is accurate.

Clarification of researcher bias: Due to choosing case studies that have been successful, I acknowledge that there is a potential researcher bias to the study.

Presentation of negative or discrepant data: The research presents some findings that are contrary to the overarching conclusions and the inclusion of these add credibility to the general account.

Mitigating the potential 'Hawthorne effect' of interviews and surveys: The Hawthorne effect is where research participants articulate the expected answers not as an effect of the experiment but due to the attention that has been paid to their situation. ${ }^{8}$ In order to mitigate this effect as much as possible the interview and survey questions exclude leading

8 Draper, 2002. Retrieved I5.02.08 
questions and include unbiased open questions. Refer to survey and interview question design for these particular techniques. ${ }^{9}$

\section{Literature review research}

Contemporary and classic theory and practice literature is reviewed on the topics of participatory place-making and the community wellbeing of marginalised communities and how they relate. This review positions the research question within a larger field of comprehensive dialogue about participatory design and community wellbeing and outlines the benefits for both the designers of public spaces and the users of public spaces. Participatory place-making as it relates to the research question is defined and explored through the values inherent in its practice. Historical and cultural influences that have typically dismissed participatory practices, or used them as placation within the architectural process are assessed for their impacts upon the public and the role of architecture. The different types and misperceptions of participation are identified and more comprehensive and authentic definitions of participation are proposed. Conclusions are drawn about how participation benefits both the participant's community wellbeing and the design professionals by redeploying their conventionally defined roles in the production of community spaces.

Community wellbeing is defined from the literature and its significance identified. The importance and benefits of community wellbeing is discussed both generally and specific to marginalised communities. Conventional public space designis then evaluated for how it has affected these types of communities and their wellbeing.

Links are drawn between how participatory practice enhances specific aspects of community wellbeing. In addition, some qualities of public spaces are discussed for how they lead to enhancing community wellbeing.

The chapter conclusion discusses how this review of literature contributes to answering the research question. It provides a summary table drawing together these findings and concludes with identifying several significant community wellbeing aspects that are enhanced by participatory processes.

\section{Research measurement tool}

In order to investigate the research question further through conducting case studies, a community wellbeing indicator measurement is proposed. From the field of community psychology, five prominent community wellbeing indicator frameworks are reviewed for their contribution to developing a holistic definition of community wellbeing. The indicators 
relevant to the thesis question are applied to form an indicator framework that measures the enhancement of community wellbeing resulting from participation as experienced by the case study communities.

\section{Case study research}

Case study research was deemed the appropriate strategy for exploring the thesis question. As participatory place-making is a process that is generally characterised by an intensive period of time and activity that concludes in creating a public space, the resultant impacts of community wellbeing are able to be identified as distinctly relating to this process.

As the research was inspired from contact with an effective local example of community participation, selecting every case study community from the New Zealand context would perhaps expose examples that are more relevant for practitioners working within New Zealand's specific circumstances. The ease of accessing these communities is a positive factor affecting the research outcomes and the possibility of providing some encouragement for the featured communities and others communities with similar characteristics is desirable. The information used to explore the research question was gathered from conducting interviews and community wellbeing indicator surveys with the participants from each placemaking project. Patterns started to emerge from the survey and interview findings that related particular enhanced community wellbeing dimensions to specific stages of the participatory process.

The four studied New Zealand communities demonstrated that participation in place-making had enhanced their community wellbeing. Both their causes of disempowerment and the place-making projects undertaken are diverse, but there are many similar steps in the process they undertake to address the issues and articulate a built form from. A distinctive characteristic across the four case studies is that their style of participatory process is intuitive and incremental; and therefore is a product of their community's ecology, not an externally prescribed process.

Gisborne: A group of youth from Gisborne's skateboarding community formed a leadership committee to promote the benefits of a new youth centre addition to the Alfred Cox Skatepark to the local council and wider community. The unsupervised existing skatepark environment was identified as the main cause of the disrespectful and abusive behaviour occurring over a long period of time that affected the environment, its users and the adjacent commercial and residential premises. The positive transformation of the user's 
behaviour was bought about through the community engagement process led by the youth leadership committee and youth workers.

Moerewa: The community and township redevelopment in Moerewa has been discussed above; its continuing decline in employment, local economy and associated social issues had been tolerated for a long time until the community decided to address these issues through a series of community analysis and visioning meetings. The community-wide participation in the planning process enabled the community to create some substantial economic and social changes that were reflected and supported by their new commercial and recreational spaces along the township's main street.

Motukaraka: Ngai Tupoto hāpū embarked upon a participatory process to increase the cultural and functional capacity of their existing rural marae and housing at Motukaraka, Hokianga. The community participated in a long-term planning process to develop additional marae support housing and cultural facilities to retain the constantly emigrating hāpū member population and support the community's aspirations.

Otara: A trust group consisting of long-term Otara residents developed a sustainable papakāinga concept located in residential Otara to provide sustainable lifestyle, employment and educational opportunities for local community members. The concept arose as a collective vision from a series of community regional workshops as a response to the lack of opportunities available to the population of predominantly displaced and urbanised Māori and Pacific Island families.

The case study research chapter discusses each case study separately and provides a description of the place-making project, the intentions of the participatory processes utilised and how they contribute to enhancing specific community wellbeing enhancements. The case study conclusion discusses the general findings and provides a summary table that identifies the corresponding findings across all case studies. These integrated findings form conclusions on the most effective principles, process intentions and most significantly enhanced aspects of community wellbeing.

\section{Research conclusions}

While reconciling the outcomes from the entire research undertaken, key conclusions became predominant that correspond across all the case study and literature review findings. The conclusions are discussed in relation to answering how participation in place-making enhances the community wellbeing of marginalised communities. 


\section{Literature Review}

\section{I Community participation in place-making}

\section{Definition, politics and values}

Participatory design practice redefines the contributors, expertise and beneficiaries of public space decision-making.

Participation has become a buzzword evident by the many interpretations articulated in policies decreeing that it is a necessary component of any public work. ${ }^{10}$ Reis illustrates the ambiguity of the term as it alludes to many different degrees and types of user involvement outlined through writers such as Arnstein, Johnson, Malpass and Wulz." "The lack of agreement over its use arises because the term in itself does not specify the degree of user control, over what it is, and when it takes place." 12

Till states that because the participatory process affects people's lives it is inherently political. ${ }^{13}$ The equal distribution of decision-making control becomes the channel to creating effective public spaces that are truly reflective of a process of value negotiation between the participants and other stakeholders. "Partial participation is when there is not equal power in how the decision is made: 'the final power to decide rests with one party only'."14 The principles of democracy draw attention to the values inherent in the process of architectural production. Participation necessitates an active engagement with the people that will use public spaces, forcing it to be a process that is continually responsive and responsible to the circumstances of the community. ${ }^{15}$ Blundell Jones, Petrescu \& Till state that involving citizens in determining decisions about the places they inhabit is an important, perhaps critical, aspect of people feeling a sense of belonging to their communities, “...true participation in the processes of change is becoming increasingly rare but at the same time is increasingly needed."16

Participatory design is a structured process of assisting communities to discern a physical 'vision' for their environment, which is different from people articulating their opinions. Opinions from individuals sometimes become a barrier in moving towards a solution, what landscape architect Randy Hester calls "participatory gridlock where nothing is agreed upon" and the process of participation becomes futile. ${ }^{17}$ Furthermore, Francis remarks that

\footnotetext{
10 Blundell Jones, et al., 2005. p. xiii

II Reis, 2000. [citing Arnstein, 1969; Johnson, 1979; Malpass, 1979; Wulz, 1985] p. 2

12 Reis, 2000. p. 2

13 Till, 2005. p. 29

14 Till, 2005. [citing Pateman, Participation and Democratic Theory, p.7I] p. 27

15 Blundell Jones, et al., 2005. p. xv

16 Blundell Jones, et al., 2005. p. xiv

17 Francis, 2003. [citing Hester, Refrain with a View, 1999] p. 60
} 
attempting consensus between the conflicting desires of users ends up suppressing particular needs and resulting in a universally unsuitable design. Till discusses a new concept of the conventional approach of 'problem-solving', as replacing the exclusionary identification of the problem and search for a solution with "the idea of designing as 'sense making'." 18 This implies an exploration and acknowledgement of the concrete and complex realities of people's lives that disturbs the functionalist architect's abstract spatial response. Till suggests that the act of ordinary 'conversation' can provide an engaged and valid starting point to participatory design and keeps the process open to the possibilities and contingency of the life of and within a building.

"...the knowledge contained in the conversations of ordinary people, of participants, contains the germs of new spatial possibilities. The trick is how to recognise this, how to identify the 'real possibilities present in those fleeting, extraordinary, nonprofessional moments of indeterminacy, undecidablity and ambivalence."19

Till quotes from Shotter's book, The Cultural Politics of Everyday Life, when he argues that participatory place-making ensures public spaces are formed from the context it is situated in, “...Shotter calls for a knowing 'from within', a 'developmental' knowledge that adjusts to and grows out of the social-cultural surroundings in which it is situated." 20 It seems that participatory place-making deliberately seeks to express the community's identity and values through the active decision-making of community members. It is an act of producing environments that have significance for whole communities of people; the scale of work includes public spaces, community facilities and public housing. As discussed in this thesis, the emphasis is on the community's involvement in the process of decision making, not on the participatory construction of architecture, such as self-building, nor the participatory management, as in co-operative housing.

\section{Conventional public space designwithout public participation}

The contemporary concept of participatory design has come from a long line of influential movements and reactions to the Modern Movement. The architects and planners of the Modern Movement idealistically believed that the radical spatial re-creation of cities would revolutionise the social life of the city. They believed that freeing people from living and working in the oppressive disorder of the old cities and thrusting society into an ordered environment would transform the social strife of their time. Fishman states the virtuous

18 Till, 2005. p. 36. As stated by John Forester

19 Till, 2005. [citing Shotter, Cultural Politics, p. 52] p. 36

20 Till, 2005. pp. 32-33 
motivations of these revolutionaries "The great city, they argued, was no longer modern. Its chaotic concentration was not only inefficient and inhumane, it was unnecessary as well." 21 Visionaries like Ebenezer Howard, Frank Lloyd Wright and Le Corbusier individually took it on themselves to visualise entire solutions to the urban and social problems surrounding them. They rejected the idea of gradual improvements to the cities of the nineteenth century, and planned a radical new creation that would replace their "hate" of the old cities described as "a cancer, an uncontrolled, malignant growth that was poisoning the modern world."22

These wholly transformed urban environments would not only replace the antiquated disorder of the physical environment, they were expected to cause social change. Wright concluded that the visionary planner must dominate and transform the city and give it "a soul". ${ }^{23}$ The new environments that were to effect the social changes were created in isolation by Howard, Wright and Le Corbusier. Their ideal cities were not developed in collaboration with other professionals or lay people, hence the designs they worked on became "more and more elaborate models of their basic ideas." 24 They were confident that the solutions for the urban issues would come from a new utopian form, a solution that did not engage with the specificity and diversity of the actual lives of the city's citizens. Their energies were withdrawn from the encumbering urban complexities and invested into advancing their creative and intellectual capacities to produce ideal cities that were "works of art." 25 This reinforced their elite specialised role and their autonomous design control over urban life. Solutions were produced for society that expressed the planner's individualised social values.

A distance is revealed between the theories of these three planners and the realities of the citizen's lives. This distance is illustrated when Fishman states the classic utopian dilemma:

To appeal to everyone on the basis of universal principles is to appeal to no one in particular. The more glorious the plans are in theory, the more remote they are from the concrete issues that actually motivate action. ${ }^{24}$

In his seminal lecture at a conference in Liege in 1969, Giancarlo de Carlo questioned the architecture of the Modern Movement's capacity to have a public. ${ }^{26} \mathrm{He}$ argued that the architect's role in society and the architectural image produced became limited to a representation of the class in power. ${ }^{26}$ Architecture was classed as a specialised profession and he argued that from this restricted creative elite position, the structures of bourgeois

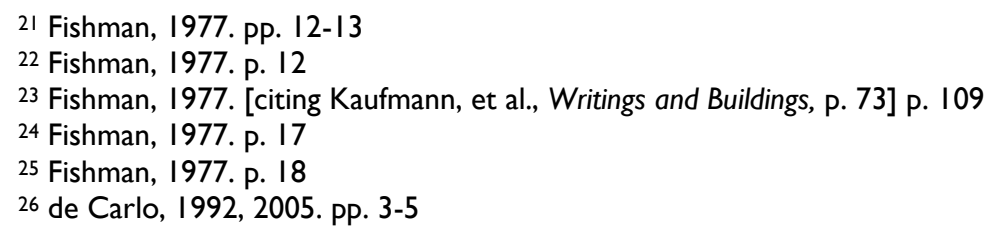


professionalism disabled architects to engage with the actual issues of the user. The architect's 'solution' was to respond only to the architectural brief strictly defined by the client developer. Typically, priority was given to the interests of the client developer who, as Lynch suggests, were commonly more concerned with the increase of profit margin ${ }^{27}$. De Carlo states that the client developer was less interested with public needs outside of relations between the "critics and entrepreneurs, land owners, connoisseurs and architects." 28

Following De Carlo, it seems that real community issues and problems are neutralised into 'how' to solve a problem, with no attention to 'why' the issues exist. Architectural process is set up to be primarily 'problem solving'; the desires and issues are identified by the client developer and turned into solutions that are sourced from the client developer's current knowledge and is consistent with their individual values.

This approach to design invites questions as to where and when does the influence of the public feature in the design of their public spaces? This question is particularly appropriate to examining public housing estates built as part of the large-scale redevelopment period of the 1960's in Britain. The crises that occurred from the rapid degradation of these buildings into "ghettos of the deprived"29, demonstrated the failings of the attempted 'solutions' of mass homogenous housing. The many sectors that contributed to developing these solutions somewhat failed to provide for the diversity of social needs of the inhabitants.

A key reaction to the orthodox designer's control of cities as influenced by the theories of the Garden City and modernism was expressed in Jane Jacobs' book of 1961 The Death and Life of Great American Cities. Jacobs attacked the principles that had shaped the modern planning of cities and claimed that the only way to learn about how urban design can promote social and economic vitality is to learn about how the real life of cities work. Jacobs is concerned with the human scale of interaction with the architectural elements of the city, the uses of sidewalks, neighbourhood's and parks. In specific relation to community participation, she states that attention must be paid to the real order of life that "is struggling to exist and to be served" 30 which she claims is dishonestly masked over by pretended order.

\footnotetext{
27 Lynch, 198I. pp. 40-4I

28 de Carlo, 1992, 2005. p. 7

29 Towers, 1995. p. xiii

30 Jacobs, |96I. p. 25
} 


\section{Publicluser exclusion from planning public environments}

The public have conventionally been excluded from architectural production as being grouped as 'non-expert', and are limited to being 'consumers' of public spaces that are intended to meet their needs. Blundell Jones, Petrescu \& Till suggest the removal of people from decisions caused by modernism's "layers of bureaucracy and specialist procedures" 31 has created a position that separates the users from public space developments that can only be filled by the technical expert. Effectively, the planning professional's authoritative position of intervening between the users and the design of the building has obscured and mystified the design process. Till suggests that the obscurity of the process has been caused by structures that are not conducive to "transparent" 32 communication between expert and non-expert. Because the non-expert status of the user's isolate them from the traditional design process, their "nascent, but unarticulated desires" 33 are not able to be expanded upon and translated into the design. Zeisel sympathises with the designer's complex predicament as many aim to create public spaces that will meet the various social and psychological needs of its unknown users.

The gap between decision maker and user is too great to be overcome by designers using only a personal perspective. If government regulations or the free market would ensure that users' needs were taken into account, there would be no problem. But this does not appear to be the case. ${ }^{34}$

Zeisel outlines the difficulty of planning for users' needs in examples of mass design, such as large public areas or workplaces, because of the anonymity and unavailability of the users to the designers.

Governments, factory owners, corporations, and other often well-intentioned groups of people contracted with designers to construct settings and objects for the masses of people to use daily...In mass designs like this, designers have two clients: those who pay for what is built and those who use it (Madge, 1968). The user client has no choice and no control. This situation presents designers with a problem: no matter how much they negotiate with paying clients, it is difficult to plan for the needs of user clients, who are neither well known nor readily available to plan with. ${ }^{35}$

Lynch suggests that participation is a powerfully radical idea, as it decentralises the decisionmaking process to the users and "reinforces their sense of competence, and seems more likely to result in a well-fitted environment" 36 . However, Lynch claims that the current state of planning, where the public users are so far removed from decision-making processes because of the many complexities, presupposes users to be "incompetent" decision makers.

\footnotetext{
31 Blundell Jones, et al., 2005. p. xiv

32 Till, 2005. p. 28

33 Till, 2005. p. 31

34 Zeisel, J. 1984. p. 34

35 Zeisel, 1984. p. 50
} 
...there are indivisible goods... places used by numerous transient clients... conflicting interests... unknown clients...there are clients who are unaware of their own requirements, or of what they might value if they had the opportunity. ${ }^{36}$

This dilemma of designing large-scale developments that are designed for everyone but no one in particular, calls into question the 'progressive' impact mass production and standardisation has had upon our public spaces. To only be a 'user' of environments created by experts, particularly in the case of public housing, sets up an insubstantial relationship of the dweller to the dwelling that is alienating and lacks the fulfilment of the desire to truly call a place 'home'. Furthering the argument that public housing designed 'for' the public lacks a sense of ownership for its inhabitants, de Carlo suggests that these neighbourhood environment's consequently result in decay because of the lack of user participation and appropriation in the building's production and ongoing management.

The neighbourhoods' and buildings planned 'for' the users decay because the users, not having participated in their planning, are unable to appropriate them and therefore have no reason to defend them. ${ }^{37}$

de Carlo outlines the differences between the resulting forms and relation to people that arise from the contrasting practices of "process planning" and "authoritarian planning." Authoritarian planning translates clearly defined objectives into a built form that becomes fixed in time once constructed. This permanency of form imposes its architectural qualities upon the lives of the inhabitants, influencing behaviour and causing the inhabitant to adapt without being able to alter the form satisfactorily. de Carlo states that this is only one part of the necessary dialectical relationship between people and their environment, in their ability to adapt to each other. The architectural object is also required to be adapted by the user as practical and creative needs transpire.

He suggests that authoritarian planning only concentrates on one aspect because "...the plan is usually conceived assuming that it is easier, quicker and more profitable to condition people than to condition the environment." 38 The denial of human influence upon the environment renders these forms inadequate over time because they will remain physically inactive forms that are not built with a capacity to encourage active engagement and adaptation.

The issue of the unknown user raises the question of whether it is possible for designers to produce environments that genuinely support the users' freedom of choice in how the spaces can be used, adapted and personalised. As will be discussed later in this chapter, several designers and movements address these concerns by identifying design approaches

\footnotetext{
36 Lynch, 198I. p. 44

37 de Carlo, 1992, 2005. p. 16

38 de Carlo, 1992, 2005. p. 20-21
} 
that provide these opportunities. Movements such as Community Architecture, Environment Behaviour research and techniques such as Post-occupancy Evaluation sought to redress this lack of user involvement.

In conclusion, the theory reviewed identifies how the detachment between citizen user and professional expert has resulted in an approach to architectural planning that inhibits the architect from using their knowledge in combination with the perspective of the user. ${ }^{39}$ Knowledge is applied and contained within the view and values of the client developer and architect, and is less able to be responsive to the actual needs of the users, for whom the built form has been planned.

\section{Practices of participation}

\section{Misperceptions of participation}

Participation is a term that is sometimes used idealistically to express a willingness to include others in decision-making. At times the process falls short of reflecting the public's voice because the transformative meaning is misunderstood as merely attaining a notion of public 'input'. The editors of Architecture and Participation; Blundell Jones, Petrescu \& Till, state that participation is commonly organised into regeneration programmes but that the processes used often stifle the voices of the users. ${ }^{40}$ Typically, the project outcome renders the users participation tokenistic and reduces the interest of users to be involved in future projects. U.S. planner, Sherry Arnstein, devised in 1969 'The Ladder of Citizen Participation'4l that sought to capture the varying degrees of planner's claims of practicing participation. The eight levels are sorted from top to bottom, grouped from a high degree of citizen power, down to degrees of tokenism and then to non-participation. The range from the top level is Citizen Control, Delegated Power, Partnership, Placation, Consultation, Informing, Therapy and Manipulation.

These misperceptions of participation have been shown to exist in participatory processes within the government sector. In 2002, the New Zealand government's Community and Voluntary Sector Working Party produced a report assessing the relationship between the government and community sector. One of the chapters discusses how participatory processes can be effective. It also highlights the shortcomings of participatory democracy that the community sector has experienced through consultation processes with the government sector. The major findings articulated by the community organisations are:

39 Till, 2005. p. 31

40 Blundell Jones, et al., 2005. p. xiv

${ }^{41}$ Arnstein, 1969. 
- The community sector's expertise and knowledge "have been often ignored by government agencies" and their potential contribution has been undervalued, resulting in underachievement of outcomes.

- Iwi and Māori partnership is unfulfilled in relation to the Treaty of Waitangi and there exists "palliative and ineffectual" approaches of the government towards addressing Māori self-development.

- The "processes are ineffective," where community organisations have wasted time and resources when the process often hasn't reached the decision-making stage, consultation time "has often been too short," government investment and valuing of professional experts over community experts, decision-making control remains centralised.

- Acknowledgement is given to government departments where community consultation has been inclusive, however, often participatory processes, such as project steering groups have been formed in the "urgent phases of policy development," limiting participants to tokenistic involvement. ${ }^{42}$

With the historical influence of Modernism, architectural and planning practice has become guilty of resisting many aspects of participation in the face of the culture it has cultivated. Till suggests that architects are threatened to operate beyond the perfected model of practice perpetuated by the idealised tenets of the Vitruvian Triad. ${ }^{43}$ The Vitruvian Triad upholds the idealised values of commodity, firmness and delight. Till states that true participation undermines these values.

Contingent reality first upsets the carefully laid plans of utility (users can be so annoyingly unpredictable). Second, it ignores many of the values held high by architectural culture (for example, the public hardly share architects' obsession with the refined detail). Third, it brings into play issues that are overlooked by the Vitruvian Triad (most notably issues of the social and political world). ${ }^{44}$

Blundell Jones et al., argue that the media culture has possibly encouraged engagement between the public and architecture. However, this portrayal of engagement is to the detriment of the authentic participation, as what is displayed by the populist television 'makeover' programmes is that architecture is based on the superficial image. "But the media, with its emphasis on image and surface, can lead to false participation, turning us into passive consumers and not active doers and makers..."45 Taste and the transience of consumer culture dominate the screen, dislocating the experience and function of the livedin space.

42 NZ Ministry of Social Policy, August 2002. pp. 49-50

43 Till, 2005.

44 Till, 2005. p. 29

45 Blundell Jones, et al., 2005. p. xv 


\section{Frameworks for participation}

Sanoff states that for the participatory process to be truly democratic there is a requirement for the conventional architectural process to be departed from, and made procedurally transparent and open to dialogue in able to gain the user's trust. The designer's energies are to be concentrated towards creating a new connection between the differing knowledge bases of the designer and user that allows both parties to talk in the same language that can then be translatable into the built form. He stresses the importance of providing a structured open dialogue for people to discuss their differences, to "permit issues to surface that have normally been swept aside." 46 Appropriate decisions are only reached by collaboratively working through and subsequently reducing tensions between users, and Sanoff believes that this is the only effective representation of the democratic system. ${ }^{46}$

Contemporary versions of the citizen participation ladder identify a range of techniques from the lowest degree of participation, as Informing, Consultation, Involvement, Collaboration and up to Empowering. These also outline the related promises made to the public and the tools used to engage the public in the each of these techniques. The 'Public participation spectrum' diagram below highlights the respective commitments made to the public and examples of public engagement methods.

46 Sanoff, I990. p. I 
Figure I: Public participation spectrum ${ }^{47}$

\begin{tabular}{|c|c|c|c|c|}
\hline INFORM & CoNSULT & INVOLVE & COLLABORATE & EMPOWER \\
\hline Objective & Objective & Objective & Objective & Objective \\
\hline $\begin{array}{l}\text { To provide the } \\
\text { public with } \\
\text { balanced and } \\
\text { objective } \\
\text { information to } \\
\text { assist them in } \\
\text { understanding the } \\
\text { problem, } \\
\text { alternatives, } \\
\text { and/or solutions }\end{array}$ & $\begin{array}{l}\text { To obtain public } \\
\text { feedback on } \\
\text { analysis, } \\
\text { alternatives, } \\
\text { and/or decisions }\end{array}$ & $\begin{array}{l}\text { To work directly } \\
\text { with the public } \\
\text { throughout the } \\
\text { process to ensure } \\
\text { that public and } \\
\text { private concerns } \\
\text { are consistently } \\
\text { understood and } \\
\text { considered }\end{array}$ & $\begin{array}{l}\text { To partner with } \\
\text { the public in each } \\
\text { aspect of the } \\
\text { decision including } \\
\text { the development } \\
\text { of alternatives and } \\
\text { the identification } \\
\text { of the preferred } \\
\text { solution }\end{array}$ & $\begin{array}{l}\text { To place final } \\
\text { decisionmaking in } \\
\text { the hands of the } \\
\text { public }\end{array}$ \\
\hline $\begin{array}{l}\text { Promise to the } \\
\text { public }\end{array}$ & $\begin{array}{l}\text { Promise to the } \\
\text { public }\end{array}$ & $\begin{array}{l}\text { Promise to the } \\
\text { public }\end{array}$ & $\begin{array}{l}\text { Promise to the } \\
\text { public }\end{array}$ & $\begin{array}{l}\text { Promise to the } \\
\text { public }\end{array}$ \\
\hline $\begin{array}{l}\text { We will keep you } \\
\text { informed }\end{array}$ & $\begin{array}{l}\text { We will keep you } \\
\text { informed, listen to } \\
\text { and acknowledge } \\
\text { your concerns, } \\
\text { and provide } \\
\text { feedback on how } \\
\text { public input } \\
\text { influenced the } \\
\text { decision }\end{array}$ & $\begin{array}{l}\text { We will work } \\
\text { with you to ensure } \\
\text { that your concerns } \\
\text { and issues are } \\
\text { directly reflected } \\
\text { in the alternatives } \\
\text { developed and } \\
\text { provide feedback } \\
\text { on how public } \\
\text { input influenced } \\
\text { the decision }\end{array}$ & $\begin{array}{l}\text { We will look to } \\
\text { you for direct } \\
\text { advice and } \\
\text { innovation in } \\
\text { formulating } \\
\text { solutions and } \\
\text { incorporate your } \\
\text { advice and } \\
\text { recommendations } \\
\text { into the decisions } \\
\text { to the maximum } \\
\text { extent possible }\end{array}$ & $\begin{array}{l}\text { We will } \\
\text { implement what } \\
\text { you decide }\end{array}$ \\
\hline $\begin{array}{l}\text { Example } \\
\text { techniques to } \\
\text { consider }\end{array}$ & $\begin{array}{l}\text { Example } \\
\text { techniques to } \\
\text { consider }\end{array}$ & $\begin{array}{l}\text { Example } \\
\text { techniques to } \\
\text { consider }\end{array}$ & $\begin{array}{l}\text { Example } \\
\text { techniques to } \\
\text { consider }\end{array}$ & $\begin{array}{l}\text { Example } \\
\text { techniques to } \\
\text { consider }\end{array}$ \\
\hline $\begin{array}{l}\text { Fact sheets } \\
\text { Websites } \\
\text { Open houses }\end{array}$ & $\begin{array}{l}\text { Public comment } \\
\text { Focus groups } \\
\text { Surveys } \\
\text { Public meetings }\end{array}$ & $\begin{array}{l}\text { Workshops } \\
\text { Deliberate polling }\end{array}$ & $\begin{array}{l}\text { Citizen advisory } \\
\text { committees } \\
\text { Consensus- } \\
\text { building } \\
\text { Participatory } \\
\text { decisionmaling }\end{array}$ & $\begin{array}{l}\text { Citizen juries } \\
\text { Ballots } \\
\text { Delegated } \\
\text { decisions }\end{array}$ \\
\hline
\end{tabular}

\section{Examples of participatory practice}

There exist many modes of participation that practitioners employ to engage user-communities in environmental planning and decision-making. The following paragraphs outline several different examples of participatory practice that illustrate the variety of approaches and outcomes of participation.

\section{Participatory strategies of the Community Architecture movement}

Practitioners of the community architecture movement such as Rod Hackney and Ralph Erskine undertook participatory strategies that started with relocating their offices into residential areas that were perceived by authorities as slum clearance areas. The intention of the community architecture movement was to provide on-site direct interaction between designers and local communities to enable users to be actively involved in the restoration of their environments. The core principle was that "the environment works better if the people who live, work and play in it are actively involved in its creation and management." 48

47 International Association for Public Participation. Retrieved 2006.

48 Wates \& Knevitt, 1987. pp. 16-19 
The political and socialist atmosphere that architecture found itself in towards the end of the 1960s bought about an 'egalitarian' idea of participatory design. As discussed above, the approaches of authoritarian planning for environments such as mass housing estates resulted in areas of deep social strife,

...the Broadwater Farm incident was a forceful indication that these traditional remedies for urban unrest were not getting to the root of the problem, and increasing attention was paid to another aspect of the problem, one which had previously been little noticed by those in authority. This was the link between social unrest and the degree of control that people had over their environment. ${ }^{48}$

In the early 1980s the Community Architecture movement was publicly commended and validated by the Prince of Wales in his 1984 speech to the 150th anniversary celebrations of the Royal Institute of Architects. He praised the community architecture movement as the hope for the future after attacking the planning profession's ignorance of "the feelings and wishes of the mass of ordinary people in this country." ${ }^{48}$

\section{Participation through physical environment modification}

In addressing the dilemma of designing environments in order to allow current and future user involvement, several practitioners, such as Bentley et al, discuss the designing of flexible and resilient elements that enable the unknown users to personalise and physically adapt their environments. ${ }^{49}$ Zeisel gives the example of elements such as movable partitioning and alternative facades that offer users the ability to physically reorder and add to spaces providing users with an enhanced fit and "more direct control over their surroundings." 50

\section{Transparent design processes for user involvement}

The delegation of environmental problems to the specialised technical guidance of the designer is an attitude that Sanoff thinks we need to move beyond, in fact he believes that many of the problems can best be solved by the user's active participation in the design decisions about their environment. ${ }^{51}$

Sanoff identifies several techniques of 'design assistance' that enable designers to initiate and involve users in decision-making about their designed environments. Sanoff states that the foundation of the participatory process is increasing people's awareness of the problem. ${ }^{51}$ Once this awareness is established and the users understand more about the impacting relationship between people and their environment, Sanoff suggests, "the decisions that they make will have an abounding effect on the quality of the environment." 51 He proposes that

49 Bentley, et al., 1985.

50 Zeisel, 1984. [citing Habracken, 1972; Wampler, 1968] p. 50 
participatory methods of communication that are free from specialist technological encumbrances will provide a new social technology to the fields of architecture and planning:

Currently employed methods of user participation disenfranchise the user because the methods of communication have not changed to accommodate a non-design orientated population. ${ }^{51}$

Sanoff has practiced many modes of involvement, which he states are compressed abstractions of the complex processes of conventional design so as to capture the participant's interest. He employs a range of strategies from game simulations to the direct involvement of participants in a structured decision process, to workshops where participants learn from one another as the process evolves. Gaming strategies simulate people-environment interactions where people are sensitised to community problems and decision strategies that work towards influencing "individual behavioural changes." The direct involvement of participants in the design process must be structured with clear roles for participants, especially leadership to guide the process for maximising the fullest contribution of all participants. "Success in this approach is often associated with the quality of guidance through the decision procedure." ${ }^{\prime \prime}$ The most inter-relational and interactive of the methods is the 'workshop process' that is utilized for raising the levels of awareness of the issues within people's environments. Participants' bring their insight of particular situations into a structured communication process where all participants' directly learn from each person. The knowledge and skills gained from this intense process can then form the basis of an effective planning strategy.

\section{Participation through Human-environment interaction}

Amos Rapoport's work in the field of 'man-environment interaction' which is defined as the systematic study of "the mutual interaction of people and their built environment," 52 provides in-depth perceptions of the users' participative role in shaping their environment. One of Rapoport's fundamental questions is to identify the characteristics of people groups which affect the way in which their public space is shaped. ${ }^{52}$ This aspect is particularly relevant to community participation and community wellbeing as Rapoport investigates the meaning that environments have for people once they are actively engaged in influencing it. He then asks what effects public spaces have upon human behaviour, mood or wellbeing. 52 Rapoport discusses the field of geography's understanding of people-environment behaviour that ranges from 'environmental determinism', where there is a belief that the design of the environment determines the social behaviour of people, to 'probablism'. Probablism is where public spaces are settings for human activities and is not determining "but that some choices

5I Sanoff, 1978. PP. I-2 
are more probable than others in given physical settings." 52 The main aspect that is particularly relevant to this thesis is where Rapoport asserts that meaningful environments result from participation in different ways, through action, use, involvement and perception.

The success of areas generally, whether residential or centre city, depends on the meaning they have for residents; meaning is the result of action, use and movement, i.e., of involvement (Prokop 1967, Buttimer 1972) and this is signified and signalled by visible signs of action. ${ }^{53}$

Environments that contain meaning for people because of their participation in it, are an important aspect of building a sense of belonging and identification with a place, and in turn impact a community's sense of wellbeing. The direct influence users can have with their physical environment sets up an 'ecology' that is interdependent; the environment is able to be adapted and the environment adapts the behaviour of the inhabitant. The action of participatory design is an expression of a community's identity and becomes a physical sign of the community's perception of itself.

How one understands environments, their meaning and affective impact, may be related to action and the ability to make an impress on the environment. Particularly in residential areas, this gives a sense of competence, understanding, meaning and leads to a sense of satisfaction with both the environment and oneself. ${ }^{53}$

Rapoport suggests that in cases where people-environment interaction is forbidden, the occurrences of vandalism, like graffiti and property damage, is an attempt to fulfil a fundamental need to make an impression on the environment. Rapoport stresses the importance of the environment to show "visible signs of human activity" ${ }^{53}$ to encourage user's competency and ability to modify their environment. He asserts that designers have made a misjudgement when they seek to reinvigorate places by solely designing using characteristics such as variability, instead of involving the public that will ultimately activate and humanise the built form.

\section{Community development approaches to participation}

Community development organisations, such as community trusts and youth organisations, are typically formed to respond to and represent the direct needs of the community.

Freeman states that their effective approach to development is sourced from an intimate knowledge of the cultural and social issues and their goal is to improve these by utilising the resources available within the community:

The people actually living in the community comprise the best resource for those enjoined with the task of development. They understand community needs, what is reasonable and how the community can be motivated. They also recall what has

52 Rapoport, 1977. pp. 1-2

53 Rapoport, 1977. p. 380 
happened in the community previously and aware of the feelings of alienation, apathy and disempowerment that may be present." 54

Public engagement and participation has been established through their work which makes the organisation an obvious partner and facilitator for the participatory development of the community's public space.

Wates and Knevitt state that "[d]evelopment trusts are emerging as the most effective type of organisation for involving communities in their own development at a neighbourhood or town level." 55 Similarly Eketone \& Shannon and Kruger state below that in New Zealand community-led initiatives are often more effective than those externally run:56

It is acknowledged that New Zealand grassroots ventures succeed over imported or imposed enterprises with enhanced self-employment opportunities, pride, morale and community support for local enterprise. ${ }^{57}$

It is also significant, both for Māori and for all citizens, that almost all the initiatives that 'work' in problem resolution are those controlled and directed by their members, rather than those which have the answers delivered by 'experts' 58

The ideology of community development is one that seems to parallel that of participation, as it asserts that the most successful approach to development is for the citizens to be actively responsible for the decisions that affect their lives. The role of community development workers is not to take charge of a community by bringing along their own ideas, but to collaborate and help them to find their own resources and solutions from within their own community. Wates and Knevitt outline this generative role, "Their unique and essential essence is in combining an entrepreneurial function with social responsibility." 59 Wates and Knevitt compare the community wellbeing outcomes of the different methods of using conventional planning versus community development methods in regeneration projects. "Already many development trusts have proved successful at regenerating areas where other methods have failed and in generating a sense of pride and community spirit." ${ }_{59}$ Benefiting the community is the main aim, as the organisation is not only concerned with the physical change of the community's environment but with the development and wellbeing of the people. Community development organisations are more likely to be involved in projects that affect significant proportions of the community as one of their key characteristics is that they are locally situated and local people drive the vision. The ability to respond to the issues arise out of the social nature of the relationships between the members and locals. Speculation is not part of the process as the needs are communicated directly. Wates and

\footnotetext{
54 Freeman, 2006. p. 21

55 Wates \& Knevitt, 1987. p. 125

56 Kruger, Retrieved II.2008.

57 Kruger, Retrieved II.2008.

58 Eketone \& Shannon, 2006. [citing Shannon and Young, 2004] p. 223

59 Wates \& Knevitt, 1987. pp. I25-126
} 
Knevitt suggest other unique characteristics that make them to be "the most promising vehicle for development in the future." ${ }^{99}$ Their non-profit legal structure ensures they do not exist as a commercial business, any money received is directed through the organisation to the projects. Additionally, their independence from government or business sectors ensures that only the community's interests are included, this retains autonomy from political changes. ${ }^{59}$

\section{Contemporary participation techniques}

These pioneering participatory approaches helped to bring forth different methods of engaging people in developing public spaces that are still currently used today. Broome discusses the multitude of techniques but highlights that above all, a framework for contribution and fair decision-making must be created in order for participatory practice to be constructive:

Participation techniques must offer a process that can reconcile opposing points of view to arrive at an acceptable consensus, and achieving this with a large group of people is a complex problem...60

The New Zealand Urban Design Toolkit identifies numerous participatory techniques to be used at different stages of the process. Examples of community engagement \& visioning stage techniques include community meetings/hui, community surveys \& interviews, design workshops, environmental awareness techniques, scenario planning and urban design games. The various task group engagement techniques commonly utilised are focus groups, reference groups and planning and briefing workshops. In order to aid communication and participation there are visual presentation techniques used such as interactive displays, interactive models and participatory appraisals ${ }^{61}$.

60 Broome, 2005. p. 68

${ }_{61}$ NZ Ministry for the Environment, 2007. pp. 26-34 


\section{Benefits of participation: redefining the contributors, expertise and beneficiaries}

\section{Benefits of participation for user participants}

Empowerment and the personal development of participants' seem to be the significant outcomes of participant involvement in public space decisions. These are developed through the processes that engage community members to be actively involved in changing their circumstances and develop their group collaboration skills.

Mangin reflects that the perpetuation of the 'culture of poverty' is rarely remedied by public housing schemes that are planned by central organisations such as governments and institutions. ${ }^{62}$ People's capacity for decision-making soon yields to a reliance on the 'system,' and dependence is formed. However, Mangin states that when people are actively involved in choices about their environment, major changes occur in their lives, "and even more if they build their own houses and communities." 63 Sanoff suggests there is more than just a strong architectural product at the completion of a participatory process; that community cohesion is built through establishing a group identity and developing the individual's skills. "[T] he user group is strengthened as well by learning more about itself." 64

The principles of participation recognise the varying types of expertise that all participants can offer to the design process. Some perceptions of user-participation assume that the user takes on the role of the designer, as the users knowledge is sometimes considered inconsequential to informing the project. However, in participatory design, the users' knowledge is considered to be of equal importance to the designer's knowledge. 65 The users' intimate and everyday experience of space and the observation of lifestyle patterns is crucial information for the design of any public area or space. As the user often notes these environmental perceptions unconsciously, the role of the designer is to educate and draw out these experiences.

The participatory process requires that the responsibilities and skills of each party are to be maximised and extended in their own unique roles, so that their complementary expertise produces an environment which is a rich collaborative effort.

Where environments have decayed because they have not been defended by the users who had no involvement in their development or modification, de Carlo contrasts the process to one that includes user participation in planning decisions:

62 Rapoport, 1977. [citing Mangin, 1970, p. xxxii] p. 372

${ }^{63}$ Rapoport, 1977. [citing Mangin, 1970, p. xxxii] p. 372

64 Sanoff, 1990. p. 7

65 Sanoff, 1978. p. I 
...the act [of architectural participation] becomes liberating and democratic, stimulating a multiple and continuous participation...it also makes it [the built form] resistant to the wear and tear of adverse circumstances and changing times. ${ }^{66}$

This suggests that participation opens up the process that can bring groups of users 'alive' to the possibilities for change, and at the same time creates a vehicle that gains momentum to continue to influence change. The participatory process is not limited to the life and completion of the singular 'project'. This means that the future users are able to benefit through their involvement. Lynch reinforces this important principle that takes into account the future users as well as the present ones. He states that where a type of participation, named 'user congruence' is practised that this must be a significant characteristic. User congruence is "the extent to which the actual users or inhabitants of a space control it, in proportion to the degree or permanence of their stake in it"67. He sees this as having the following advantages:

...the better fit that flows from control by those most familiar with place use and most motivated to improve it, and the greater security, satisfaction and freedom to operate which is thereby afforded them. ${ }^{67}$

Perhaps the most powerful benefit of participation is the understanding that people can affect the wellbeing of their own and others lives through the decisions they make. Sanoff states that this realisation increases people's awareness of the consequences of a decision. 68 Once a community is conscious of its state and aware that it has the capacity to influence this state, then, de Carlo claims, it consequently moves to change this by direct action. ${ }^{69}$ Sanoff proceeds to outline that one of the most important benefits of participating is the sense of empowerment gained from influencing a decision:

Participants also have a sense of influencing the design decision-making process and increased feelings of responsibility in decision-making. Our experiences in involving people in the process of design indicate that the major source of satisfaction is not so much the degree to which individual needs have been met but the feeling of having influenced the decisions. However, this is often exploited to create illusions of user participation and thus raises ethical issues. 68

In aiming to extend these significant user benefits, both Sanoff and Till echo Arnstein when they warn that the benefits of participation must not remain limited to placating participants. ${ }^{70}$ When considering public space or community projects, participatory design in contrast to conventional architectural processes, must be directly responsive to the social needs of communities. This can open up opportunities to harness the resources the

\footnotetext{
66 de Carlo, 1992, 2005. pp. 15-16

67 Lynch, I 98 I. p. 208

68 Sanoff, 1990. p. I

69 de Carlo, 1992, 2005. p. 16

70 Till, 2005. p. 26
} 
community has to meet its needs. Sanoff states that "...participation results in a greater meeting of social needs and an increasing effective utilisation of resources at the disposal of a particular community."7l Participatory design is unique in that the needs of the community can be directly articulated and responded to during the course of the process. This results in solutions that are specific and grounded in the reality of situations, and therefore has a stronger impact on enhancing the wellbeing of communities.

\section{Benefits of participation for design professionals}

Till states that public participation processes present opportunities for design professionals to be challenged by social realities, to reframe their knowledge from the users perspective and to be informed by the wealth of information on needs and values of the users. ${ }^{72}$ In conventional architectural practice, the architect often uses the architecture produced as captured in the image to defend the state of the architecture. This image of the architectural object features no inhabitant 'disturbing' the much considered form and is subsequently frozen in time. Focus on the image and the denial of the use of the object omits an opportunity for architecture and architects to be continually connected with the reality of inhabitation.

This view is supported by Till who states that participation "confronts architects with issues that they may otherwise have preferred to either hide from, or else delay dealing with, for as long as possible."73 Authentic participatory processes challenge architects to move beyond the protection of the architectural image to socially responsive architecture that is produced and maintained by a collective of experts.

Till suggests that the participatory process may threaten the professional identity for architects, who are traditionally perceived as the 'experts'. However, he encourages that the unique knowledge of architects does not need to be relinquished in the process, but rather "redeployed" from a new perspective; that of the user living in the context of their environment. Till and Lerup ${ }^{74}$ state that architectural participation calls for architects to project themselves into the physical and social context of the architecture, to understand how people react to the built form. Zeisel suggests that the discipline of Environmental Behaviour Research provides a method that aims to identify the "needs, desires and reactions of users to their surroundings, thus enabling designers to better negotiate with users and understand the effects decisions will have on them." 75

\footnotetext{
7I Sanoff, 1990. [citing Cashden, et al., 1978] p. i

72 Till, 2005. p. 31

73 Till, 2005. p. 30

74 Till, [citing Barker, Ecological Psychology, p. 16 as quoted in Lerup, Building, p. 156] p. 32

75 Zeisel, I98I. p. 35
} 


\subsection{Marginalised communities \& community wellbeing}

\section{Defining marginalised communities in Aotearoa/New Zealand}

Several recent national studies have highlighted two major aspects in defining marginalisation; firstly, a disproportionate lack of access to material resources and secondly, a lack of appropriate engagement in influencing societal decisions.

Poverty is not simply low income; it is an inability to influence outcomes in a regular and meaningful way. Within New Zealand there is a growing proportion of the population that are alienated by a sense of disengagement and distrust. Many felt that they no longer have control over events, the society they worked for has disappeared and things no longer made sense... Kawachi and Kennedy (1997) suggest that reducing income inequality offers the hope of revitalising social cohesion and a prospect of greater social wellbeing. ${ }^{76}$

Other definitions of marginalisation in New Zealand highlight the underlying identity and cultural loss for communities, “...poverty was viewed as encompassing loss of tradition, identity, families, friends, relationship to land, values and beliefs in addition to economic resources." 77 'Marginalised communities' in this thesis is defined as groups in specific geographical areas in New Zealand where a high concentration of the population experience many of the aforementioned circumstances. Most relevant to this thesis is the citizens' capacity to influence decisions. Hawkes states that society has been conditioned to delegate important decisions to experts. This leaves citizens with little experience in influencing immediate and crucial community concerns and the "sense of powerlessness breeds apathy and resentment."78 On evaluation, he expresses that citizens are primarily motivated to be involved by believing that their contribution is valued and will be utilised. In order for citizens to influence decisions, a framework for engagement must be created. Sanoff suggests that participatory processes offer this as it defends the interests of people whose needs would be otherwise ignored. ${ }^{79}$ Furthermore, Arnstein argues that citizen participation is able to facilitate the distribution of control over decision-making and states that participation without this "redistribution of power" makes it:

an empty and frustrating process for the powerless. It allows the power holders to claim that all sides were considered but makes it possible only for some of these to benefit. It maintains the status quo. ${ }^{80}$

The Christchurch City Council's 'Social Wellbeing report' demonstrates many national and international studies that highlight the negative impacts of marginalisation upon aspects such as community wellbeing and local participation:

\footnotetext{
${ }^{76}$ Christchurch City Council N.Z. (Retrieved II.04.06).

77 Williams, et al., 2003. p. 37

78 Hawkes, 2003. p. 16

79 Sanoff, 1992. p. 60

80 Sanoff, 1990. [citing Arnstein, 1969] p. 6
} 
....inequality...manifests in increasing sickness and premature death, eats at the core of civil society, for example a declined participation and decrease in community infrastructure, means societies show social disintegration, increases individual malaise, ultimately impedes productivity and economic growth and impairs functioning of democracy. ${ }^{81}$

In this thesis research, the selected case study communities exhibit some of the characteristics of marginalised groups in New Zealand, namely youth and low-income Māori and Pacific Island communities.

\section{The impacts of mono-functional \& socially homogenous development upon marginalised communities}

The social issues of 'suburban neurosis', the lack of community infrastructure and physical isolation from employment opportunities and basic amenities are the most commonly quoted symptoms of suburban developments of the 1950s and $60 \mathrm{~s} .{ }^{82}$ In the provision of public housing and environments by external agents for populations of people on low incomes, these types of environmental characteristics have negatively affected the wellbeing of the inhabitant communities. Some state housing suburbs of New Zealand created in the 1950s seemed to have effectively spatially segregated these low-income populations from mainstream society. Both Schrader and Thorns ${ }^{83}$ highlight the negative social impacts of inadequately planned suburbs, both government \& private developments, that had omitted social infrastructure such as facilities for community interaction and employment:

Unfortunately, community planning for Porirua wasn't as advanced as the physical planning. The National government's decision to target the provision of state housing to the poor combined with the traditional bias towards young families to create a monochrome society in which everyone was of similar age and had similar outlooks and wants... Rob Olsen who grew up in Porirua in the 1960s, summed it up: "You basically had a huge version of Nappy Valley: heaps of young kids, no entertainment, no halls, no theatres and as a consequence you had a whole lot of people stuck out here, twenty kilometres from Wellington, wandering around aimlessly looking for things to do. ${ }^{84}$

Commonly also, the lack of economic resources to maintain and invest in these geographical areas typically develop negative environmental conditions such as physical deterioration, abandonment or overcrowding and vandalism. 85

\footnotetext{
81 Christchurch City Council N.Z. (Retrieved I 1.04.06). [citing Kaplan 1996, Bobak et al 1999, Fiscella 1997, Kawachi \& Kennedy 1995, 1997, Wilkinson 1994, Labonte 1997; Sandel 1997, Cox 1998, Raphael 1999; Sampsoon 1990, Crawford 1995, Wilkinson 1999; Wilkinson 1996, Raphael 1999; Glyn \& Milband 1994; Cox 1995, Kawachi 1997]

82 Schrader, 2005. p. 188

83 Thorns, 2002. p. 117

${ }^{84}$ Schrader, 2005. [citing Quaintance, June 1998. 'Porirua: The Unfortunate Experiment', North and South, p. 82] p. 182

85 Rapoport, 1977. p. 383
} 


\section{Socio-economic homogeneity \& social exclusion}

Mangin, Thorns and Rapoport ${ }^{86}$ all suggest that a lack of choice is the major marginalisation in cases where low income, non owner-occupant populations have been homogenously grouped to particular streets, neighbourhoods or suburbs. This approach can sometimes perpetuate the causes of poverty. Close residential proximity to other people that experience similar distress can compound conflict between residents. This can also extend to neglecting or vandalising public spaces that either hold no meaning for the residents or inhibit their behaviour. Thorns discusses the negative impact of socio-economic homogenous planning that results in social exclusion:

The excluding of people from the mainstream of society, within the city and the wider social context, provides the basis for the formulation of ghettoes and an underclass of marginal and deprived people. It creates a waste of human potential and can become a destabilising factor upon society ${ }^{87}$ Social exclusion is the process by which certain individuals are denied access to positions and resources to live a fully participative life. The excluded are those who fall outside the regular, paid workforce and the welfare safety net. 88

The case study communities in this research employ participatory practices that typically seek to engage socially excluded groups, realising their lack of access to positions of influence.

\section{Defining community wellbeing}

Contrary to the somewhat vague idealism this term may stir up within people, 'community wellbeing' has been rigorously defined by many authors. Prilleltensky offers an encompassing definition of community wellbeing along with its benefits,

Community well-being is a positive state of affairs in which individuals within the community, as well as the community as a whole, are able to fulfil their needs and aspirations. To fulfil their needs and aspirations... [the community members] benefit from the following values: caring and protection of health, self-determination, education and personal development, collaboration and democratic participation, respect for diversity, supportive community structures, and social justice. ${ }^{89}$

Many psychologists have attempted to empirically define the indicators of community wellbeing. The most well known community psychologists have arrived at some theoretical foundations labelled with such overarching themes as a 'sense of community'. Chavis warns of the difficulty that science will have with defining a 'feeling' people have of the social state

\footnotetext{
86 Rapoport, 1977. [citing Mangin, 1970, p. xxxii] p. 372; Thorns, 2002. p. I50; Rapoport, 1977. p. 368

87 Thorns, 2002. p. 150

88 Thorns, 2002. p. 152

89 Prilleltensky, c.2006. [citing James \& Prilleltensky, 2002; Nelson \& Prilleltensky, 2005] p. 22
} 
of their community. Chavis, citing Sarason, states that a sense of community has a tangible quality:

"It is a phrase which is associated in the minds of many psychologists with a kind of maudlin togetherness, a tear-soaked emotional drippiness that misguided do-gooders seek to experience." Yet, [Sarason] maintained, people knew when they had it and when they didn't. 90

Sarason goes onto define a sense of community as a perception of connectedness with others and a responsibility to maintain interdependence through reciprocal actions. ${ }^{91}$ In the following subchapter titled 'Measurements of Community Wellbeing', five community wellbeing indicator theories are reviewed and used to create a framework to assess the community wellbeing enhancements of the four case study communities. These theories encompass many psychological aspects of community wellbeing, that include civic \& political participation, sense of pride \& belonging, reciprocity, social capital, influential capacity, cultural participation and social support. Social capital which refers to characteristics such as social connectedness and resources is one of the major dimensions of community wellbeing. Statistics New Zealand's 200I study defined the key indicators of social capital in New Zealand as personal and institutional trust, civic engagement, voluntary activity, cultural \& recreational participation, giving material \& personal resources and meeting societal obligations. ${ }^{92}$

\section{Links between local participation \& community wellbeing}

Voluntarism and involvement in local associations are common forms of participation.

Thorns, citing several studies, discusses how involvement in local level initiatives can activate citizens' ability to influence events, increase local identity and pride and build a "collective consciousness." 93 These factors contribute to enhancing community wellbeing:

Prestby, Wandersman, Florin, Rich and Chavis (1990) demonstrated how participation in [neighbourhood] associations met instrumental and social needs of members. The community development process is "activated" when citizens perceive their ability to influence events in order to obtain needs through participation in collective action. ${ }^{94}$

Hawkes, Thorns and McNeely, all suggest that local involvement can generate community wellbeing and vice versa. ${ }^{95}$ Hawkes states that the citizens' belief in their capacity to make a

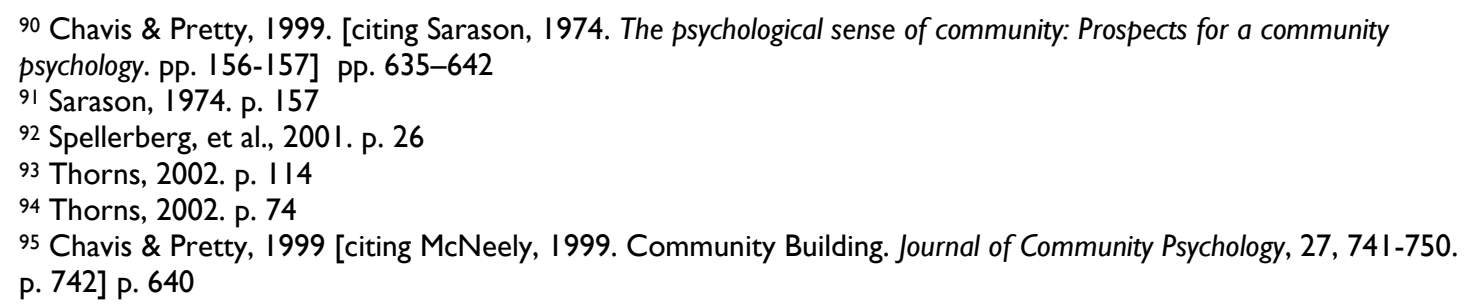


difference motivates their involvement, ${ }^{96}$ which would also suggest that their involvement increases the perception of their own capacity. Thorns demonstrates how local neighbourhood action can be both the cause and effect of a sense of community. ${ }^{97} \mathrm{He}$ also highlights that when citizens share a strong sense of community, it contributes to increasing their individual and group empowerment to collaborate and change their local problems. This in turn can "mediate the negative effects of things over which they have no control." 98 The various types of participatory practices that work toward enhancing community wellbeing all apply principles that seek to change the structures of control. This change occurs by removing the "barriers that prevent people from participating in the issues that affect their lives." 99 In order for participatory processes to be effective in addressing the needs of marginalised communities, both Eketone \& Shannon and Thorns state that participants must personally develop a belief in their ability to exercise power. 100 They note that support from intermediaries, such as community development workers of agencies, will be required to achieve these beliefs and abilities:

... the most disempowered people, may have been excluded for so long [from participating] that they no longer believe in their right or ability to exercise power... the interpersonal skills of the worker [may be needed] to encourage them to: increase their belief and ability to take effective action; develop group consciousness; reduce the tendency to blame themselves; assume personal responsibility to make change...

\section{Public space developments that enhance community wellbeing}

Thorns states that the physical environment of communities is an integral influence on the development and identity of the community: "The development of community (like human development) is inseparable from its environment." 101 He suggests that community wellbeing can be enhanced through identifying public space qualities that facilitate positive community interactions.

In addition, Chavis and Wandersman demonstrate several studies where communities have developed awareness and identified environmental problems that led them to create local action groups: "Most neighbourhood organizations are formed as a response to the threat or reality of physical deterioration."'102 Further studies show that the development of community cohesion and a sense of community can lead to reconciling negative perceptions and factors of the environment. ${ }^{103}$ This can result in "greater satisfaction with the

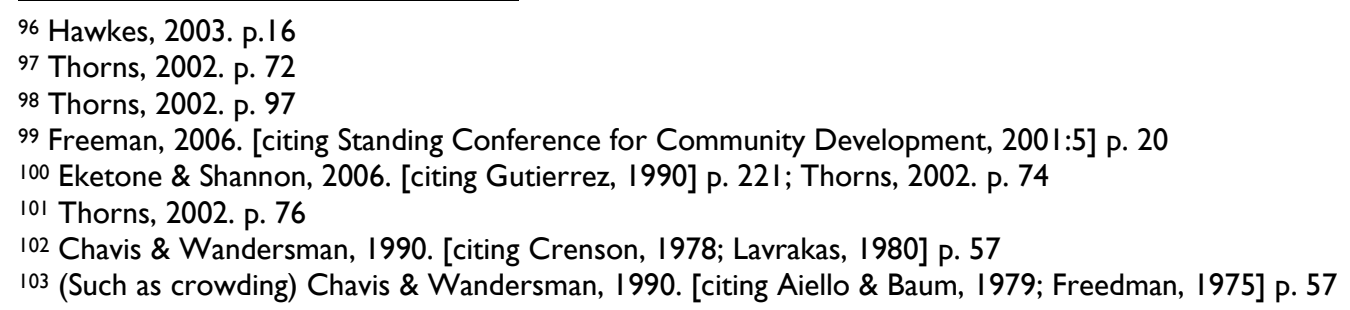


[neighbourhood] and more positive impressions which can lead to neighbourhood stability and growth."104 McNeely and Thorns claim that the process of community members developing self-reliance and collaboration capabilities has successfully increased social capital and wellbeing by:

...neighbours learning to rely on each other, working together on concrete tasks that take advantage of new self-awareness of their collective and individual assets, and in the process, creating human, family and social capital. 105

\subsection{Literature review summary findings}

The integrated findings drawn from the literature review confirm that community participation in place-making does enhance the wellbeing of marginalised communities. Table I below shows a summary of the integrated findings from the literature review. The related findings are grouped together and given a summary heading and these headings have been grouped under the three major community wellbeing dimensions that have emerged.

Each enhancement finding included in Table I is referenced below and denotes how many authors contribute to this finding.

\section{References for following table:}

A Till, Sanoff, de Carlo

B Chavis \& Wandersman, Thorns

C Sanoff

D Freeman

E Wates \& Knevitt

F Thorns

G Rapoport, Zeisel

H Sanoff, Wates \& Knevitt

${ }^{\mathrm{I}}$ Till

J Rapoport

K Lynch, Till, Wates \& Knevitt

L Arnstein, Wates \& Knevitt

M Till

N Blundell Jones et al., Rapoport, Thorns

- Rapoport, de Carlo

P Chavis \& Wandersman citing Ahlbrandt \& Brophy, 1975; Bradford \& Marino, 1977; Goetze, 1979; Pearce, 1979; Pol, Guy \& Bush, 1982

104 Chavis \& Wandersman, 1990. [citing Ahlbrandt \& Brophy, 1975; Bradford \& Marino, 1977; Goetze, 1979; Pearce, 1979; Pol, Guy \& Bush, 1982] p. 73

105 Chavis \& Pretty, 1999 [citing McNeely, J. Community Building. Journal of Community Psychology, 27, p. 742] p. 640 


\section{Community wellbeing dimensions enhanced by participatory place-making}

\section{EMPOWERMENT \& GROUP CO-OPERATION}

\section{Social responsiveness}

Enhances quality of users environment through process that is continually responsive \& responsible, liberating \& democratic $A$

Increases empowerment \& collaboration to create social initiatives to address local 'problems'B

Gains public interest and users trust by transparent process that is open to dialogue ${ }^{c}$

Removes barriers to citizens acting to change the issues that affect their lives ${ }^{\mathrm{D}}$

Increases entrepreneurship \& social responsibility through community development organisation-led participation ${ }^{\mathrm{E}}$

\section{Group cooperation \& implementation skills}

Develops relevant skills \& gain support ${ }^{F}$

Builds group identity, develops skills and strengthens connections of participant group ${ }^{C}$

Encourages users competency in modifying their environments $G$

Enhances participant insight \& learning to plan strategies through direct interaction ${ }^{c}$

Increases citizen access to public decision-making through ongoing collaborative processes ${ }^{\mathrm{D}}$

Increases community engagement in environment decisions through community development organisation-led participation ${ }^{\mathrm{D}}$

\section{Shared visions for local environment}

Increases participant-identified solutions to environmental 'problems' \& offers most successful approach'

Builds sense of pride, community spirit and successfully regenerates environments through community development organisation-led participation $\mathrm{D}$

Increases utilisation of participants' local knowledge \& inspires spatial possibilities ${ }^{\mathrm{I}}$

Enhances the meaning and identity environments have for participants」

\section{CITIZEN REPRESENTATION}

\section{Ability to influence}

Sense of competency \& well-fitted environment results from decentralising decision-making to users \& value negotiation between stakeholders ${ }^{k}$

Enhanced equality of decisionmaking control between users \& experts $\mathrm{L}$

\section{Citizen representation $\&$ value of contribution}

Defends the interests of underrepresented participants $c$

Engages with social realities \& circumstances of participants \& undermines generalisations $M$

Increases conflict reduction and resolution between participants due to effective leadership, clear roles \& structured open dialogue $c$

Enhances the value of participants' specific knowledge \& contributionc Increases designers knowledge of users environmental needs, experiences, expectations and values $^{M}$

\section{SELF/COMMUNITY AWARENESS \& BELONGING}

\section{Sense of belonging, collective consciousness \& identity with place}

Enhances sense of community belonging \& identification with place $^{\mathrm{N}}$

Increases participants' influence \& local identity, pride \& collective consciousness $F$

\section{Self-awareness \& positive} lifestyle changes

Increases participant awareness of consequences of their decisions \& increases community wellbeing $C$

Effects major behaviour \& lifestyle changes ${ }^{\circ}$
Satisfaction, positive perceptions \& safety of local environment

Decreases negative environmental perceptions \& increases area satisfaction ${ }^{P}$

Increases neighbourhood safety \& local action ${ }^{F}$ 


\section{$3 \quad$ Measuring community wellbeing}

\section{I Community wellbeing indicators}

In order to answer the research question:

Does community participation in place-making enhance the wellbeing of marginalised communities, and if so, how? - the study requires a research technique that can measure the extent and the qualities of community wellbeing that have been enhanced. Indicators that 'indicate' the presence of community wellbeing will be developed and questions to test these indicators will be incorporated into a survey. The survey will investigate if community wellbeing has been enhanced as a result of the community's participation in a place-making project. Salvaris and Wiseman state that community wellbeing indicators serve to translate broad community values and goals into tangible signifiers that can be identified, articulated and assessed within the lives of people in the community:

Tools which can help citizens, communities and policy makers identify and agree on a reasonably small number of goals translated into tangible and concrete outcomes and indicators are extremely valuable in a complex and contradictory world. ${ }^{106}$

The indicators for use in this research are developed from five community wellbeing indicator theories that were selected for their applicability to the research question. The intention of selecting a range of theories of differing type and scope was to develop a comprehensive understanding of how community wellbeing can be measured. Each theory measures different aspects of community wellbeing. The group of five theories used in this research covers the following issues: evaluating the competency of the community; the progress and development of the community; the 'sense of community' that member's experience; the wellbeing gained from networks and partnerships with wider society; and the overall health due to the active engagement of members within a community.

\section{Definition and rationale for community wellbeing indicators}

While there is strong agreement that the concept of community wellbeing is vitally important to the life of communities, the plethora of attributes, values and goals that are encompassed by the term make it a challenging concept to describe. Raymond Bauer, a pioneer of the post-war social indicator movement notes that the real purpose of community wellbeing indicators is to "enable us to assess where we stand and are going with respect to our values and goals". 107

106 Salvaris \& Wiseman, 2004. p. 15

107 [citing Bauer, 1966, p. I] p. I5 
Salvaris and Wiseman state that a community wellbeing indicator is not simply a statistic, but a "measure of something that is important or valuable." 108 Often these attributes are difficult to measure or describe, so Salvaris and Wiseman suggest the development of a framework that will describe the "outcomes that would show whether we are achieving community progress and wellbeing." 109 They assert that the framework must demonstrate clear evidence that the most important outcomes are measured, as opposed to the most available or easily measurable outcomes. 110

Salvaris and Wiseman state that currently, community wellbeing indicator frameworks are being created mainly as a "core mechanism for democratic, accountable and integrated policy making."'I In New Zealand, community wellbeing enhancements are typically assessed when considering outcomes of government policy. However, this research tests the relation of community wellbeing specifically to community participation in public space improvements.

\section{Overview of five community wellbeing indicator theories}

Below is an overview of each indicator theory that is incorporated into the case study framework. These theories are used to formulate survey questions for use in the community wellbeing survey. This overview includes the aim and rationale of each indicator theory and the specific emphasis and scope of the measurement and its application to the case study framework.

\section{Indicator Theory 1: Salvaris and Wiseman (2004).}

\section{"Commonly used indicators of community progress and wellbeing"}

This theory is featured in the draft scoping report paper titled Mapping Community Wellbeing: Using community wellbeing indicators to choose goals and measure progress. 12 The indicators identified in this theory are presented in a summary framework that is in "common use by many community wellbeing frameworks" 13 and can be implemented as the basis for developing indicators for both local and national levels. The framework includes the community wellbeing dimensions commonly known as the 'triple bottom line'. These include social, economic and environmental wellbeing, with the addition of cultural participation, and political/civic participation. The wide range of community wellbeing issues and goals that are measured by outcomes are based on both objective and subjective evidence. Objective

\footnotetext{
108 Salvaris \& Wiseman, 2004. p. 17

109 Salvaris \& Wiseman, 2004. p. 17

110 Salvaris \& Wiseman, 2004. p. 17

III Salvaris \& Wiseman, 2004. p. 5

112 Salvaris \& Wiseman, 2004.

113 Salvaris \& Wiseman, 2004. p. 27
} 
evidence includes quantifiable attributes such as participation rates in local community organisations. Subjective evidence comes from, for example, a question asking - is there an increase of trust in public institutions?

In a similar fashion to how this research explores how participatory design acts as a vehicle for enhancing community wellbeing, Salvaris and Wiseman highlight that the process of developing community wellbeing indicators has the potential to act as an important mechanism for the democratic engagement of citizens. They state:

Participatory community wellbeing projects can create opportunities for citizens to 'create new visions of the future, develop new working relationships across old boundaries and define (the community's) assets, problems and opportunities in a new way' (Redefining Progress, 1998)...At a time when most research and anecdotal evidence shows a sharp decline in civic participation and a weakening of democratic processes and political trust, this may be their greatest merit in the longer term. ${ }^{114}$

\section{Indicator Theory 2: Cottrell (1976).}

\section{"Measurement of Community Competence: Summary of concepts used"}

Lochner et al's paper, Social Capital: a guide to its measurement (1999) featured a theory titled Measurement of Community Competence: Summary of concepts used which were developed from Cottrell's (1976) Eight essential dimensions \& preconditions of a competent community. 115 Cottrell is the principal theorist of community competence, which he defines as a distinctly group phenomenon of the collective ability to solve problems. The eight dimensions that define community competence primarily focus on the social capital and political efficacy available within the community. Social capital is represented by the following indicators; commitment to the life and activities of the community; participation and belonging to civic and recreational groups; and the social support provided by organisations and individuals. Political efficacy is the community's ability to harness the appropriate resources for facilitating and implementing the necessary changes required to meet the needs of the community. The article proceeds to discuss how one condition can bring about another; that an adequate level of social capital in a community generates the outcome of political efficacy. This framework is of particular interest to the areas of health promotion and education as it has establishes a practical application "in assisting communities to mobilise resources to implement social change." 16 The measurements of community competence outlined by Lochner et al are provided in summary form in Table 2 (p. 153) for the reason that the

\footnotetext{
114 Salvaris \& Wiseman, 2004. p. 22

115 Lochner, et al., 1999. p. 268

116 Lochner, et al., 1999. p. 267
} 
concept of community competence remains abstract and requires "more grounded theory building through discovery in the field." 17

The emphasis on measuring the development of the community's political skills is essential for inclusion in measurement survey as the analytical skills such as decision-making enable people to engage with and influence the process. Participation is maximised and ensures that the values of the local community are adequately represented in decisions.

\section{Indicator Theory 3: McMillan \& Chavis, (1986)}

\section{"Summary of concepts used in the measurement of Sense of Community"}

This theory was developed by McMillan \& Chavis (1986) titled Four Sense of Community dimensions. ${ }^{118}$ The concept of measuring the 'psychological sense of community' was originally formulated by Sarason (1974), and at least thirty separate studies have been published since the 1970's. 119 Community psychologists McMillan and Chavis later refined the concepts into four dimensions:

Membership is the feeling of belonging or of sharing a sense of personal relatedness. The second element is influence, a sense of mattering, of making a difference to a group and of the group mattering to its members. The third element is reinforcement: integration and fulfilment of needs. This is the feeling that members' needs will be met by the resources received through their membership in the group. The last element is shared emotional connection, the commitment and belief that members have shared and will share history, common places, time together and similar experiences. ${ }^{120}$

The definition of a sense of community emphasises the collective and relational characteristics as opposed to the individual experience and behaviour and is accordingly measured at a community level. ${ }^{121}$ The indicator measurements are predominantly based in the geographical context, for example, the quality of the neighbourhood community relations.

The content of this indicator theory is essential for inclusion in the case study framework. This is because the four dimensions highlight the benefits of wellbeing only a group working together can offer to an individual. Also, the indicator theory is important to include as it simultaneously attributes the positive aspects of both the relational community and the geographical community to community wellbeing. This dual focus is relevant to all of the case study's goals of enhancing the relationships between people in the community and to their geographical environment through the mechanism of a participatory project.

\footnotetext{
117 Lochner, et al., 1999. [citing Eng \& Parker, 1994, p. 204] p. 267

118 Lochner, et al., 1999. pp. 263-265

119 Lochner, et al., 1999. [citing Hill, 1996] p. 262

120 McMillan \& Chavis, 1986. p. 4
} 


\section{Indicator Theory 4: Wills (2004)}

\section{"Just, Vibrant and Sustainable Communities: A Framework for Community Wellbeing"}

This theory was developed by Wills for the Local Government Community Services Association of Australia. ${ }^{122}$ This theory, like indicator theory I, is built upon the sociocultural, economic and environmental qualities of community life. This theory primarily informs community development work facilitated by local councils in Australia and is intended to assist with planning and evaluation at a local level of community. The approach is to re-orientate the influence that local governments have towards the community wellbeing outcomes of liveability, equity, conviviality, vitality, adequate prosperity, sustainability and viability. These outcomes are derived from a model developed by theorists Labonte and Hancock in the health promotion field where the indicators of a healthy community are attributed to the wellbeing of the integrated social and physical environment. ${ }^{123}$ The main emphasis of the theory is to ensure that local governments foster and sustain a holistic approach to community wellbeing that integrates the goals of democratic governance, belonging and identity to a geographical community, active citizenship, embracing cultural values, social justice and social capital. The decision to acknowledge the dimension of social justice as an individual entity is unique to this indicator theory. The inclusion of the social justice dimension in the case study framework is crucial, as its indicators are able to measure the extent to which the marginalised circumstances have been improved by the participatory process. Wills highlights that the social justice dimension acknowledges the equal rights of individuals:

Social Justice... recognises the intrinsic value of each individual; recognises the differences in access to power, information, services and resources; calls on social equity to be mainstreamed so that it emerges from the systemic processes of democratic local government and management; ensures that any disadvantages resulting from factors associated with aboriginality, ethnicity, age, gender, disability, socio economic status or location are addressed. ${ }^{24}$

\footnotetext{
121 Lochner, et al., 1999. p. 262

122 Wills, 200 I. pp. I-7 and features also in Salvaris \& Wiseman, 2004.

123 Labonte \& Hancock, 1993. Healthy and Sustainable Communities

124 Wills, 200I. p. 3
} 
Indicator Theory 5: Pyke et al. (2005)

"Illustrative Victorian Community Indicators Framework"125

This theory is developed by Pyke, Wiseman, Heine, Langworthy, Raysmith, \& Salvaris. (2005) titled Measuring wellbeing, engaging communities: Sustainable strategies for the development of Community wellbeing indicators by Victorian local governments and their communities. This theory measures the promotion of democracy within the local community. The intention of the Victorian Community Indicators framework is to assess attempts to make a closer and integrated connection between local government level policy planning and the wellbeing of communities. This is attempted by effectively engaging local citizens in the simultaneous process of community planning and the development of community wellbeing indicators. The theory identifies that the key task in developing democracy is to strengthen community engagement through local governments supporting citizens to participate in the process of identifying community concerns and priorities. The priorities identified by the citizens through the process of community planning are then translated into indicators that reflect the community's vision of a healthy state of development. The theory proposes that a constructive consequence of citizen engagement in a community planning process,

...can be an important way to strengthen people's sense of belonging and participation in their local community (which contributes to community strengthening and social capital) and to improve local democracy. ${ }^{126}$

The theory has a particular emphasis on investigating a proliferation of new forms of community governance that are "based around integrated community wellbeing measures and community planning developed with direct citizen participation." 127 It identifies that many new forms of governance and citizen engagement have arisen from communities that have actively responded to powerful negative pressures and circumstances. Pyke identifies these negative factors as including "economic decline, population loss, weakening community cohesion, and central government neglect." 128 These transformative examples of community's developing their own future and common goals in the face of negative pressures are particularly relevant to the participatory processes and projects undertaken by the case study communities of this research.

The indicators included in the theory framework have been informed by national census data, reports, and a "stocktake of domains, issues, indicators and data sets currently used by most Victorian local governments" and are considered representative of "the most important elements of a healthy and sustainable community." 129 The theory's framework is

\footnotetext{
125 Pyke, et al., 2005. p. I-52

126 Pyke, et al., 2005. p. 6

127 Pyke, et al., 2005. p. 5

128 Pyke, et al., 2005. p. 5

129 Pyke, et al., 2005. p. 32
} 
directed to all sectors of society; local governments working in the areas of community development, planning and local service provision; independent community organisations, and local citizens.

The theory describes community wellbeing indicators as 'key measures' that are able to form a tangible depiction of the "overall health and development of a community, in all the areas that matter." 130 This depiction enables the formation of a strategic foundation for community planning. This theory is important to include in the case study framework for its broad and comprehensive consideration of all aspects of the quality of life for society. Additionally it is noted for its practical application and current use by local governments throughout Australia.

From all the sectors of community life represented, the dimensions titled Social, Culture, Built Environment, and Democracy and Citizenship are the most relevant to the measurement of community wellbeing in the four case studies. The description of each of these dimensions and their respective group of indicators, sourced from a wide variety of professional sources, provide a credible model of the potential ability for communities to progress their vision. 


\subsection{Creating a case study community wellbeing indicator framework}

The end goal of this framework is to compile a comprehensive range of indicators from the five theories into a case study framework that will form the survey questions for measuring the community wellbeing enhancements.

\section{Overview of the case study framework \& definition of terms}

From the five theories, a range of inter-related dimensions (D) and indicators (I) of community wellbeing have emerged. These have been grouped under three overarching themes (OT). Survey questions (SQ) to test the indicators are derived from this framework. The structure of the framework is illustrated in Figure 1.

The term dimension is used in this research to identify the main aspects of community wellbeing. Within each dimension there are several indicators that 'indicate' specific aspects of community wellbeing.

Figure 2: Framework structure and terms

\begin{tabular}{|c|c|c|c|}
\hline $\begin{array}{c}\text { Overarching } \\
\text { Themes } \\
\rightarrow \\
\text { (3 in total) }\end{array}$ & $\begin{array}{c}\text { Dimensions } \\
\rightarrow \\
(10 \text { in total })\end{array}$ & $\begin{array}{c}\text { Indicators } \\
\rightarrow \\
(31 \text { in total) }\end{array}$ & $\begin{array}{c}\text { Survey } \\
\text { Questions } \\
\text { (2I in total) }\end{array}$ \\
\hline \multirow{2}{*}{ OT } & D & $\begin{array}{l}\text { I } \\
\text { I }\end{array}$ & SQ \\
\hline & D & $\begin{array}{l}\text { I } \\
\text { I }\end{array}$ & SQ \\
\hline \multirow{4}{*}{ OT } & D & $\begin{array}{l}\text { I } \\
\text { I } \\
\text { I } \\
\text { I }\end{array}$ & $\begin{array}{l}\text { SQ } \\
\text { SQ } \\
\text { SQ }\end{array}$ \\
\hline & D & $\begin{array}{l}\text { I } \\
\text { I } \\
\text { I }\end{array}$ & $\begin{array}{l}\text { SQ } \\
\text { SQ } \\
\text { SQ }\end{array}$ \\
\hline & D & $\begin{array}{l}\text { I } \\
\text { I } \\
\text { I }\end{array}$ & $\begin{array}{l}\text { SQ } \\
\text { SQ } \\
\text { SQ }\end{array}$ \\
\hline & D & $\begin{array}{l}\text { I } \\
\text { I } \\
\text { I }\end{array}$ & $\begin{array}{l}\text { SQ } \\
\text { SQ } \\
\text { SQ }\end{array}$ \\
\hline \multirow[t]{4}{*}{ OT } & D & $\begin{array}{l}\mathrm{I} \\
\mathrm{I} \\
\mathrm{I} \\
\mathrm{I} \\
\mathrm{I} \\
\mathrm{I} \\
\mathrm{I} \\
\mathrm{I}\end{array}$ & $\begin{array}{l}\text { SQ } \\
\text { SQ } \\
\text { SQ } \\
\text { SQ } \\
\text { SQ } \\
\text { SQ }\end{array}$ \\
\hline & D & $\begin{array}{l}\text { I } \\
\text { I } \\
\text { I }\end{array}$ & $\begin{array}{l}\text { SQ } \\
\text { SQ } \\
\text { SQ }\end{array}$ \\
\hline & D & $\begin{array}{l}\text { I } \\
\text { I }\end{array}$ & SQ \\
\hline & D & I & SQ \\
\hline
\end{tabular}

130 Pyke, et al., 2005. p. 6 I 


\section{Creating the case study framework from the five theory dimensions}

\section{Developing the overarching themes and dimensions}

Refer to Table 2 'Case study dimensions derived from five theories' in appendix (p. I53). The five theories were tabulated to show both the range of dimensions and how the related dimensions were grouped. These grouped dimensions were then summarised into three overarching themes for use in the case study framework. These are: Local Democracy and Governance, Active Citizenship and Social Capital, and are elaborated on below. In combination, enhancements in respect to these overarching themes result in a healthy level of community wellbeing.

Table 2 shows that some individual dimensions feature under more than one of the overarching themes. This has occurred because the indicators of these dimensions determine which overarching theme they relate to. For example, the theory dimension titled 'Influence' features under both the 'Local Democracy and Governance' and 'Active Citizenship' overarching themes.

The dimensions from the five theories that are included in the case study framework principally measure the relational nature of community wellbeing. The dimensions that cannot be directly impacted by community participation are excluded. These are dimensions such as economic growth activity and natural environmental resources. They remain important in their ability to indicate community wellbeing in those particular spheres of life, but are outside the scope of this study.

\section{Developing the indicators}

Refer to appended Table 3 'Case study indicators derived from five theories'.

Under each of the three overarching themes, these grouped dimensions and their respective indicators are tabulated to show how the case study indicators are derived.

While there are limits in the ability of indicators to capture the entirety of the wellbeing of a community, indicators are able to measure specific aspects that are important for understanding what key factors should be incorporated into building the wellbeing of communities. ${ }^{131}$ Salvaris and Wiseman assert that the more concise, relevant and accessible the indicator questions are to the local citizens, the more the important and concrete matters of the citizen's lives will be captured. ${ }^{132}$

\footnotetext{
131 Pyke, et al., 2005. p. 5

132 Salvaris \& Wiseman, 2004. p. 30
} 
Featured below is a table of guidelines to developing community wellbeing indicators from

Salvaris and Wiseman's (2004) Mapping Community Wellbeing report. The case study

framework for this research is underpinned by all the guidelines displayed.

(5) Good indicators measure important community outcomes ${ }^{133}$

The most important characteristic of a good set of community wellbeing indicators is that they provide an easily understandable guide to the state of play and trends in relation to the issues that matter to a particular community or group of citizens. The overall set of indicators should therefore:

- Be informed by an agreed, transparent framework of values and goals.

- Provide a sound basis for translating these goals and values into concrete outcomes.

- Strike the right balance between keeping the number of indicators small enough to provide a clear, focussed picture and comprehensive enough to adequately cover the highest priority economic, social, environmental, cultural and governance trends. As a general rule a suite of between 15 and 25 indicators seems to be $a$ useful target.

- Be meaningful and appropriate for the particular geographical and jurisdictional level.

- Include both objective evidence (e.g. crime rates) and subjective measures (e.g. are citizens feeling safer?).

- Be capable of showing both overall trends and trends in relation to particular population groups (e.g. capacity to be disaggregated by gender, age, race, ethnicity etc.). This will also allow indicators to be used to show changes in distributional as well as aggregate outcomes.

- Be capable of being expressed in plain language that resonates with relevant audiences.

\section{The case study framework}

The first overarching theme is Local Democracy and Governance, featured in Table 3,

p.154. This is demonstrated when effective leadership and management structures have been established. Vision-making and advocacy capabilities are developed and supported by these structures. Pyke et al demonstrate an example of these dimensions:

An active, confident and capable community shapes its own future by engaging its citizens in decision-making and fostering a stronger voice in determining the future. It is recognised that democratic principles and processes affect the quality of life of all citizens. ${ }^{134}$

The essential prerequisites of local democracy and governance are:

- Facilitation of democratic decision-making is established within the community.

- Skilled and experienced people positioned in a role that allows them to maximise the use of their unique skills.

- Trust in leadership formed through carrying out roles responsibly and effectively.

- Vision-making and advocacy, exercised by the community members' abilities to articulate the direction that the community is going in to obtain the required resources and partnerships necessary to reach their goal.

- Accurate and transparent representation and articulation of the beliefs and values of the community.

133 Salvaris \& Wiseman, 2004. p. 19

134 Pyke, et al., 2005. p. 46 
The second overarching theme is Active Citizenship. It is demonstrated by the collective commitment and ability to progress the community's vision, which is characterised by the community's active participation and membership to political and civic activities. Lochner et al demonstrate an example of these dimensions:

...the extent to which individual values are shared among community members will determine the ability of a community to organise and prioritise its need-fulfilment activities. A strong community is able to fit people together so that people meet others' needs while they meet their own. ${ }^{135}$

The essential prerequisites of active citizenship are:

- Community involvement in political, civic and social activities to the extent that initiative and responsibility is taken for the future of the community.

- Active and collective response initiatives develop through the community members' ability to perceive and address the local issues.

- Reciprocity and a shared mutuality occurs between individuals in the community.

- A sense of membership to the community is felt by the community members that empowers them to represent and advocate for the community's needs.

The third overarching theme is Social Capital. It is demonstrated by the extent of socially co-operative networks within the community that meet the common good of the individuals. The essential prerequisites of social capital are:

- Quality interactions between people provide positive experiences that enhance the bonds between people, increasing levels of interpersonal trust, solidarity and resilience in the community. ${ }^{136}$

- Friendships, mutual care and assistance are shared as a common form of support for each other.

- A sense of pride, safety, connectedness and satisfaction with both the relational and geographical aspects of the community. This is increased by and also results from community members meeting the needs established by the community. ${ }^{137}$

- Local services and facilities organised in a way that is relevant and accessible for the needs of the local community.

- Mutual support networks provide an internal feeling of safety and increases an "optimistic outlook on life." This creates opportunities for people to pursue "higher order activities...that also give meaning to our lives."'138

135 Lochner, et al., 1999. [from McMillan \& Chavis, 1986] p. 8

136 Lochner, et al., 1999 [from McMillan \& Chavis, 1986] p. 8

137 Pyke, et al., 2005. p. 33

138 Pyke, et al., 2005. p. 33 


\section{Developing the survey questions from the framework}

The case study framework shown in Table 4 includes the overarching themes, dimensions and indicators along with the survey questions.

Table 4: Case study framework \& survey questions

\begin{tabular}{|c|c|c|c|}
\hline $\begin{array}{l}\text { OVERARCHING } \\
\text { THEMES }\end{array}$ & DIMENSIONS & INDICATORS & SURVEY QUESTIONS \\
\hline \multirow[t]{2}{*}{$\begin{array}{l}\text { LOCAL } \\
\text { DEMOCRACY \& } \\
\text { GOVERNANCE }\end{array}$} & $\begin{array}{l}\text { Vision-making } \\
\& \text { advocacy } \\
\text { capability }\end{array}$ & $\begin{array}{l}\text { Indicator I. People in this community try to } \\
\text { influence what happens in this community } \\
\text { Indicator 2. Residents have strong opinions about } \\
\text { way things are done }\end{array}$ & $\begin{array}{l}\text { - After being involved in this project, I wanted } \\
\text { to be involved in future decisions that affected } \\
\text { my community... (derived from Indicators } \\
\mathrm{I}, 2,7 \text { ) }\end{array}$ \\
\hline & $\begin{array}{l}\text { Effective } \\
\text { leadership \& } \\
\text { management }\end{array}$ & $\begin{array}{l}\text { Indicator 3. Community Leaders/Town council are } \\
\text { effective } \\
\text { Indicator 4. Can trust community leaders }\end{array}$ & $\begin{array}{l}\text { - After being involved in this project, my trust } \\
\text { in the community leaders that were a part of } \\
\text { the project had... (derived from Indicators } 3,4 \text { ) }\end{array}$ \\
\hline \multirow[t]{4}{*}{$\begin{array}{l}\text { ACTIVE } \\
\text { CITIZENSHIP }\end{array}$} & \begin{tabular}{|l|} 
Political, civil \\
and civic \\
participation \& \\
commitment \\
\\
\end{tabular} & $\begin{array}{l}\text { Indicator 5. Participation in social, political and } \\
\text { community organizations } \\
\text { Indicator 6. Participation in sporting and recreation } \\
\text { activities } \\
\text { Indicator 7. People feel they have an active role in } \\
\text { making community function } \\
\text { Indicator } 8 . \text { People are willing to contact e.g. Phone, } \\
\text { write a letter to local officials }\end{array}$ & $\begin{array}{l}\text { - After being a part of this project, my } \\
\text { involvement in local community groups and } \\
\text { activities had... (derived from Indicators 5,6) } \\
\text { - After being involved in this project, I wanted } \\
\text { to be involved in future decisions that affected } \\
\text { my community... (derived from Indicators } \\
1,2,7 \text { ) } \\
\text { - After being involved in this project, I had } \\
\text { more interest in decisions that were being } \\
\text { made by the local council and government... } \\
\text { (derived from Indicator } 8 \text { ) }\end{array}$ \\
\hline & $\begin{array}{l}\text { Collective } \\
\text { action }\end{array}$ & $\begin{array}{l}\text { Indicator 9. Percentage of people believe its } \\
\text { important to work together rather than alone to } \\
\text { improve the conditions of the area } \\
\text { Indicator 10. Percentage of people volunteering } \\
\text { (regular and occasionally) } \\
\text { Indicator II. People speak out about differences } \\
\text { and work together to find ways to solve differences }\end{array}$ & $\begin{array}{l}\text { - How important was it to you that people in } \\
\text { your community worked together rather than } \\
\text { alone to improve the conditions of the area? } \\
\text { (derived from Indicator 9) } \\
\text { - After being involved in this project, I wanted } \\
\text { to volunteer more of my spare time to my } \\
\text { community... (derived from Indicators } 10,13 \text { ) } \\
\text { - After being involved in this project, it had } \\
\text { helped our community to work together to } \\
\text { find ways to solve our problems... (derived } \\
\text { from Indicator II) }\end{array}$ \\
\hline & $\begin{array}{l}\text { Reciprocity \& } \\
\text { Responsibility }\end{array}$ & $\begin{array}{l}\text { Indicator I2. Care about what my neighbours think } \\
\text { of my actions } \\
\text { Indicator 13. People engage in favours, e.g. Lending } \\
\text { of goods } \\
\text { Indicator 14. People feel that what happens in } \\
\text { community can affect them }\end{array}$ & $\begin{array}{l}\text { - After being a part of this project, I cared more } \\
\text { about what people in my community thought } \\
\text { of my actions... (derived from Indicator I2) } \\
\text { - After being involved in this project, I wanted } \\
\text { to volunteer more of my spare time to my } \\
\text { community... (derived from Indicators I0,I3) } \\
\text { - After being involved in this project, I felt I } \\
\text { could benefit more from what happened in my } \\
\text { community... (derived from Indicator I4) }\end{array}$ \\
\hline & \begin{tabular}{|l|} 
Empowerment \\
\end{tabular} & $\begin{array}{l}\text { Indicator I5. Feel that I am an important part of } \\
\text { this community } \\
\text { Indicator 16. People are willing to stand before an } \\
\text { outside group and state community needs } \\
\text { Indicator 17. Sense of optimism about the future of } \\
\text { the community }\end{array}$ & $\begin{array}{l}\text { - After being involved in this project, I felt like I } \\
\text { was a more important part of this } \\
\text { community... (derived from Indicator I5) } \\
\text { - After being a part of this project, my } \\
\text { willingness to ask for what our community } \\
\text { needs from local officials (like council) had... } \\
\text { (derived from Indicator 16) } \\
\text { - After being a part of this project, I felt more } \\
\text { positive for the future of my community... } \\
\text { (derived from Indicator I7) }\end{array}$ \\
\hline
\end{tabular}




\begin{tabular}{|c|c|c|c|}
\hline \multirow[t]{4}{*}{$\begin{array}{l}\text { SOCIAL } \\
\text { CAPITAL }\end{array}$} & $\begin{array}{l}\text { Sense of pride, } \\
\text { belonging \& } \\
\text { connectedness } \\
\text { to community }\end{array}$ & $\begin{array}{l}\text { Indicator 18. Sense of pride in community/ Proud to } \\
\text { tell others where I live } \\
\text { Indicator 19. My neighbourhood is a good place for } \\
\text { me to live, its important for me to live here } \\
\text { Indicator 20. Would be sad if had to move } \\
\text { Indicator 21. Care about what community looks like } \\
\text { Indicator 22. Casual interaction with other } \\
\text { Indicator 23. Use services in town } \\
\text { Indicator 24. People in community have most (some, } \\
\text { few or none) of friends living in community } \\
\text { Indicator 25. Neighbouring patterns and } \\
\text { relationships with people in neighbourhood e.g. } \\
\text { Number of neighbours one can identify by first name } \\
\text { or recognise, Number of people know well enough to } \\
\text { visit }\end{array}$ & $\begin{array}{l}\text { - After being a part of this project, I felt more } \\
\text { proud of my community... (derived from } \\
\text { Indicators I8,20) } \\
\text { - After being involved in this project, I think } \\
\text { that it had made this area a better place to } \\
\text { live in or to come to... (derived from } \\
\text { Indicators } 19,20 \text { ) } \\
\text { - After being a part of this project, I cared } \\
\text { more about what the community/area looked } \\
\text { like... (derived from Indicator } 2 \mathrm{I} \text { ) } \\
\text { - After being a part of this project, the amount } \\
\text { of times I talked to others I saw around my } \\
\text { area had... (derived from Indicator } 22 \text { ) } \\
\text { - After being involved in this project, my } \\
\text { knowledge of local services and facilities } \\
\text { had... (derived from Indicators } 23,3 \mathrm{I} \text { ) } \\
\text { - After being a part of this project, my } \\
\text { friendships with people in the area had... } \\
\text { (derived from Indicators } 24,25 \text { ) }\end{array}$ \\
\hline & $\begin{array}{l}\text { Interpersonal } \\
\& \\
\text { organisational } \\
\text { trust }\end{array}$ & $\begin{array}{l}\text { Indicator 26.Percentage of people who can get help } \\
\text { from friends, family or neighbours when needed } \\
\text { Indicator 27. Percentage of people who feel they can } \\
\text { trust people who live in their area } \\
\text { Indicator 28. Sense that this is a safe healthy } \\
\text { environment in which to raise children }\end{array}$ & $\begin{array}{l}\text { - After being involved in this project, it had } \\
\text { helped our community to work together to } \\
\text { find ways to solve our problems... (derived } \\
\text { from Indicators } 9,1 \mathrm{I} \text { ) } \\
\text { - After being involved in this project, I knew } \\
\text { more people that I could trust to help me if I } \\
\text { was in a crisis situation... (derived from } \\
\text { Indicators 26,27) } \\
\text { - After the community was involved in this } \\
\text { project it had helped to make this area safer } \\
\text { for people to be in... (derived from Indicator } \\
28 \text { ) }\end{array}$ \\
\hline & $\begin{array}{l}\text { Equality / } \\
\text { tolerance }\end{array}$ & $\begin{array}{l}\text { Indicator 29. Percentage of people who believe their } \\
\text { community is an accepting place for people from } \\
\text { diverse cultures and backgrounds } \\
\text { Indicator 30. Percentage of people who think } \\
\text { multiculturalism makes their life better }\end{array}$ & $\begin{array}{l}\text { - After the community was involved in this } \\
\text { project, I think that this place was more } \\
\text { accepting of people from different cultures } \\
\text { and backgrounds... (derived from Indicators } \\
29,30 \text { ) }\end{array}$ \\
\hline & $\begin{array}{l}\text { Social } \\
\text { supports }\end{array}$ & $\begin{array}{l}\text { Indicator } 31 \text {. Instrumental, emotional and } \\
\text { informational support }\end{array}$ & $\begin{array}{l}\text { - After being involved in this project, my } \\
\text { knowledge of local services and facilities } \\
\text { had... (derived from Indicators } 23,3 \text { I) }\end{array}$ \\
\hline
\end{tabular}




\section{$4 \quad$ Case studies}

\section{I Case study methodology}

The purpose of this study is to conduct primary research investigations within several case study communities that will assist in answering the research question. Conducting a case study is a suitable approach as it allows a variety of in-depth data to be collected that relates to a particular activity, in this case, a participatory place-making project.

Using four cases studies allows enough breadth for common findings to emerge and be quantified across all of the case studies. This number of case studies also sufficiently illustrates a wide application of participatory measures to the different types of issues occurring in a variety of marginalised communities.

\section{Selection Criteria}

This exploration requires a set of case studies that displays what appear to be successful examples of enhancing community wellbeing through community participation in placemaking. To be suitable, the case studies required the following. First, the research question limits the selection of communities to those where a significant amount of the population experience marginalisation (as defined in the literature review). Secondly, that the primary aim of both the process and the resulting built form is the enhancement of the quality of life for the specific community. Thirdly, that the process of decision-making for the project had to distinctly involve members of the community that were to be affected by the built development.

The above selection criteria was the only basis of choice for the case studies and as a result the selection is made up of one predominantly Pacific Island community, two predominantly Māori communities and one predominantly Pākehā community.

Two of the place-making projects have been completed over 5 years ago, and the other two are currently being built. However, the crucial component for measuring is the involvement of the participants in the decision-making process, which is typically concentrated at the early stages of a project, before any buildings are produced.

\section{Method for contacting case study communities}

The four case study communities were discovered through a variety of approaches. As previously mentioned, the case study community of Moerewa was first encountered before the thesis was undertaken. A comprehensive internet search was conducted, relevant networks of people and organisations were contacted and lists of contacts for potential case studies were compiled from resource reports and books. Initially, around ten of the most prospective projects were recorded. Telephone contact was made with the key facilitators 
to assess the appropriateness of the participatory process to the research question and the communities' willingness to contribute to the research.

\section{Methods of Investigation}

A variety of investigative procedures were required to collect a sufficient amount of information to answer the thesis question.

\section{Interviews}

The purpose of employing the technique of interview research is that it provides a valuable method for initiating dialogue that is able to reconstruct accounts of experiences: "By engaging others in dialogue in the interview process, interviewees may recreate their "world" through discourse organised around time and consequential events." 39 The interview method is used for two reasons: that it initiates dialogue for building an accumulative first-hand representation of the context and history of the community. Secondly, a recreation of the details of a process is able to emerge from the dialogue.

\section{Surveys}

The purpose of conducting survey research is to deduce the specific attributes of community participation that have been generalised, by sampling a representative population. Surveying has the advantage of asking focused questions and the ability to obtain rapid feedback from participants. Theoretically, surveys have the ability to achieve a greater amount of participation in a short period of time due to the relatively small amount of time the survey participants are required to invest.

\section{Supplementary Research}

Additional research was conducted from other available sources including the internet, published reports and multimedia material. These sources provide a greater objective representation of the communities and organisations that facilitated the projects.

\footnotetext{
139 Herndon \& Kreps, 1995. [citing Riesmann, 1990; Geist, \& Dreyer, 1993]
} 


\section{Interview methodology}

The aim of the first stage of the research is to collect a wide range of information relating the interviewees' perceptions on the success of the projects, the process and the contribution to community wellbeing from the facilitation of each.

\section{Interview design}

Refer to Form I in appendices, pages I59-160. A series of open-ended interview questions about the process was formulated, structured to follow the chronological order of the project. The initial questions asked the interviewees to describe their personal roles in the project; how they were engaged and what experience and skills they bought to the project. The second stage asked for the description of the context and situation of the community before the inception of the project; summarising the positive and negative characteristics of the community. The rationale for these questions was to provide a perspective of the community before and after the project so that the changes in the community that were due to the impacts of the project could be identified. The third set of questions aimed to understand the motivations and goals for the project; who initiated the idea, what needs were being responded to, any external influences, and what outcomes were aimed for. The fourth set of questions asked for the description of the whole process of the project; who was involved, what influence the participants had on decision-making, how this influence impacted the process, who benefited from the process, and an opinion on the necessity of the participatory process in achieving the intended outcomes. The next set of questions ask the interviewee to reflect on the process after the completion of the project; if the goals were achieved, to what extent did the participatory process contribute to achieving the goals, and what difference the participatory process has made to the community's wellbeing. The final set of questions ask for access to documentation produced at all of the stages of the project that would illuminate the process more.

\section{Selection of interview participants}

On-site, face to face interviewing is limited to the key people of each case study. They are people who have an immediate understanding of the community as well as the rationale and significance the project possesses for the continuing development of the community. As mentioned in the case study methodology, the key facilitators were contacted by phone to ask for their agreement to contribute to the research. 


\section{Method of data collection}

Interviewing the key facilitators of each project on site allows the greatest access to information regarding the context of the process and the community and additionally decreases the possibility of misinterpretation. Visiting the project site and the wider context it is located in is important to gaining an objective awareness of the social, economic, environmental and cultural influences upon the community. To maximise the benefits arising out of mutual dialogue, the interviews are dictaphone recorded to cause the least disruption to the dialogue and then transcribed.

\section{Survey methodology}

Community wellbeing indicators are selected and developed from five indicator theories sourced from the fields of community psychology, public health promotion, and local through to national government community wellbeing indicator frameworks.

As discussed in the summaries of the five indicator theories, it remains imperative that the attributes of community wellbeing are distinguished from the attributes of individual wellbeing. The measurement of community wellbeing will be deployed at a community level using two methods; the survey questions will be directed to asking the individuals' evaluation of the community's wellbeing, and these individual responses will be aggregated to represent a community response.

\section{Survey aim}

The aim of the survey research is to measure the indicators of community wellbeing that were enhanced by the individuals' participation in the place-making projects.

\section{Scope of measurement}

Community wellbeing as defined by the literature review proves to be an open-ended term that encompasses a large breadth of qualities. For the purposes of this research, the scope is limited to the relevant qualities of community wellbeing that could result from the community member's involvement in a participation process. It is also important that the scope of the selected indicators is relevant to the scale of the projects, as the range of indicator theories range from the focus being on a neighbourhood block and up to a national level. The scale of measurement of community wellbeing in this case study research is limited to the 'local geographical community' which is typically the site and immediate surrounding geographical area. For example, one of the case study's develop a range of different sites along a main street of a small town, therefore the 'community' affected would be defined as anyone who dwells in or uses these areas. The design of the survey questions 
will identify the 'community' as being related to the location and people affected by the place-making project.

The survey is a cross-sectional measurement, with data collected at one point in time. It is important to note that the case studies are at different stages of project completion.

\section{Survey design}

Refer to Form 2 in the appendices. The style and structure of the survey questions are influenced by several popular and widely established questionnaire instruments. Both the question styles used in the reports titled 'Quality of Life in New Zealand's eight largest cities' $^{\prime} 140$ and the 'Sense of Community Index' questionnaire ${ }^{141}$ are used to develop the style of the case study survey questions. These examples provide appropriate and accessible formats for asking the perceptions of individuals who have been involved in a process of relating to others and their environment.

\section{Question aim and structure}

The control for the survey is created by including an initial contextual statement to every question which limits the evaluation of community wellbeing to resulting from the participant's involvement in the project.

The questions ask the participant to evaluate their alignment with each statement question by rating them. The continuous Likert scale is selected for use as it is a common tool used in social research to rate items on a I-to-5 or I-to-7 Disagree-Agree response scale. ${ }^{142}$ The main scale used in the survey ranges in degrees of strong agreement to strong disagreement with the statement question. For example:

2. After being involved in this project, I wanted to be involved in future decisions that affected my community

\begin{tabular}{|l|l|}
\hline $\begin{array}{l}\text { strongly } \\
\text { agree }\end{array}$ & \\
\hline
\end{tabular}
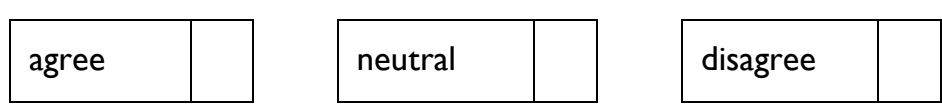
\begin{tabular}{|l|l|}
\hline $\begin{array}{l}\text { strongly } \\
\text { disagree }\end{array}$ & \\
\hline
\end{tabular}

The two other question scales ask for an alignment with the statement question using either a three point scale rating whether the subject in question has increased, stayed the same or decreased, or a four point scale rating if the subject is very important ranging down to not important. This quantitative data is then able to be expanded upon by providing space for respondents to note the reasons for their response.

140 Gatt et al., 2003. Reports released in 200I, 2003 and 2007.

141 Chavis, 2003. pp. I-2

142 Trochim, Retrieved 20.06.06. 
This opportunity for qualitative data is intended to provide an explanation of the reasons for the changed or continued levels of community wellbeing. It will also help to illuminate if there are any misunderstandings in relation to the interpretation of the questions and may also provide a highly personal account of the impact that the place-making projects have had for the participants. There is a further opportunity to extend the qualitative data in the space provided at the end of the survey questions asking if the participants wish to add any more thoughts about their involvement. As previously mentioned, the projects for all of the four case studies were at different stages of completion at the time that the survey was conducted. Consequently, the questions are framed from the stage that the project is in, that is either close to culmination or completed. The two projects that were completed frame the question retrospectively, for example: "After being involved in this project, I think that [...]" The other two projects that were in the later stages of completion at the time of the survey are framed as current questions, for example: "By being involved in this project, I think that $[\ldots] "$

\section{Potential variables and bias}

The questions are formulated and structured to combat a range of potential biases. It is assumed that there will possibly be natural bias occurring in the respondents' answers. The 'Hawthorne effect' and 'self-lifting' biases, when selected participant's tend to respond in a way that will most please the researcher, are counteracted by always relating the respondents' perception of their own involvement to tangible outcomes that are apparent in the community. The 'habit' bias of answering tick boxes similarly without considering each question on its merit, are counteracted by randomly alternating the different answer scales, separating each answer and question from the next with the 'reason line', and slightly changing the context wording at the start of each question. In order to maximise comprehension of the aim of the survey, the first question asks what parts of the placemaking project the participants were involved in. This strategy aims to ground the following tick box questions within the established community participation process of decision making.

\section{Method of administering and distributing survey forms}

Several strategies were employed to maximise the accessibility and ease of filling out and returning the survey. Considering that the sample population would not have sufficient access to email, hard copies of the survey were posted to participants. The survey form was designed to be filled in by hand with the answers to the questions responded to with a tick with an additional comment below. The individual survey forms were mailed to the 
addresses supplied by the participants with a pre-addressed and stamped return envelope included. The layout of the instructions and questions on the double-sided, two paged coloured form are designed to be clear and succinct and to create visual appeal. The number of questions are kept to a minimum with ample clear space around them. The university letterhead is included as required and helps to confirm the legitimacy of the research. To ensure a higher response rate, the closing instructions feature the date of the two week time limit for filling out and returning the form along with the researcher and supervisor's contact details. An information sheet, refer to Form 3 in the appendices, is attached to the survey explaining the overall research and intention of the survey, the assurance of the participant's anonymity and confidentiality in their responses, a reference to more information included on the back of the survey, and an offer of the research summary to be distributed when completed to the participants.

\section{Survey participants}

In order to measure how community participation in place-making has enhanced community wellbeing, the sample population is limited to the participants of this process. In acknowledging that there exists only a relatively small number of people that are involved in each case study, it requires that as many of those participants as possible contribute to the data collection.

\section{Definition of participants}

This research defines a 'participant' as a local community member that was involved in the process of decision-making for the place-making project. In reference to the definitions discussed in the literature review, participation is not merely an exercise in being consulted nor is it delegated power. The differing levels of participation in this research ranges from people that were present and contributed to decisions being made at community meetings up to a higher level of commitment of participating in decisions from the project inception and maintenance of the built form beyond the completion.

\section{Identification of sample population}

Due to the differing scale and contexts of the projects, the number of participants involved in making decisions for the place-making projects varies between case studies.

In order to reduce the potential bias in the survey caused by the possible selection of participants being limited to those who were positive about their involvement in the process, the participants were identified by three different methods. Initially the key contact people of each case study provided a list of the participants that they could remember along with known telephone, address or email contact details. The second method employed was 
to direct a search through web sites and other documentation or publications that featured the names or links to the participants. The third method was to telephone the people identified from the first and second method to question if they could identify any omitted participants.

The two projects that were completed more than five years ago have a greater marginalisation in gathering the optimum population, as a small percentage of the participants have subsequently moved away and are uncontactable. Despite the considerations mentioned above, each case study has an identified sample population that encompasses a fair representation of the people that have participated in various capacities and therefore can present an extensive picture of the means of participation.

\section{Method of contacting and obtaining participation in survey}

All of the identified participants were individually contacted by the researcher via a telephone call. During this call the research was explained, including details of the interview with the key contact person and the ethics approval gained. The intention for the survey research was described and the participants were asked for an indication of their willingness to participate in the survey. All of the participants contacted agreed to participate by completing the survey.

\section{Survey response rate}

Several days after the two week limit for returning the completed surveys was over, a small proportion of the surveys for each case study had not been returned. Follow up calls were made to all of the confirmed survey participants to check if they had received the survey in the mail and duplicate surveys were sent out to participants who had not received the survey. All efforts were made to retain the anonymity of the participants by limiting the questioning to their receipt of the survey. 


\subsection{Description \& Findings}

\section{CASE STUDY 1: Gisborne skateboarding park youth centre}

Through a participatory process involving youth who used the skatepark and the local community, the participant group developed a proposal for the addition of a youth centre office \& clubrooms building to the existing skateboarding park at the Alfred Cox skatepark complex.

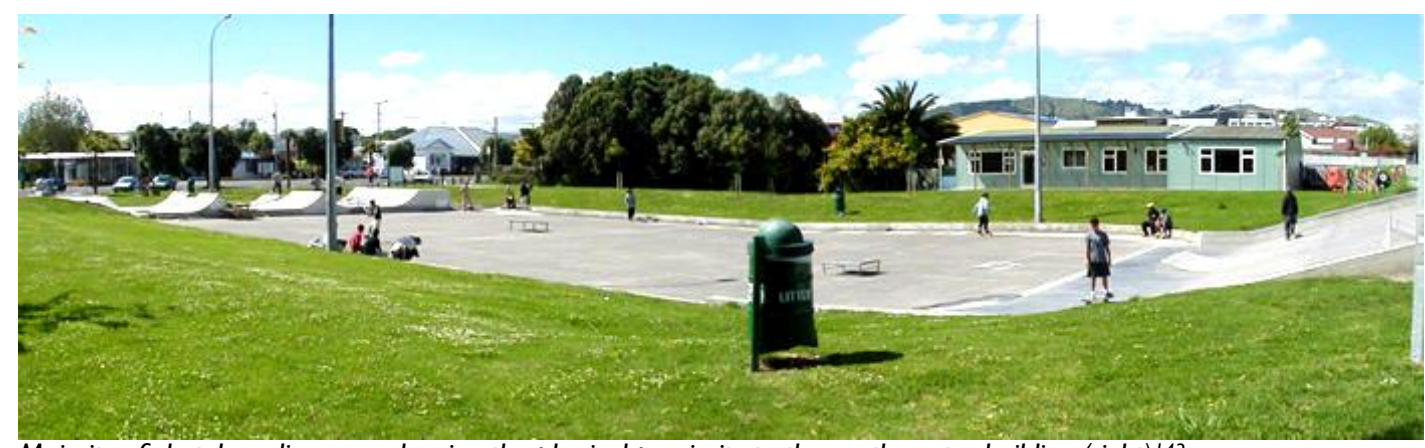

Majority of skateboarding area showing the physical proximity to the youth centre building (right) ${ }^{143}$

\section{Project location \& site description}

The Alfred Cox skatepark complex is located approximately five minutes walk from the centre of Gisborne city. The skatepark area is situated on the corner of the larger grassed park site and perimeter surrounded on two sides by residential housing, one side by businesses including Pizza Hut, with the skatepark area abutting Grey Street, directly opposite from the Gisborne Information Centre.
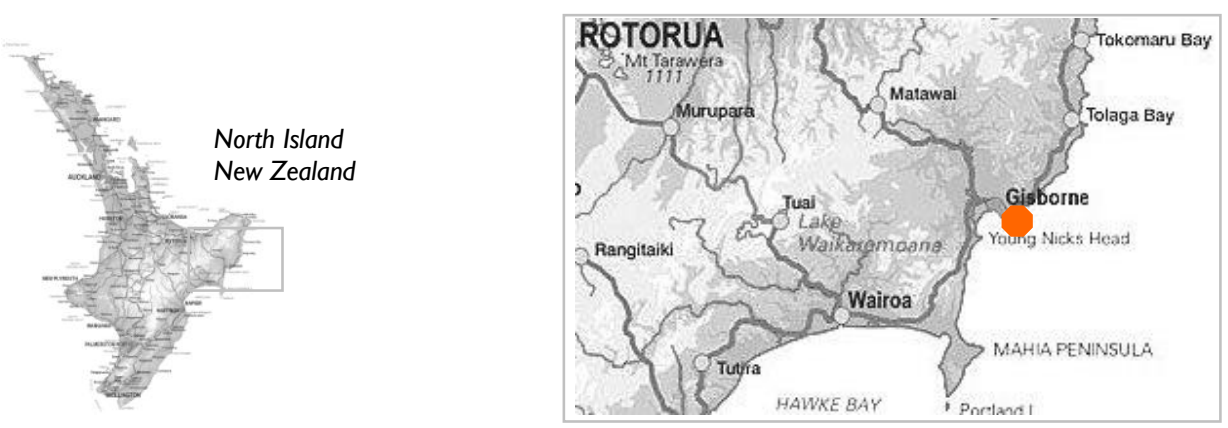

\section{Contextual history of the original skatepark and user community}

Originally, the Alfred Cox Park was used as a roller skating rink, which had lost popularity over the years. Two employees, from Gisborne District Council (GDC), one of them Terry McMillan, had the idea of turning the area into a usable skateboarding park. GDC consulted

143 Skatepark directory, Retrieved 17.05.2006. 
associated businesses and the community, planning was carried out by an Australian skatepark specialist and funding was secured for the project.

The new skateboarding park was completed in late 1998, and while providing a useful and enjoyable recreational space for the youth of Gisborne, it had many problems arising out of issues such as overcrowding, no adult supervision, property being stolen and incidences of violence.

It just got so crowded with kids... about one hundred to one hundred and fifty kids down there with no adults...every week there would be two or three newspaper articles about bikes being stolen, and skateboards being stolen, kids being bullied and big fights, massive fights constantly happening all the time. ${ }^{144}$

The businesses and residents that surrounded the skatepark started to complain about the violent and uncontrolled behaviour and increased noise levels. Gisborne Information Centre had also complained.

The youth have caused over-crowding, inside seats have been used to lie on...they have created an extra demand on staff, who should be focused on visitors...car parks associated with skateboard park making it impossible for visitors, especially camper vans, to find a park... ${ }^{145}$

Other behaviours occurring in the skatepark were bullying, littering, vandalism, drug and alcohol use and gang activity and fights, "...they actually came down there to have a fight, it was a place where people met to do things." 146 Subsequently a 7pm closure bylaw was created for the park and was enforced for about six months. Local renowned gangs met on the site often and had many seriously violent altercations. GDC were eager for an approach that would appropriately manage the uncontrolled behaviour.

...they were having big scraps, some quite serious stuff happening. So the whole public was up in arms about the whole thing...the skatepark idea was great, and it was awesome that the kids are using it, but...the Council hasn't thought about how to manage it. And so people were in dire straights, and nobody knew what to do. ${ }^{147}$

Around the same time, the Gisborne Youth for Christ (YFC) workers were running a weekly club from a neighbouring suburb's surf club that included some of the youth that used the skatepark and assisted some to attend a skate competition in Whakatane.

\footnotetext{
144 Tims interview, August 2006.

145 Gisborne Youth for Christ. 1999. p. 3

146 Kingsbeer interview, August 2006.

147 Tims interview, August 2006.
} 


\section{Interviewees and project role}

The main contact and interviewee for this place-making project is Dave Tims who was the director of Gisborne YFC, working in Gisborne to assist youth and community development. YFC is an international charitable organisation, and YFC New Zealand is a national body of fifteen centres with each centre operating as its own incorporated society. Tims' project role was to facilitate the youth user group to promote and manage the facility development of the youth centre building "passing on the vision...the big picture stuff"' 148 and apply for funding. Three other people who had key roles in the participatory process were interviewed to provide accompanying information. Graham Breckell is the manager of Gisborne Information Centre, his project role involved assisting in promoting the youth centre proposal to the Gisborne community. Shane Kingsbeer was at the time of the project, a fourteen year old skateboarder and a member of the Surf and Skate club (SAS club). His project role included being a SAS youth leadership committee member to represent the skatepark users views and to promote the youth centre to the wider community and GDC. Terry McMillan is the manager of the Parks and Services Division of GDC, his project role was to provide project manager services on behalf of the GDC.

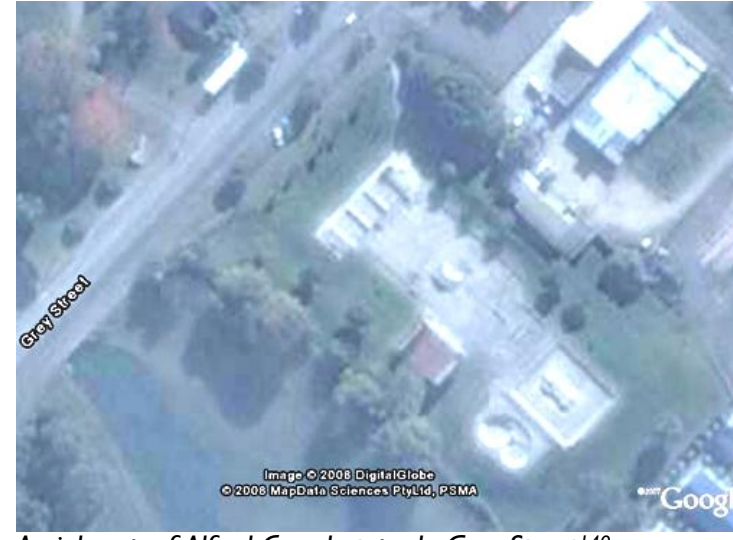

Aerial map of Alfred Cox skatepark, Grey Street ${ }^{149}$

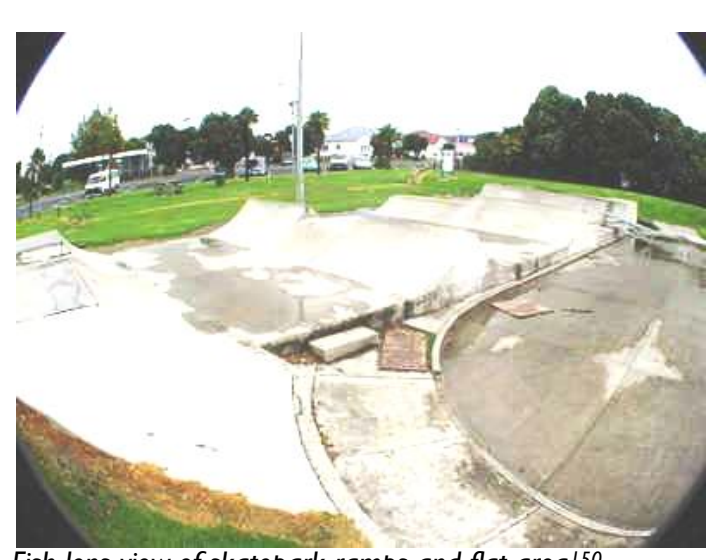

Fish lens view of skatepark ramps and flat area ${ }^{150}$

148 Tims interview, August 2006.

149 Google Earth, Retrieved 28.02.08.

150 Skatepark directory, Retrieved 17.05.2006. 


\section{Case study findings \& interpretation}

\section{Profile of community participants in project}

Twenty surf and skate club members were involved in the decision-making process for the youth centre development. From this larger group the four members of the youth leadership committee collaborated with the four other stakeholders from council, local police, business sector and YFC youth workers to form the working group. The surveys were sent to the contactable members of SAS, the youth leadership committee and the YFC youth workers as these participants were the most consistently involved throughout the public space project. Survey forms were mailed to the six contactable participants, and four survey responses were received which gives a $66 \%$ response rate. All of the respondents' participated in most of the identified stages of the project; the parts of the project that most participated in were the community meetings, small group meetings, organising and directing the project, getting others involved in the project, making decisions about the project, presenting the project to others, designing buildings or areas and helping to build the initial project buildings and areas.

\section{Method of interpretation and presentation}

The interview information, additional material and survey responses are interpreted to provide evidence of the specific dimensions of community well being that were enhanced by the participatory process. The raw data from the survey is presented in tables to illustrate the accumulated findings. The category abbreviations are: strongly agree (SA), agree (A), neutral $(N)$, disagree $(D)$ and strongly disagree (SD). 


\section{Participatory processes \& community wellbeing findings}

\section{PROJECT INCEPTION PROCESSES:}

\section{Overview}

The local people associated with the skatepark organised a meeting to discuss solutions to the negative social behaviour at the skatepark. In order to create a positive environment at the skatepark, two YFC youth workers decided to volunteer their time to organise events and build a respectful group attitude amongst the users based at the skatepark. A surf and skate club, SAS, formed with up to thirty members meeting weekly at the park where the youth ran their own competitions and developed teamwork skills. Breckell approached the YFC workers with the youth centre addition idea to provide a responsible presence at the park to regulate users' behaviour and continue their positive involvement and role-modelling with the youth.

\section{Local community \& \\ stakeholders meet to discuss concerns}

\section{Intentions}

Local residents, businesses, GDC, YFC and the Gisborne community police organised a local meeting to collectively discuss approaches to manage the negative behaviour at the skatepark.

\section{Findings}

Enhanced Collective action: After the local community concerns meeting, Breckell took a collaborative approach to suggest to Tims the idea of developing a youth centre at the skatepark. He suggested that YFC's responsible presence would regulate the users' behaviour and retain YFC's positive involvement and role-modelling with the youth.

So Graham [Breckell] said... why don't you put some building or something on there to supervise the skate park... getting involved in the skate park. And then my role as the coordinator/director or the chairperson, was to facilitate the whole thing. ${ }^{151}$

Breckell: So when he [Dave] went to Council, saying... [about] this idea for the skate park, I went along and said I totally support the idea. We run the Information Centre right opposite and it certainly needs some controls in it. So really he did it all, I just sort of suggested that it might be an opportunity. 152

\footnotetext{
151 Tims interview, August 2006.

152 Breckell interview, August 2006.
} 
YFC youth workers

volunteer at park \& develop

skate club with users

\section{Intentions}

In responding to the community-identified concerns about the behaviour at the park, the YFC youth workers volunteered to organise group activities with the skatepark youth.

Through these activities they intended to build and role-model positive relationships and develop respectful group behaviour.

\section{Findings}

Enhanced Reciprocity \& responsibility, Vision-making \& advocacy: Breckell suggests that the rolemodelling leadership of Tims and his co-worker has encouraged the skaters to learn independent and group responsibility skills. He suggests these have consequentially enabled the youth to make positive life changes.

I suppose Dave and his team have made contact with a lot of young people, and probably turned a few lives round. And in that regard, it's probably been quite successful. I think it's probably been a really good place where some young people have learned a bit of responsibility, because what you sometimes get with these programmes is you get an older teenager taking a bit of responsibility for a group of young people, bringing them along and coaching them... generally people work better with people closer to their own age. So I think it's a positive aspect in the community. ${ }^{153}$

Enhanced Sense of pride, belonging \& connectedness to community; Interpersonal \& organisational trust: Kingsbeer comments that the YFC youth workers commitment to creating a positive attitude and environment at the skatepark changed the anti-social behaviour to establishing a participatory and positive group culture which enhanced the community's cohesion.

Yeah it definitely changed the feeling around the place just because there was a new group of people who weren't just coming on the Thursday night...they were coming down there just to hang out. And now there's a lot of people who come down there now who don't even own a skateboard and just hang out...everyone sort of just became a group. ${ }^{154}$

\footnotetext{
153 Breckell interview, August 2006.
}

154 Kingsbeer interview, August 2006 


\section{Skate club team-building}

events

\section{Intentions}

The skateclub participated in team building events such as a trip to a skate competition and organising their own local competition. The intention was to give the skaters the learning experience, to build friendships amongst them and learn group co-operation skills.

We then took them to Whakatane...to a competition and to see what's happening. And then later on the way back we said, 'how about you guys run a skate comp?' The kids basically ran it, so we wanted to make it quite clear that this wasn't an adult thing... it was going to be a kid's thing. ${ }^{155}$

\section{Findings}

Enhanced Interpersonal \& organisational trust; Political, civil \& civic participation \& commitment: Tims discusses how giving responsibility to the skaters to run the competition resulted in the skaters trusting the youth workers.

The whole idea was that the kids were the judges. They were taught the formula of how to do it, but they ran it and they picked the music... That's how we formed a level of trust with the kids over that. 156

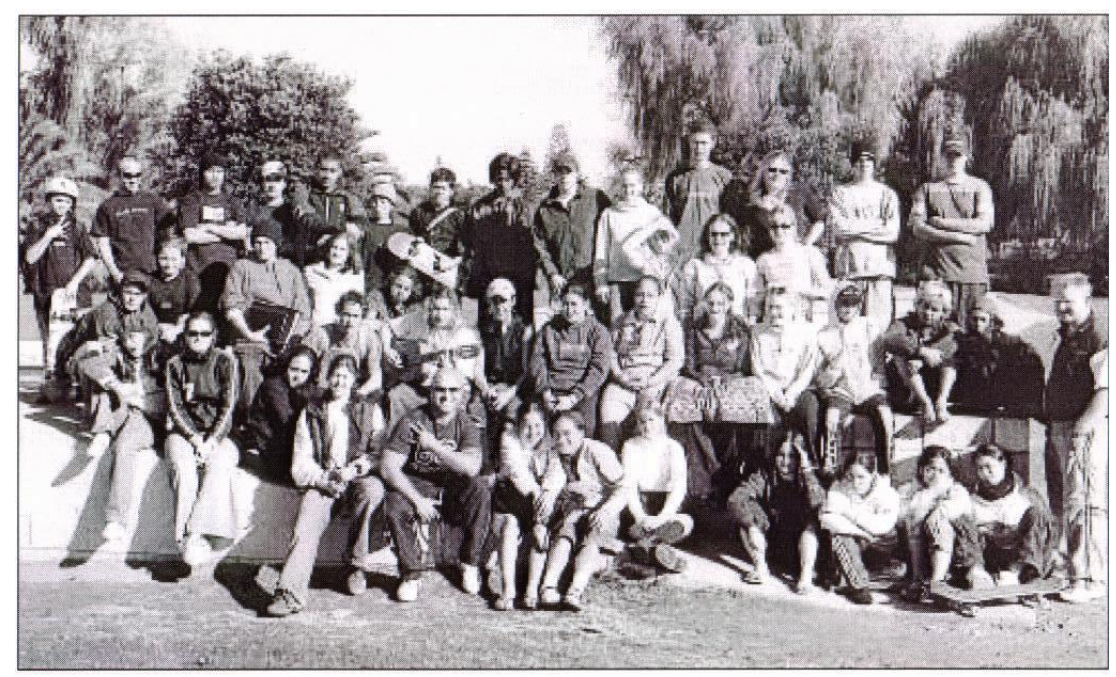

S.A.S club 2003 at Alfred Cox skatepark complex ${ }^{157}$

155 Tims interview, August 2006.

156 Tims interview, August 2006.

157 Mead, (photographer). 14.06.2003. 


\section{PROJECT BRIEFING PROCESSES:}

\section{Overview}

The youth leaders discussed the youth centre idea with the SAS club members to get their opinion on what services it could provide. A youth leadership committee formed from the SAS club members who developed the ideas for the youth centre and communicated with the other skatepark users to get their input. McMillan met with Tims to discuss possible venues and encouraged YFC to submit a youth centre proposal to the GDC, using the information gathered from the skatepark users.158 GDC were impressed by the proposal's potential and urged YFC to write a submission to the GDC annual plan. ${ }^{159}$

\section{Users involved in discussing future skatepark ideas}

\section{Intentions}

The intention of involving the youth in the youth centre discussions was to engage them in contributing to the skatepark plans. Tims and Kingsbeer discuss the effective engagement approach of employing an informal relational and conversational type of participation.

...we were always talking about it, what was going on, cos we were meeting weekly. We were down there all the time, a lot of chit chat kind of stuff... there's lots of consulting with the kids, none of that was called a meeting, it's actually just hanging around...160

Its just a group of people throwing ideas around, expressing how they feel, and what they think, trying to come to a conclusion where everyone, everyone's never happy...but to get the majority of people happy with what we do. ${ }^{161}$

\section{Findings}

Sense of pride, belonging \& connectedness: Better area to live in/come to

SA $\quad A \quad N \quad D \quad S$ Empowerment: More positive for future of community

IIII

II I II

Enhanced Sense of pride, belonging and connectedness; Empowerment; Interpersonal \& organisational trust: Tims reflects that the skaters' inclusive and appropriate engagement in the youth centre project and youth committee was a hugely positive process as it enabled the youth to be focused on an in-depth and relevant project.

...it was the kids input and the whole way we were able to include them as part of it... For that era, for those kids... Shane's [Kingsbeer] age group, he must be 22 now, it was big. ${ }^{162}$

\footnotetext{
158 Gisborne Youth for Christ, 1999. Skate \& Youth Centre Proposal.

159 Gisborne Youth for Christ, 1999. Submission to Gisborne District Council Annual Plan.

160 Tims interview, August 2006.

161 Kingsbeer interview, August 2006.
} 
All of the survey respondents strongly agree that their involvement in this project has made the area a better place to live in or to come to. One comments that, "I saw a huge change in the attitude of the people there." The respondents answered neutral, agree and strongly agree in feeling positive for the future of their community, with the strongly agree comment; "I felt positive for the skating culture of the Gisborne community."

\section{Representative youth leadership committee forms}

\section{Intentions}

Kingsbeer, age fourteen at the time, was asked to form a youth leadership committee within the group to further develop the youth centre idea. The intention was to ensure that the youth committee were learning group leadership skills and that the skatepark youth were being authentically represented.

...I guess just getting people interactive in a group thing, and then I ended up being one of the leaders... and we came up with ideas for things for the skateboarders...the idea came up about putting up an office for Dave, and a club room and a shop for the skateboarders down there, so it all sort of kept going. ${ }^{163}$

\section{Findings}

Empowerment: Feel a more important part of community

$\begin{array}{ccccc}\text { SA } & \text { A } & \text { N } & D & S \\ \text { I } & \text { III } & & & \end{array}$

Enhanced Empowerment; Political, civil and civic participation \& commitment; Collective action; Reciprocity \& responsibility: During the development of the youth centre idea, the participatory process successfully empowered and increased the personal development of the SAS club youth. The youth leadership committee took responsibility for meeting to discuss the skatepark issues with Tims and his co-worker and the committee applied for grants to employ a youth worker to supervise on site.

We also had a leadership committee made up of four kids. And they used to meet fortnightly and they would come and tell me and Simon all the issues that were happening at the skate park, and solutions and ideas that they had. And Shane [Kingsbeer] was a part of that. We asked him to form the leadership committee...It was quite big cos, these kids formed a crew...that was quite important too, because that gave them an opportunity to talk to us about what was going on, in their eyes. We got a couple of them to write... a reference. That was quite big. It was 15 year old saying why Lotteries should give us the money to employ Simon to be down there. ${ }^{164}$

\footnotetext{
162 Tims interview, August 2006.

163 Kingsbeer interview, August 2006.

164 Tims interview, August 2006.
} 
Kingsbeer reflects that being involved in the process had increased his sense of responsibility, “....it was a good thing to get involved with when I was younger... as long as I was skateboarding I was having an influence, and going to talk to Dave [Tims] about things..."165

The respondents agree and strongly agree that they felt a more important part of the community after being involved in the project, with an agree comment; "I felt a part (embraced) of the community not necessarily important."

The entrepreneurial and passionate leadership of the YFC youth workers significantly impacted the lives of the SAS club youth. The youths' empowerment has been enhanced by the supportive environment and friendships that the youth workers provided. One respondent expresses that the support and guidance they received while they were involved in the project catalysed a positive life change for them;

My involvement with the Alfred Cox Skatepark in Gisborne was very full on. I was around while the park was being shaped. Then later on when we put a building on it. I got so involved with this project that it helped change the course of my life. When I first got involved with YFC (Youth for Christ) I was unemployed, through my involvement they employed me part-time, then assisted me through a diploma in youth work. After completing the diploma I was hired as a Skatepark supervisor part-time. Also worked in Alternative Education which was established at the Skatepark. Then I moved on to train as a counsellor of which I am one paper away from a diploma. Through the whole journey YFC and other community organisations Te Ora Hou have been fully encouraging and many times financially supportive also. In a nut shell I owe a lot to my friends who journeyed with me.

\section{PROJECT IMPLEMENTATION PROCESSES:}

\section{Overview}

The YFC leadership, Breckell, Tims, McMillan, Kingsbeer and the community police formed a project team to develop the submission. Kingsbeer presented the submission to a GDC meeting with the Mayor, councillors and other community stakeholders, which they were encouraged to develop into a resource consent. ${ }^{166}$ As part of this process, several community consultation meetings were held at GDC and the park site where representatives from the youth committee and YFC promoted the concept to various community groups and major stakeholders. Fifteen to twenty community groups supported the project the whole way through and wrote reference letters. The Mayor also supported and negotiated funding to assist with the project.

165 Kingsbeer interview, August 2006.

166Gisborne Youth for Christ, 1999. 


\section{Community members \& youth committee form project team}

\section{Intentions}

The youth committee members and stakeholders associated with the park formed a project team in order to represent the skatepark community in the youth centre decisions. The intention was to also build the leadership and team work abilities of the youth members.

Tims' discusses the importance of user and stakeholders' collaboration:

[The approach] would be different in a whole lot of different contexts, but the principles would be very much the same... we've got to find ways of bringing people together...instead of us just charging in and doing it, with a whole net of consultants. ${ }^{167}$

\section{Findings}

Collective action: More important to work together to improve conditions

Collective action: Want to volunteer more time

Collective action: Community works together to solve problems

III

Political, civil \& civic participation: Want to be involved in future decisions

Political, civil \& civic participation: More involved in local groups/activities

Reciprocity \& responsibility: Benefit more from what happens in community

Sense of pride, belonging \& connectedness: More proud of community

Interpersonal \& organisational trust: Know more people to trust in crisis

Enhanced Collective action; Equality \& tolerance: One respondent said that her involvement in the project increased her team work abilities, understanding of the community's diverse needs and increased her friendships and connectedness; "The project increased my confidence in being part of a team. I also acknowledged other people's needs, their lifestyles and situations. I have met a lot of people through SAS and was a great experience to be a part of." Most respondents' think it was very important that their community worked together rather than alone to improve the conditions of the area, one respondent was undecided. One that answered very important comments; "We tried often to get people involved. Disheartening when it doesn't happen though."

Enhanced Vision-making \& advocacy; Reciprocity \& responsibility; Collective action; Political, civil and civic participation \& commitment: Respondents answered neutral and strongly agree about wanting to volunteer more of their spare time to their community, with a strongly agree comment of; "Yes very true, but soon ran out of time in a week." The respondents are

167 Tims interview, August 2006. 
hesitant in their response that by being involved in the project they wanted to be involved in future decisions that affect their community, with answers of neutral, agree and strongly agree. One respondent's agree comment was "Not necessarily. There were things I didn't want to get involved in" and another's neutral comment of "It's a lot of work, time and commitment to get involved in." These comments suggest the depth of the commitment required for the youth centre project has time and energy consequences, rather than the willingness to participate. Respondents answered neutral, agree and strongly agree about feeling they could benefit more from what happened in their community after being involved in the project, with the strongly agree comment of; "I saw the community I lived in, in a better more healthy way." The respondents' involvement in local community groups and activities had mostly stayed the same, with one respondent saying it had increased with the comment of; "The more exposure we had, the more people invited us to see/visit/join their groups." The respondents answered neutral, agree and strongly agree that being involved in this project helped their community to work together to find ways to solve their problems, with the neutral comment of; "Some people were unable to see the positive work. But many people helped because their children skated there."

Enhanced Sense of pride, belonging \& connectedness to community: Respondents answered neutral, agree and strongly agree that they felt more proud of their community, with the accompanying agree comment of; "Yes many times I saw things that made me feel proud. But also showed an unseen side to the community."

Enhanced Interpersonal \& organisational trust: Respondents agree and strongly agree about knowing more people they could trust to help them if they were in a crisis situation, with the strongly agree comment of; "Yes as time went on great friendships were formed." 


\section{Project team develop \\ submission \& youth \\ present to council}

\section{Intentions}

Kingsbeer, as the youth representative, presented the submission to the Mayor and councillors. The intention was for GDC to understand that the users have been represented in developing the youth centre and to gain maximum support from the council authorities for the project.

\section{Findings}

Empowerment: More willing to ask officials to meet needs of community Political, civil \& civic participation: More interest in decisions made by officials Vision-making \& advocacy capability: Want to be involved in future decisions

$\begin{array}{ccccc}\text { SA } & \text { A } & \text { N } & \text { D } & \text { S } \\ \text { II } & & \text { II } & & \\ & \text { II } & \text { II } & & \\ \text { I } & \text { I } & \text { II } & & \end{array}$

Enhanced Empowerment; Political, civil and civic participation \& commitment; Vision-making \& advocacy: Kingsbeer reflects on the positive challenges of promoting the youth centre and the enhanced teamwork that resulted from the project teams' collaboration,

I was a bit nervous and I think at one stage they had delegates from around New Zealand came to the skatepark and we talked about it to them...To get what we wanted this is what you had to do, so everyone got behind it and by doing that, they can't ignore it, they had to end up agreeing. And we helped convince them really. ${ }^{168}$

McMillan, in his role as GDC Parks and Services manager, was impressed with the participation, commitment and articulation of the skatepark users in expressing their aspirations for the youth centre addition at the Council meetings on the project's development;

The meetings were quite well attended. I was quite impressed with the way the young skaters could voice, express their ideas and opinions. I was quite impressed because in a lot of council meetings, people sit there and don't actually say what they mean and mean what they say. So it was quite refreshing, they were really good to deal with. ${ }^{169}$

The respondents' willingness to ask for what their community needed from local officials (like councils) after they had been involved in the project had stayed the same and increased, with an increased comment of; "Definitely, I even applied for grants to help get more equipment."

The respondents varied between neutrality and agreement that by being involved in the project they had more interest in decisions being made by local government and wanted to

\footnotetext{
168 Kingsbeer interview, August 2006.
}

169 McMillan interview, August 2006. 
be involved in future decisions that affected their community. One neutral comment was;

"No not really." The answers and comments suggest that the respondent's perceive the link between political decision-making and the development of local projects to be inconsequential.

\section{Youth promote \& seek support from local stakeholders}

\section{Intentions}

Kingsbeer presented the youth centre concept to local iwi and the Safer Communities Council who represent many of the major social service organisations. The intention was to gain community-wide support for the project in order for it to proceed.

\section{Findings}

Reciprocity \& responsibility: Care more about what community thinks Effective leadership \& management: More trust in community leaders Equality \& tolerance: Community more accepting of different backgrounds Sense of pride, belonging \& connectedness: More knowledge of local services Sense of pride, belonging \& connectedness: Talked to others in area more Sense of pride, belonging \& connectedness: More friendships in area Collective action: Community works together to solve problems

$\begin{array}{ccccc}\text { SA } & \text { A } & \text { N } & \text { D } & \text { S } \\ \text { II } & \text { I } & & & \text { I } \\ \text { III } & & \text { I } & & \text { I } \\ \text { II } & \text { I } & \text { I } & & \\ \text { IIII } & & & & \\ \text { III } & & \text { I } & & \\ \text { III } & & \text { I } & & \\ \text { I } & \text { II } & \text { I } & & \end{array}$

Enhanced Political, civil and civic participation \& commitment; Collective action; Reciprocity \& responsibility: Tims states that around fifteen to twenty community groups in total supported the project the whole way through and wrote reference letters. He discusses how the surrounding residential and commercial properties were very enthusiastic about the youth centre proposal and willingly agreed to the resource consent submission.

With the proposal and the resource consent we actually had to get a yes from all those people around us. And the response to that was like 'wow, real awesome, great!'... So the Pizza Hut, the Information Centre and the residents who lived along there were stoked. It was all part of the resource consent stage, them being ok with it, so a lot of consulting, too much. 170

The Mayor wrote a reference letter for the youth centre and negotiated funding with YFC to assist with resource consent approval, land lease and service connection options.

The respondents mostly agree and strongly agree that they cared more about what people in their community thought of their actions after they had been involved in the project. One

170 Tims interview, August 2006. 
of the respondent's agree comment's was; "I was aware that always many people in the community knew who I was," while one respondent strongly disagrees with the statement and comments that; "I'm not too worried about what people think, but we have a neutral/gentleman's agreement with Gisborne Council and we usually respond to their ideas.”

Enhanced Effective leadership \& management: The respondents' trust in community leaders after they had been involved in the project had mostly increased, with the comment; "In many areas they increased, I felt that some community leaders were also against the project too." There was one answer that it had stayed the same and another that it had decreased with the accompanying comment of; "[Increased] with some individuals, decreased with others."

Enhanced Equality \& tolerance: The respondents answered neutral, agree and strongly agree that their community was more accepting of people from different cultures and backgrounds after they had been involved in the project, with the neutral comment of; "Gisborne is very small, so cultural interaction was limited."

Enhanced Sense of pride, belonging and connectedness to community; Social supports: All respondents are unanimous that their knowledge of local services and facilities in the area had increased after they had been involved in the project. One respondent added; "We constantly looked for support from the community while we ran holiday programmes." Both the amount of times the respondents' talked to others they saw around the area and their friendships with people in the area had stayed the same and increased after they had been involved in the project, with the respective increased comments of; "We became seen by the public, which gave a lot of rapport" and "Definitely. More conversation with parents, supporters, teachers." In asking that if being involved in this project helped their community to work together to find ways to solve their problems, the respondents answered neutral, agree and strongly agree, with the neutral comment of; "Some people were unable to see the positive work. But many people helped because their children skated there."

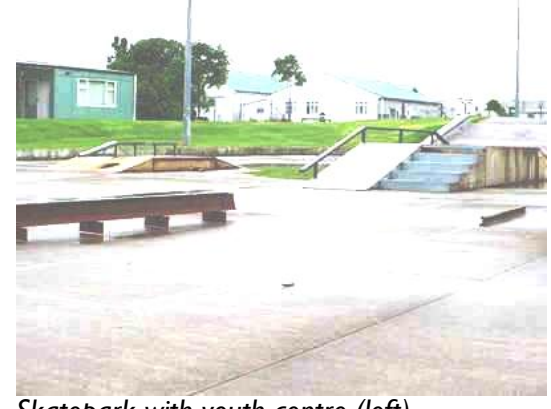

Skatepark with youth centre (left)

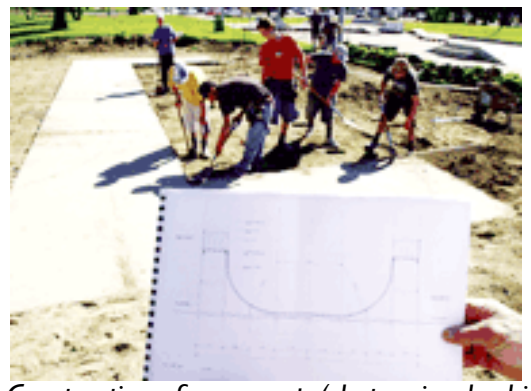

Construction of new ramp (skaters involved in designing) 


\section{PROJECT COMPLETION PROCESSES:}

\section{Overview}

Fundraising and setting the budget started in July 1999 by YFC/SAS and construction started in August. One of the surrounding businesses supported the development by allowing the building materials to be stored on their site. Construction of youth centre was completed in 1999, with the SAS club youth involved in planning the opening of the youth centre.

\section{Project team presents \\ opening of completed project building}

\section{Intentions}

The opening of the completed youth centre addition aimed to involve many community members to represent the community-wide process. Tims discusses the SAS club members involvement in planning the opening event,

...they were involved in the opening; we were always talking about it, what was going on...because we were meeting weekly. We were down there all the time... because Shane was heavily involved he'd tell the guys what was going on, as much as he could as a 14 year old. ${ }^{771}$

\section{Findings}

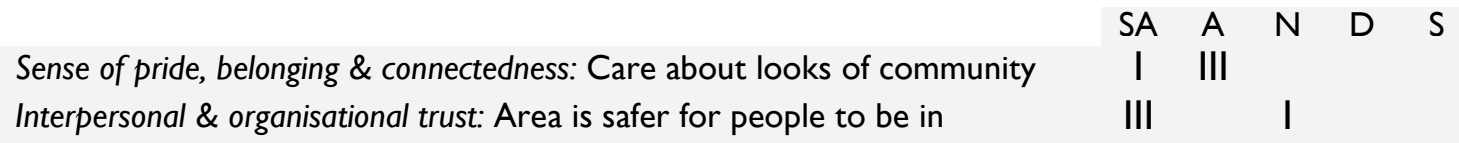

Enhanced Collective action; Reciprocity \& responsibility; Empowerment: One respondent attributes the success and appeal of the completed youth centre to the involvement and commitment of the skatepark users in the long process of decision-making about the youth centre development.

After many months of design mock-ups [by youth club and leaders], fundraising, council meetings and approved actions, it was great to see youth primarily involved in the final decisions that were made. The new design, clubrooms and flood lights enhanced the Alfred Cox Skatepark making it a safer and far more inviting environment that parents willingly could leave their younger children for an hour or so and feel comfortable with the public users and supervision during this time. The clubrooms enabled the small group of volunteers to have a 'base point' which provided support, first aid, time out area's (computers, televisions, ping-pong tables, etc) and food and drink for the youth that skated there during the day. The involvement of the project however proved to be very hard work, and toll taking trying to please all areas of the board [community stakeholders], over an extremely long process, however the Gisborne community supported the project 100\% all the way bringing everyone closer together.

171 Tims interview, August 2006. 
Tims admits that while there were a few initial "teething issues" after the youth centre was completed, with a few skateboards being stolen, he states that there occurred a change from a 'culture of fear' between users at the skatepark to a positive attitude towards each other over the course of the project, "... over the period of a year, the whole culture changed from being one of fear about stuff happening..."172

Enhanced Interpersonal \& organisational trust; Sense of pride, belonging \& connectedness to community: Tims expresses that the skatepark users and wider community involvement in the youth centre project has resulted in respectful behaviour at the skatepark. This is shown through the responsible use of the facilities in comparison to the typical behaviour that the public expects.

...people forget the history of what it was like seven years ago. People just accept it now, that's what a skatepark is. Although outsiders... who don't know anything about skateparks, you can tell the difference because its graffiti free, it's tidy, it's clean. ${ }^{173}$

The respondents agree and strongly agree about caring more about what the community/area looked like after they had been involved in the project. Respondents answered neutral and strongly agree that their involvement in this project helped to make this area safer for people to be in, with the strongly agree comments of; "There were adults who helped by supporting what was done by us (YFC) working there" and "Security and adult supervision was put in place along with flood lights - not part of the original plan however made the park safer for the younger skaters." Tims comments on the change in the 'vibe of the area' with greater attraction and connection of the wider community to the skatepark's central location.

...it attracts a whole bunch of young people into the park area now. So yeah it definitely has changed the vibe. I thought it was quite brave of the Council to pick that area to do a skate park. Often skate parks are done in hidden places, out of the way of the public eye. But they actually allowed them to be in a very central area.

Large amounts of positive feedback came from the parents and the wider community, particularly about the transformation of the park from being an unsafe place to a safe area. Tims states that he can't recall any disappointing feedback, which also helped to develop a positive and broad community profile for SAS and YFC.

It was pretty good; there was a good buzz in town. It gave us a huge profile. Just no disappointing feedback, and basically the skate park went from being unsafe to being a safe place. So lots of good feedback from parents, saying 'I feel safe now sending my kids down there'. ${ }^{174}$

172 Tims interview, August 2006.

173 Tims interview, August 2006.

174 Tims interview, August 2006 


\section{POST-CONSTRUCTION PROCESSES:}

\section{Overview}

GDC continues their support for user involvement at the skatepark by providing two types of part-time youth employment at the park. A skatepark cleaning contract was set up with the youth centre and two positions are provided for skatepark supervision during the holiday season.

\section{GDC provides skatepark employment to continue user involvement}

\section{Intentions}

The employment positions at the skatepark are provided by GDC to support user involvement at the skatepark and to continue YFC's positive work with the youth.

\section{Findings}

Enhanced Reciprocity \& responsibility: The cleaning and supervision employment enables the skatepark users to continue their responsibility and role-model respectful behaviour to other users. One respondent comments that employment at the skatepark helped to assist with some major changes in their life.

...I got so involved with this project that it helped change the course of my life. When I first got involved with YFC (Youth for Christ) I was unemployed, through my involvement they employed me part-time [as a skatepark grounds cleaner]...After completing the diploma I was hired as a Skatepark supervisor parttime. Also worked in Alternative Education which was established at the Skatepark... 


\section{CASE STUDY 2: Moerewa township \& economic initiative developments}

In response to the negative social and economic issues of the township, a series of community-wide meetings started in 1998. The community collectively envisioned and implemented several place-making projects that sought to integrate and progress three areas of urgent need in the community; the visual character of public space, the social development and the economic development of the community. Five main areas of the town were developed, enhancing or creating new venues that facilitated the growth of the commercial, recreational, public utility and cultural aspects of the community.

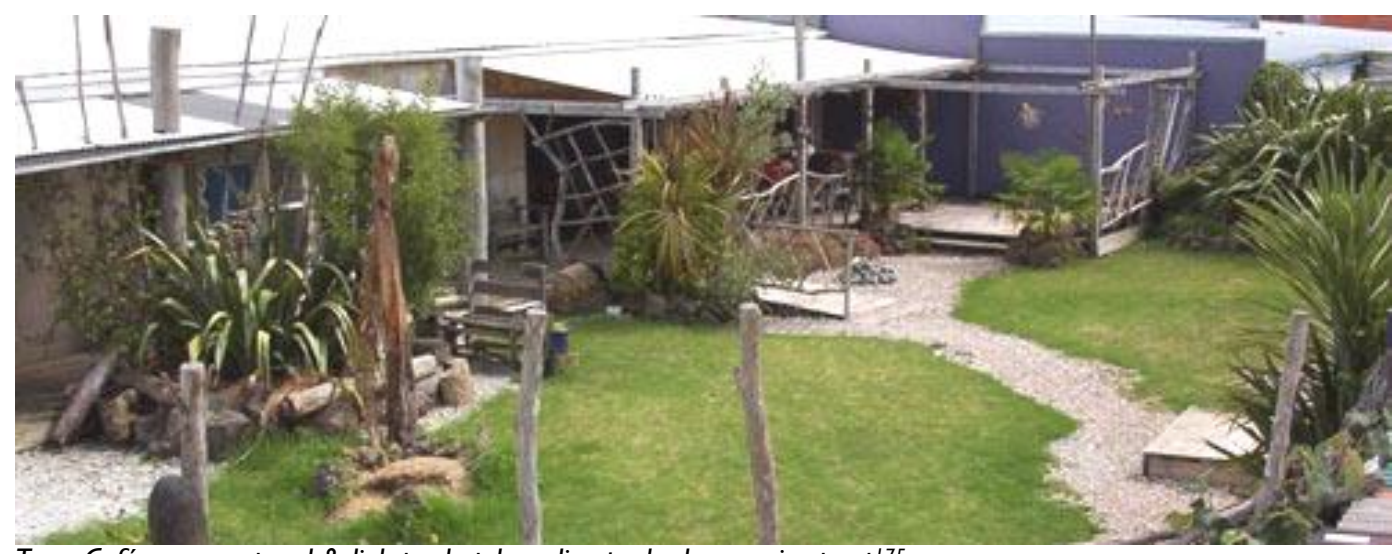

Tuna Café rear courtyard \& link to skateboarding park along main street ${ }^{175}$
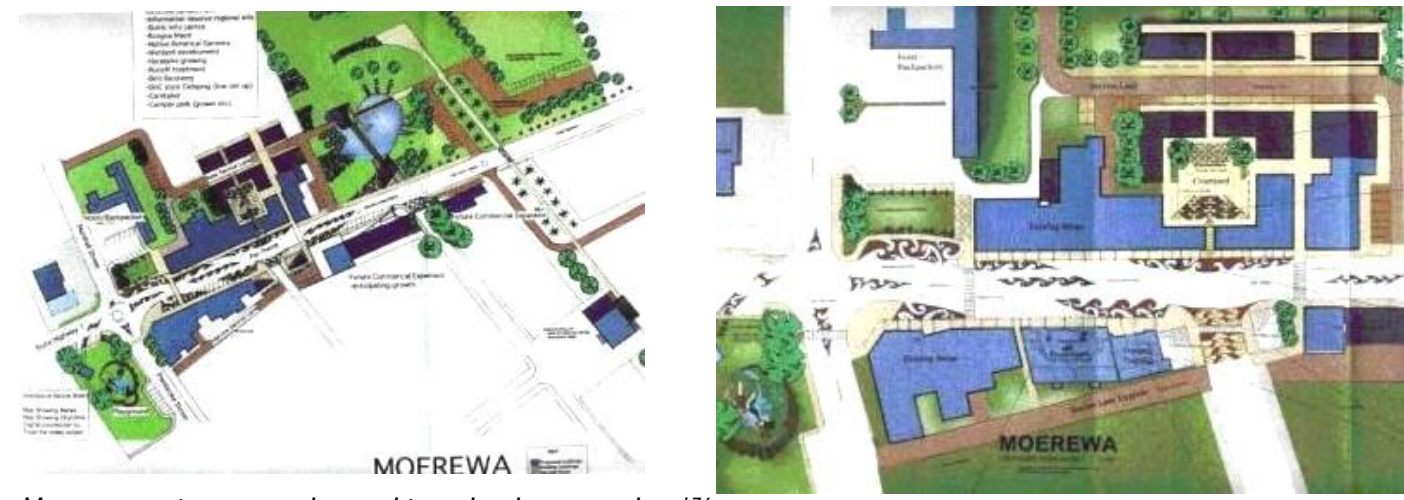

Moerewa mainstreet and township redevelopment plans 176

\section{Project location \& site description}

The public space project is situated in the township of Moerewa, located in central Taitokerau (Northland). The town's centre and main street is located on state highway one. Its population of approximately 1650 people live either in a semi-suburban environment surrounding the main street shopping centre or on rural properties.

175 He Iwi Kotahi Tātou trust, Retrieved 17.05.2006.

176 He Iwi Kotahi Tātou trust, Retrieved 17.05.2006. 

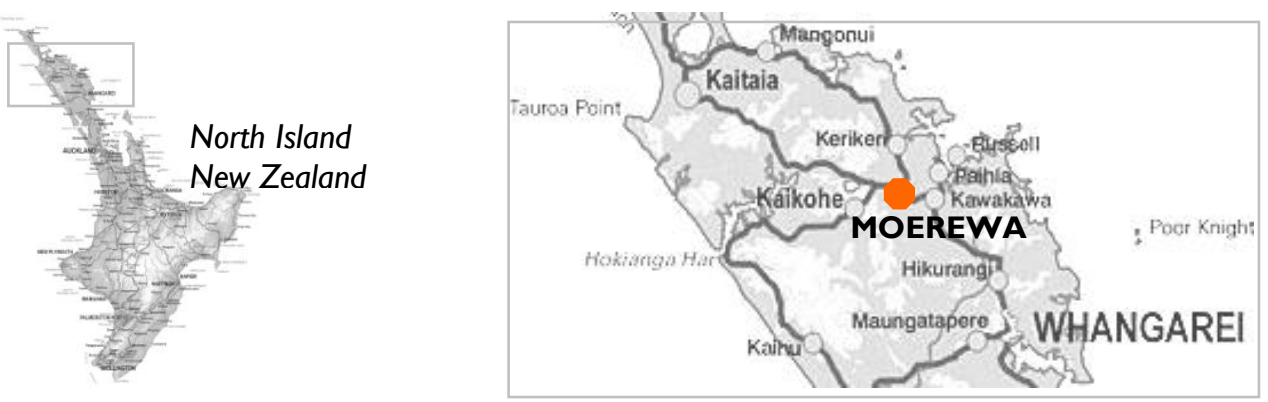

\section{Contextual history of Moerewa community}

The settlement of Moerewa, originally named Waipuna, emerged in the 1940's from the relocation of many displaced and landless Māori from the Taitokerau region. They settled initially into "about thirty, one to two room abandoned American transit huts at the back of the Moerewa freezing works" ${ }^{177}$ and later on into a new Māori housing scheme in the Taumatamakuku subdivision.

Moerewa has suffered most recently from the major economic, environmental and political changes of the 1980's that led to the closure and radical downsizing of the two main industries that employed many locals, the AFFCO Freezing Works and the Bay of Islands Dairy Company. The number of local businesses operating in Moerewa dropped from twenty eight to as low as five.

The decisions being made had a major negative impact on the people of Moerewa. For many years following this period the township battled to survive. The once vibrant community was soon to be known for a raft of negative statistics - violence, crime, alcohol and drug problems, unemployment, youth problems, social problems and low levels of achievement. For many these indicators of poor health, wellbeing, and socio-economic status were regarded as the norm, just the reality of Moerewa. ${ }^{178}$

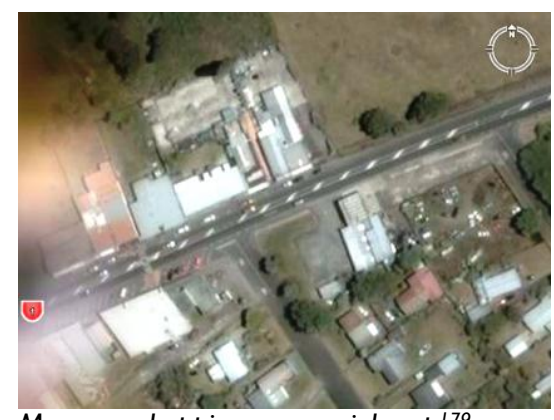

Moerewa shopping area aerial map ${ }^{179}$

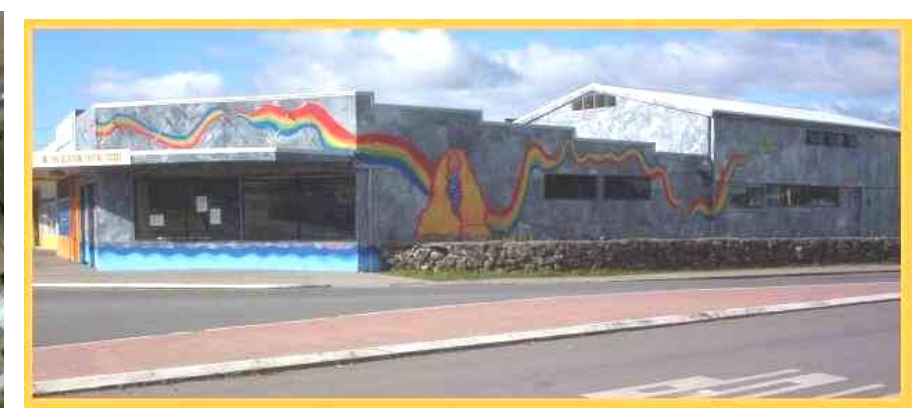

He Iwi Trust building on Moerewa main street ${ }^{180}$

\footnotetext{
177 Henare, Retrieved 17.05.2006

178 Davis, Retrieved 17.05.2006.

179 Google Earth, Retrieved 28.02.08.

$180 \mathrm{He}$ Iwi Kotahi Tātou trust, Retrieved 17.05.2006.
} 


\section{Interviewee background and project role}

A community development trust named He Iwi Kotahi Tātou Trust, abbreviated in this study to 'He Iwi Trust', was established in the early 1970's as a response to the growing unemployment problems that built up to the 1979 riot and youth issues. He Iwi Trust, located on the main street of Moerewa, is solely staffed by local people, currently employing eleven people in full and part-time roles. The work of He Iwi Trust initially focused on skillbased training, but changed the direction in the last several years to focus on a model of community development; developing programs and initiatives decided by the community members that seek to meet the needs of the community. The interviewee for this case study is Ngahau Davis, a Moerewa resident of Nga Puhi descent, who is community development worker, whanau support worker, drug \& alcohol educator for He Iwi Trust. Davis' role in the project was to ensure that all of the participatory processes were facilitated in a method that engaged the community members appropriately. Davis took responsibility to set up supportive dialogue and relationships between the community members and the consultants, such as the designers or local authorities.
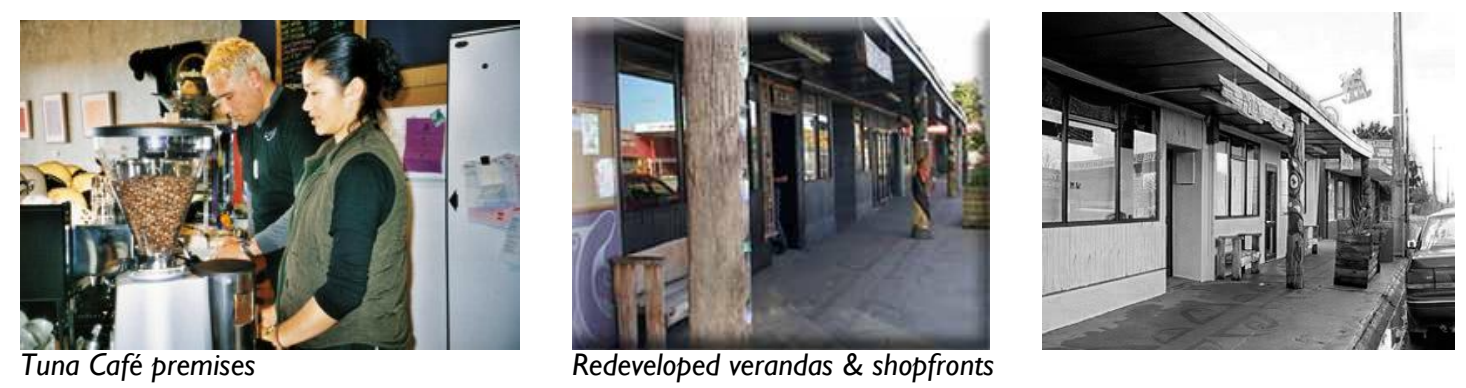

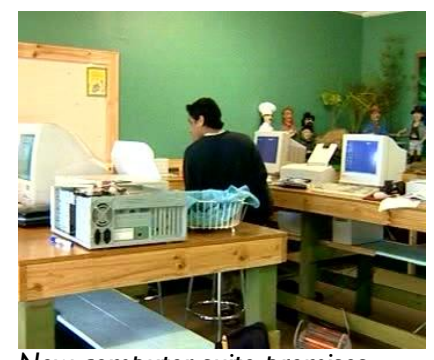

New computer suite premises
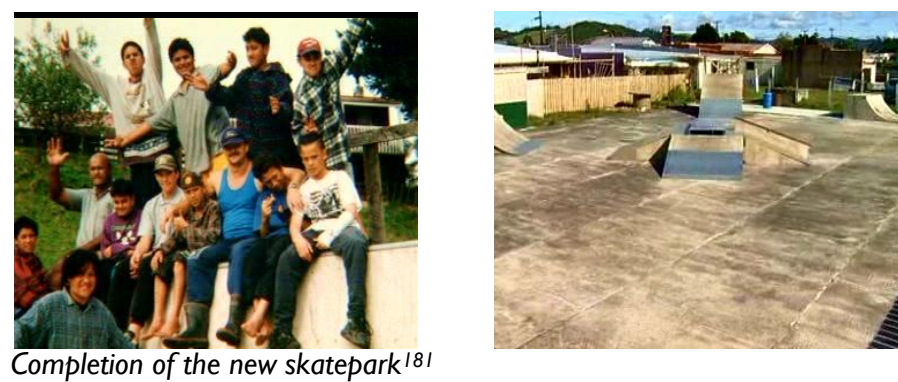

181 He Iwi Kotahi Tātou trust, Retrieved 17.05.2006. [All images on this page] 


\section{Case study findings \& interpretation}

\section{Profile of community participants' in public space project}

Davis states that approximately 10\% of the townships population which translates to 160 resident community members participated in the community workshop meetings. From these meetings the participants' split up into four working groups to implement the four town centre projects and after a few weeks, the number in each group narrowed down to approximately ten. The surveys were sent to the members of the project working groups and He Iwi Trust members as these participants' were the most consistently involved throughout the public space project. A total of eight survey forms were mailed to the contactable participants', and five survey responses were received which gives a $63 \%$ response rate. All of the respondents' participated in all of the identified stages of the project; the parts of the project that most participated in were the community meetings, small group meetings, organising and directing the project, getting others involved in the project, making decisions about the project, presenting the project to others, designing buildings or areas and helping to build the initial project buildings and areas.

\section{Method of interpretation and presentation}

The interview information, additional material and survey responses are interpreted to provide evidence of the specific dimensions of community well being that were enhanced by the participatory process. The raw data from the survey is presented in tables to illustrate the accumulated findings. The category abbreviations are: strongly agree (SA), agree (A), neutral $(\mathrm{N})$, disagree $(\mathrm{D})$ and strongly disagree $(\mathrm{SD})$. 


\section{Participatory processes \& community wellbeing findings}

\section{PROJECT INCEPTION PROCESSES:}

\section{Overview}

He Iwi Trust recognised that long-lasting changes for Moerewa would be most sustainable if the community were able to direct the changes themselves. He Iwi Trust first identified that assistance was needed to build a positive attitude about the community. This started with developing people's self-perception and empowerment which was facilitated by the town's social supports. Secondly, they identified the need to renew the physical environment; the recreational, commercial and cultural spaces, as its state had lacked opportunities for social and economic growth.

\section{Community identifies needs \& leads development process}

\section{Intentions}

Davis recounts that community-led social support programme arose to address the urgent needs of the community;

...the programme came out of just basically the need of this community...From the services in the main business area, or the lack of, and limited opportunity for anything to happen due to the old buildings, the dereliction, things like absentee landlords and basically the town itself just showed a community had been left behind and disregarded. People didn't see any value or use economically anymore... ${ }^{182}$

In order to create new opportunities for social and economic growth, the community identified that to address the disempowerment they had to be responsible for leading the changes themselves.

We were going to do the Community Development buzz. We didn't have a clue what that was; we knew it had to be led by the community. Nobody else was going to care about Moerewa more than those that lived in Moerewa. ${ }^{183}$

\section{Findings}

Enhanced Collective action; Empowerment: One respondent emphasises the significant change in the community's perceptions of their own abilities; changing from apathy to understanding the value of their own influence.

I think the major factor for me was people felt empowered; from a community that no one seemed to care, to one where people understood it was about us and our

182 Davis interview, August 2006.

183 Community Employment Group, 2002. 
ability to mobilize, pull together and make our dream a reality. Tama Tu, Tama Ora; Tama Noho, Tama Mate. To stand is to live; to lie down is to die.

\section{Enhanced Reciprocity \& responsibility: Pele Faauli, a Community Employment Group}

fieldworker who assisted the project expresses the increase in ownership of the project by the Moerewa community.

What impresses me about Moerewa is that the development has been totally community driven and owned. They are in control. 184

Enhanced Effective leadership \& management: One respondent comments on the courage and influential ability of the Trusts' facilitators against the negative odds.

Moerewa has always serviced other communities, but has never got any recognition. The leaders of the project are so brave; the job has only just started.

\section{Support of individuals in community \& self-esteem building}

\section{Intentions}

In order to prepare the community for the process of decision-making about their township,

Davis states that the first intention was to regain a positive community perception in the mindset of the people.

...that is the way we think and feel about Moerewa. ${ }^{185}$ The spirits of the people had to turn around. We were in a place of powerlessness. The question was how to regain the spirit that was a vital part of this community. How could we get back the drive and determination to take care of ourselves as a community? 186

The grassroots development enabled the community to move away from dealing with presenting issues in a superficial and adhoc way... and instead identify and work with the root causes of deprivation...these were understood to be welfare dependency, low self-esteem and powerlessness. ${ }^{187}$

The Trust and local social supports also realised the need to build the individual's selfperception. Informal support was initially provided by the Trust through facilitating selfesteem and empowerment building courses over a significant amount of time, that intended to increase the community's strength and resilience.

\section{Findings}

Empowerment: More positive for future of community

$\begin{array}{ccccc}\text { SA } & \text { A } & \text { N } & \text { D } & \text { S } \\ \text { IIII } & & \text { I } & & \\ \text { IIII } & \text { I } & & & \end{array}$

Social supports: More knowledge of local services

184 Community Employment Group, 200I. pp. I-2

185 Davis, Retrieved 17.05.2006.

186 Community Employment Group, 200I. p. I-2

187 Davis, Retrieved 17.05.2006. 
Enhanced Sense of pride, belonging \& connectedness to community; Empowerment: Davis describes below how the community members were empowered and states how it was fundamentally important to first establish the self-esteem and community spirit before any project was to be developed.

We spent three years self esteem building - raising the spirit and consciousness of the community. That was a key component of what took place in the development of this town. It is about people wanting to be part of the change makers. ${ }^{188}$ So people wanted a change, but it was about changing the thinking...And I believe we did, but we still have to... ${ }^{189}$

Most of the respondents strongly agree that they feel positive for the future of the community after being involved in the project, with one answering neutral, commenting that "We have seasons of 2 steps forward and one back. Life!"

Enhanced Social supports: The respondents' knowledge of local services and facilities in the area had increased \& stayed the same after being involved in the project.

Enhanced Vision-making \& advocacy: Davis and Cyril Heta who both work for He Iwi Trust state that the community's motivation to influence their own direction has increased, shown by the growth in people's enthusiasm, self-sufficiency and new business initiatives. Davis and Heta respectively reflect that the increase is due to the community taking responsibility and realising their potential through influencing the redevelopment project.

What we're seeing is a lot more people that are keen, creative and who want to do things for themselves and are not scared. They will...say, 'Hey look I wanna do..."'। 90

"Everyone is turning their passion - what people would call their hobby - turning it around and making their hobby their existence... we encourage them to take the step and use their skill, their hobby, their passion. Through the businesses that have started that's exactly what's happening. ${ }^{191}$

\footnotetext{
188 Community Employment Group, 200I. p. I-2

189 Davis interview, August 2006

190 Community Employment Group, 2002.

191 Community Employment Group, 2002.
} 


\section{Socio-political analysis skill building}

\section{Intentions}

Davis states that the analysis was to assist the community to understand how the town's socio-political history had limited its opportunities. It intended to empower the community to create new opportunities.

And so long term; if we wanted to create new opportunity in this community we needed to address some of the issues about creating opportunity, looking at some of the infrastructure stuff [socio-political issues] that we were having problems with. 192

Davis recalls the journey of the town and specifically changing the psychological beliefs of the local people. These have been impacted by negative pressures such as long periods of unemployment and decisions made about the community that were outside the community's control.

.... a lot of things have happened to us a town...... when we used to run workshops with people that hadn't been working for a long time we would talk and say things like, 'Hands up all those people that were at the meetings that decided to close down the dairy factory, remove the banks, cut the health services'... 193 If we can begin to understand who is making those sorts of decisions, we can understand it and respond better about it... ${ }^{194}$

\section{Findings}

$\begin{array}{lccccc}\text { Political, civil \& civic participation: More involved in local groups/activities } & \text { SA } & \text { A } & \text { N } & \text { D } & \text { S } \\ \text { Political, civil \& civic participation: More interest in decisions made by officials } & \text { III } & \text { III } & & \end{array}$

Enhanced Empowerment: By identifying the external decisions that influenced their present circumstances, the community members were empowered to move beyond their 'victim' mentality towards acknowledging and taking control of their own decisions.

...the realisation was that they had very little to do with those decisions [employment, economic and healthcare provision], but those decisions majorly impacted on the community. ${ }^{195}$

Once the community was able to take more control over issues that affected them, and were less reliant on the big companies that once ran the town, other opportunities began to emerge for Moerewa. 196

Enhanced Political, civil and civic participation \& commitment: The respondents' involvement in local community groups \& activities had stayed the same and increased. The respondents

\footnotetext{
192 Davis interview, August 2006.

193 Community Employment Group, 2002.

194 Davis, Retrieved 17.05.2006.

195 Community Employment Group, 2002.
} 
agree and strongly agree that they had more interest in decisions being made by the local council and government after they had been involved in the project.

\section{PROJECT PROMOTION PROCESSES:}

\section{Overview}

One of the first community-wide events was to organise a three day festival in 1998 called 'Moerewa Majic' to celebrate the town's past, present and future. Approximately 750 local people attended at the peak of celebrations. Next, He Iwi Trust planned two series of community-wide development meetings and undertook numerous community engagement strategies to encourage people to attend. They visited local primary schools to teach children the 'Moerewa song' for performing at the meeting to encourage parents to also attend, a banner with slogan 'Moerewa on the Move' was displayed on a main street building, leaflets were dropped challenging people to attend the meeting if they were dissatisfied with the town's circumstances, spot prize attendance incentives were advertised and the day and night before the meeting parades of kids on a fire engine and loud hailers promoting the meeting saying "Don't forget, have your say, the future's in your hands." ${ }_{197}$

\section{Township past, present \& future celebration event}

\section{Intentions}

The festival celebration intended to build connections between community members for recollecting and building the story of the town. The main messages of the festival encouraged people to understand they had a critical role in creating a positive future for Moerewa.

..it was about building the town, we had a festival for three days... and we just said be proud of Moerewa...I think we had about 750 people rock up on the Saturday to do all sorts of stuff. 198

\section{Findings}

Sense of pride, belonging \& connectedness: More proud of community Empowerment: Feel a more important part of community

$\begin{array}{lllll}\text { SA } & A & N & \text { D } & \text { S } \\ \text { IIII } & & & \text { I } & \end{array}$

Enhanced Sense of pride, belonging \& connectedness to community; Empowerment: Davis explains below the empowering messages of self-determination the festival had on the attendees.

196 Davis, Retrieved 17.05.2006.

197 Davis interview, August 2006. 
And you could feel their heads lifting, cos we were trying to break like a wairua, or spirit, that was over the community, created from years of neglect, lack of input...we were really starting to say, no, you have your say, you have rights, you can. ${ }^{199}$

After being involved in the project, most of the respondents strongly agree about feeling more proud of their community, with a strongly agree comment of, "Very passionate about 'Moerewa'." There was one disagree answer and comment, "Quite biased. Always proud to be part of my town." The respondents mostly agree about feeling a more important part of the community after being involved in the project. There was one neutral answer and comment of, "Already feel and know I am part of the picture" and one disagree answer and comment of, "Away for 25 years, but family ties to the community will always remain strong." This implies a strong affinity and history with the community that precedes the redevelopment project and suggests the long-established values of the community that Cyril Heta comments on.

Enhanced Equality \& tolerance: One respondent comments that their involvement in the community participation events of the development project increased their friendships and acceptance of other cultures in their community. The respondent comments on their increased awareness of the shared pride that other community members have about Moerewa.

The experience of this project made for new friends and to realise others were proud of Moeds [Moerewa]. There was a mix of cultures which helped break down the often racial opinions we had of another culture.

\section{Pre-development \\ community engagement \\ \& promotional events}

\section{Intentions}

In the build up to the community-wide development meeting the Trust employed a variety of appropriate and purposeful community engagement techniques to ensure there was maximum community representation in the decisions.

\section{Findings}

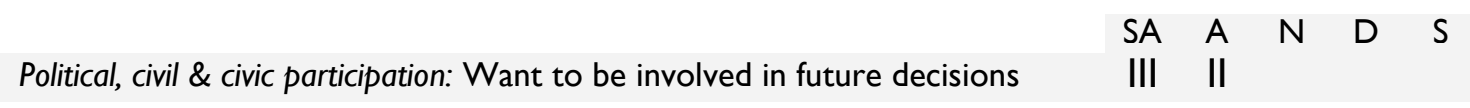

198 Davis interview, August 2006.

199 Davis interview, August 2006. 
Enhanced Political, civil and civic participation \& commitment: The engagement strategies were deemed successful in gaining a large amount of community interest. Davis comments that the venue was filled with attendees beyond its capacity.

And I remember the meeting was chokka [full capacity]. People were hanging out the door; people were looking through the windows. ${ }^{200}$

The respondents of the surveys agree and strongly agree that they wanted to be involved in future decisions that affected their community after they had been involved in the project.

\section{PROJECT BRIEFING PROCESSES:}

\section{Overview}

Large numbers of attendees overcrowded the meeting hall. The focus questions were "what are we going to do, and where do we want to go?"201 This received an emphatic response in the participants' desire for change. From the initial community meeting, several decisionmaking forums were held to submit a proposal to council for redeveloping some existing public amenities. At the second series of meetings, workshop groups were formed to articulate 'what do you love about Moerewa?' and 'what ideas would you like to see happen for the future?' The main idea expressed was to create new opportunities for the local economy to be self-sufficient to benefit local people with employment and consequentially build social cohesion. The various 'town centre' development ideas were prioritised, then voted for. The voted ideas were a youth/public recreational area, beautification of the main street and development of public utilities, the renovation of premises and opening of several main street businesses and a community arts centre and gallery.

\section{Community-wide township visioning meetings}

\section{Intentions}

Davis facilitated the township meetings that assembled the community members, stakeholders and consultants together to collaborate on creating a shared vision.

...my role was trying to bring those parties together, creating the opportunity for dialogue to happen between the architects and what I call stakeholders, i.e., rangatahi [youth], kaumatua, kuia [elderly men and women], families, young families, more established families. Just all the different stakeholders that ... would make up a town. ${ }^{202}$

\footnotetext{
200 Community Employment Group. 2002.

201 Community Employment Group. 2002.

202 Davis interview, August 2006.
} 
Heta discusses the intention of assisting the community to recognise the value of their contribution. A key value is to recognise each person's strengths and how this approach brings forth the individual's potential.

Making sure everyone is involved is important. We figure every single person in Moerewa is of value to this place, not just a handful or just the businesses, everybody. Everybody plays a crucial part from the youngest to the oldest and I think it's because we value everyone that way, no matter. ${ }^{203}$

Davis states that engagement strategies such as collective visioning intends to challenge the apathy present in the community in order for individuals to aspire for a positive future for the community.

Because a lot of our people, just nobody had asked for their opinion about anything really, or even if it is, it's never been taken notice of...So there was a real apathy. So we had to try hard to push through stuff. ${ }^{204}$

\section{Findings}

Collective action: Community works together to solve problems

$\begin{array}{ccccc}\text { SA } & \text { A } & \text { N } & \text { D } & \text { S } \\ \text { IIII } & & & & \\ \text { III } & \text { II } & & & \\ \text { III } & & \text { II } & & \end{array}$

Political, civil \& civic participation: Want to be involved in future decision

Effective leadership \& management: More trust in community leaders

Enhanced Collective action; Interpersonal \& organisational trust: A change from apathy in the community to a desire and responsibility for circumstances to change was articulated as a major response at the first community meeting.

And the people said they wanted change. They were tired of what they had. And there were a lot of people with a lot of ideas and enthusiasm. And that's where a lot of this started off. ${ }^{205}$

The attendees voiced that were willing to invest their time and energy in volunteering to be involved in any of the four working groups that developed the projects. All respondents are unanimous in strongly agreeing that being involved in this project helped their community to work together to find ways to solve their problems. One respondent comments on the community's cohesion, collective abilities and altruism that developed through the group decision-making process.

This project helped me recognise strengths and weaknesses and how a group of people can come together with a common purpose, no hidden agendas and bring out their very best unselfishly.

\footnotetext{
203 Community Employment Group, 2002.

204 Davis interview, August 2006.

205 Davis interview, August 2006.
} 
From the outset of the project, Davis reflects that the collective dreams of the community, exclusive of any other resource like funding, was the source of the community's strong motivation and vision to make the project happen.

...we found we could work together as a community. We started with no money, so it was purely upon the dreams and the visions of what the people of Moerewa wanted to do. ${ }^{206}$

Enhanced Vision-making \& advocacy; Effective leadership \& management:: The workshop process and the subsequent formation of working groups allowed every individual the opportunity to influence the direction of the projects. The respondents agree and strongly agree that after being involved in the project, they wanted to be involved in future decisions that affected their community, one respondent extending their agree answer with, "Especially around youth." The respondent below comments on the strong community development and visioning abilities of the leadership of Debbie and Ngahau Davis who work for He Iwi Trust.

I feel the undergirding strength of our community development has been the fantastic leadership of Ngahau and Debbie Davis. And they are a couple who have a strong faith in God and felt called by God to come back to Moerewa to rebuild it... Ngahau and Debbie have a fantastic ability to work with all types of people in the community and instil vision and look for the right people for the jobs and work with any willing people.

Two respondents' comment on the strong leadership of the Trust and the enhanced unity through the community's collective ability: "This is possible because He Iwi [Trust] lead out" and "There has definitely been a greater working together as a community for its better good." The related survey response shows that all of the respondents' trust in community leaders had either stayed the same or increased after being involved in the project.

206 Community Employment Group. 2002. 


\section{Decision-making \& \\ prioritising of \\ Projects}

\section{Intentions}

The facilitators intended to direct a fair and representative decision-making process by using a voting process to prioritise which development ideas to implement.

\section{Findings}

Enhanced Effective leadership \& management: Davis comments that the decision-making method was effective in creating an agreement between community members on the main priority and direction for the town.

...it was the most democratic process, because you can't do everything, but what we feel like is the best. ${ }^{207}$

\section{PROJECT IMPLEMENTATION \& COMPLETION PROCESSES:}

\section{Overview}

When the community decided to redevelop the public amenities; a public toilet and park, they were required to engage in a council process of public consultation and decision making. Local people developed plans, consulted and gained agreement from the wider community and obtained their signatures. The public toilets and park area was opened in December 1998.

At the 'town centre' series of community meetings, the meeting attendees formed four working groups that would proceed the four town centre ideas. The numbers of members per working group narrowed down to a core group of around ten. Each group strategised the development of the ideas and provided a six month progress report. The majority of the work in the four areas had been completed by this time. A magazine article describes the outcomes:

Colourful carved posts support a building that houses an array of innovative new Māori-owned businesses, including a clothing design shop, hairdresser, web-design studio and weaving and craft centre. The Tuna Café has food so legendary... This is a thriving, friendly and attractive town - a town that recently managed to hit the front page of a lifestyle magazine. It is also a town that has been to hell and back. ${ }^{208}$

207 Davis interview, August 2006.

208 Community Employment Group, 200 I. pp. I-2. 


\section{Community conducts \\ council process \& submits \\ proposal}

\section{Intentions}

The community campaigned for adequate public facilities by facilitating the required council processes.

\section{Findings}

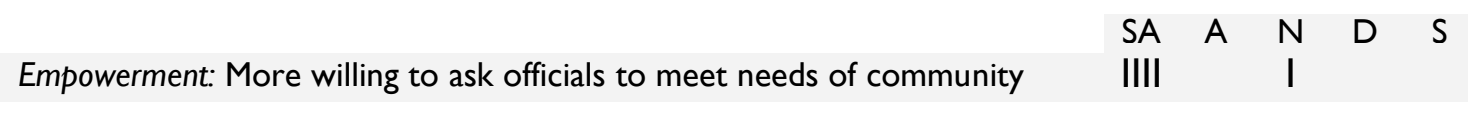

Enhanced Political, civil and civic participation \& commitment; Empowerment: Davis illustrates that the community's management of the required council process increased their comprehension of the local government systems and their capacity to collectively mobilise as a community.

It was about mobilising the people, understanding the political processes behind that to enable us to actually make something happen in this way and it was a battle won. ${ }^{209}$

Enhanced Empowerment: The respondent's willingness to ask for what their community needed from local officials (like councils) had stayed the same and increased after being involved in the project.

\section{Working groups strategise \& implement projects}

\section{Intentions}

Davis states that the intention of the working groups was to use the collective effort of the community to develop the projects. The completion of the four town centre projects required the community members to develop the necessary personal and cooperative skills during the process.

We had learned - don't get anybody from outside to do what we can do here. So it was all about getting our local people, many of whom were unemployed, involved...210

\footnotetext{
209 Community Employment Group, 2002.
}

210 Community Employment Group, 2002. 


\section{Findings}

Collective action: More important to work together to improve conditions

SA A N D S

Interpersonal \& organisational trust: Know more people to trust in crisis

Interpersonal \& organisational trust: Area is safer for people to be in

Equality \& tolerance: Community more accepting of different backgrounds

Sense of pride, belonging \& connectedness: Better area to live in/come to

Sense of pride, belonging \& connectedness: Care about looks of community

Sense of pride, belonging \& connectedness: Talked to others in area more

Sense of pride, belonging \& connectedness: More knowledge of local services

Sense of pride, belonging \& connectedness: More friendships in area

Reciprocity \& responsibility: Care more about what community thinks

Reciprocity \& responsibility: Want to volunteer more time

Reciprocity \& responsibility: Benefit more from what happens in community

$\begin{array}{cccc}\text { SA } & \text { A } & \text { N } & \text { D } \\ \text { IIIII } & & & \\ & \text { III } & & \\ & \text { I } & \text { I } & \\ \text { I } & \text { II } & \text { I } & \text { I } \\ \text { II } & \text { III } & & \\ \text { III } & \text { I } & & \\ \text { I } & \text { III } & \text { I } \\ \text { IIII } & & \text { I } \\ \text { IIII } & & \text { I } \\ \text { III } & & \text { II } \\ & \text { II } & \text { III } \\ & \text { III } & \text { I } \\ & \text { I } & & \\ \text { III } & \text { II } & \end{array}$

Enhanced Collective action; Empowerment: Community self-determination and unity has arisen as a result of working together to meet the community's needs.

We had a new park and grounds too, and they were built by the people.... We haven't finished the journey, we're well on the way, we're achieving some major milestones, and we've come to the point when we say. 'Yes we can do it, yes we can do it!' 211

There was unanimous agreement from the respondents that it was very important that people in their community worked together rather than alone to improve the conditions of the area, with one respondent commenting that [there is] "Strength in unity."

After being involved in the project, one respondent is neutral, but all others agree about knowing more people they could trust to help them if they were in a crisis situation. There was a wide range of opinion about the area being safer, where the respondents disagree, are neutral, agree and strongly agree that involvement in this project helped to make their area safer for people to be in.

Enhanced Vision-making \& advocacy; Effective leadership \& management: Davis expresses the community's new enthusiasm and empowerment that arose from the community's participation in the development projects.

The main street has had a major facelift and now houses several successful new businesses. Now we are seeing a new renaissance of creativity - the New Time, and it's exciting. ${ }^{212}$

211 Community Employment Group, 2002.

212 Community Employment Group, 2002. 
In an article celebrating the new changes, Suz Te Tai and Jennifer Martin, discuss how they attribute the catalyst for achieving their personal dream of owning and running a café in Moerewa to the community initiatives started by He lwi Trust.

...it has been the catalyst for many others as well. "The opportunity has meant this town can start to grow. As far as we are concerned, this is just the beginning of a whole lot of growth here. ${ }^{213}$

Enhanced Equality \& tolerance: Respondents agree and strongly agree that their community was more accepting of people from different cultures and backgrounds after they had been involved in the project. One respondent comments, "[l] got to know people I don't normally mix with."

Enhanced Sense of pride, belonging \& connectedness to community: The respondents generally agree and strongly agree that their involvement in this project has made the area a better place to live in or to come to. One respondent strongly disagrees and comments, "To myself and others Moerewa has always been a good place!!"

The respondent's answered neutral, agree and strongly agree in caring more about what the community/area looked like after they had been involved in the project. After being involved in the project, the amount of times the respondents' talked to others, the knowledge of local services and facilities and friendships with people in the area had stayed the same and increased.

Enhanced Reciprocity \& responsibility: The respondents' answered neutral and agree about all three statements asking if they cared more about what people in their community thought of their actions, feeling they could benefit more from what happened in their community and wanting to volunteer more of the spare time to their community, after being involved in the project. The comparative tentative tone of the respondents' answers suggests that all three of the represented indicators have not increased as significantly as other indicators.

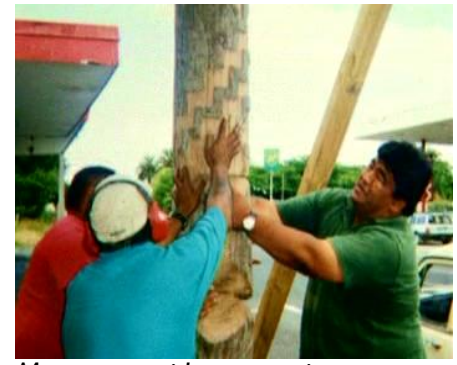

Moerewa residents erecting mainstreet veranda pou (poles)

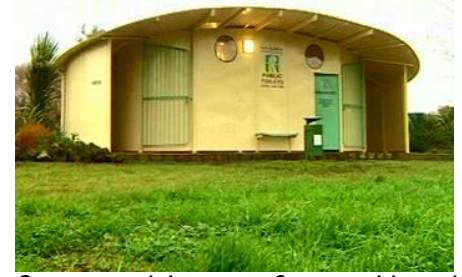

Opening celebration of new public toilets

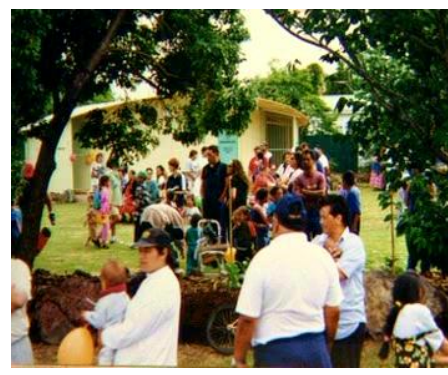

(2)

213 Te Puni Kōkiri, 2002. pp. 2-3. 


\section{POST-CONSTRUCTION PROCESSES:}

\section{Overview}

He Iwi Trust recognised the need for professional advice to assist the community's long term goals. Design Tribe Architects and Executive Management Consultancy were contracted to develop a strategic development plan for Moerewa. The strategy team facilitated focus groups and workshops with the community to collate ideas and information. The final 'Comprehensive Development Report' report included large scale town layout proposals, design detailing and images of the existing developments. Various agencies were identified as potential funders. The many physical and economic developments in the long term plan are still proceeding alongside other community ventures.

\section{Consultants conduct \\ focus groups to develop long-term plan}

\section{Intentions}

He Iwi Trust contracted a design and management consultant team to gain the professional skills needed to assist the long-term development plans of Moerewa. The consultant team facilitated focus groups and design workshops with the community to collate their ideas to form the long-term development proposal.

\section{Findings}

Enhanced Interpersonal \& organisational trust: Davis explains that the long-term plans formed from the information provided during the focus group workshops were received with enthusiasm by the community members.

So after they did those focus groups they went away and came back with a plan, and presented it back to the community, and the people just said 'yeah lets go for it'...214

\section{Community continue to develop initiatives $\&$ seek support funding}

\section{Intentions}

In order to sustain the length of time for the long-term plans of Moerewa to be completed, the community have employed a strategy of building the developments incrementally. Several agencies, organisations and companies were identified by the community to could provide financial support for the long-term plans.

214 Davis interview, August 2006. 
And we realised that the plan was going to be in the five to eight years to try and get the whole thing. We're doing it bit by bit, that's what the idea was...The realisation of this plan will take a concerted effort and a marriage of the community and public agencies." ${ }^{15}$

\section{Findings}

Enhanced Vision-making \& advocacy: The many public space and economic developments outlined in the long term plan are still proceeding today alongside other ventures such as the establishment of new Information Technology/Multimedia/Recording studio facilities based in the Trust buildings, a three full-time staffed housing energy/insulation retro-fitting project, submissions for the proposed Moerewa Community Campus, among the many other initiatives.

215 Design Tribe Architects \& Executive Management Consultancy, August 2002. p. 23 


\section{CASE STUDY 3: Motukaraka marae \& housing developments}

The place-making project is some proposed public buildings and housing to add to the existing marae buildings on the communally-owned land at Motukaraka. The proposals have arisen out of a hapu planning process that aims to fulfil the social, economic and environmental goals of the hapu and marae community of Motukaraka. The proposals were at the Resource Consent stage at time of the interview.

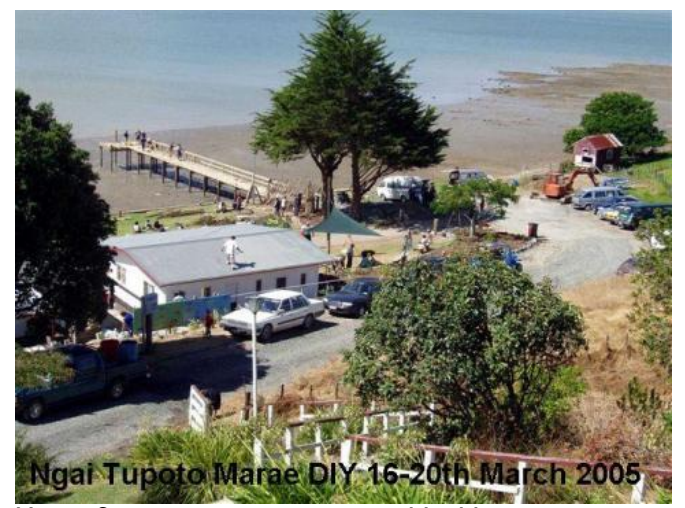

View of jetty, marae entrance and buildings During televised DIY project ${ }^{217}$

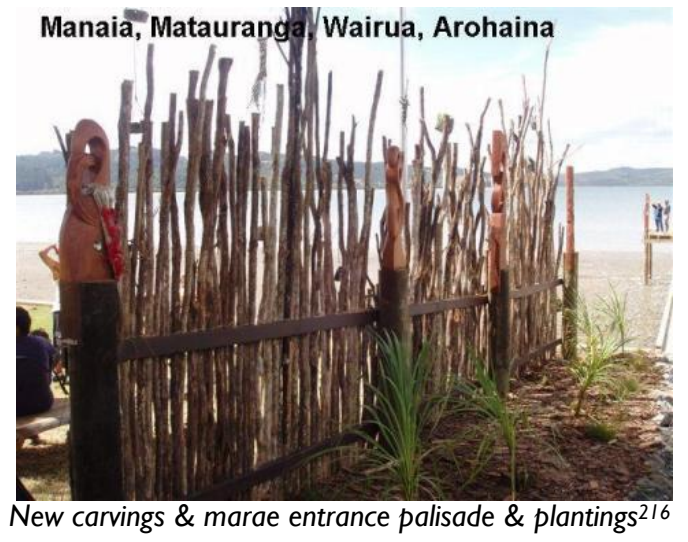

\section{Project location \& site description}

The rural region of Motukaraka is situated about thirty kilometres west of Kaikohe in the Far North. It is located on a southern peninsula of the Hokianga Inlet directly opposite and two kilometres vehicle ferry journey from the small township of Rawene.
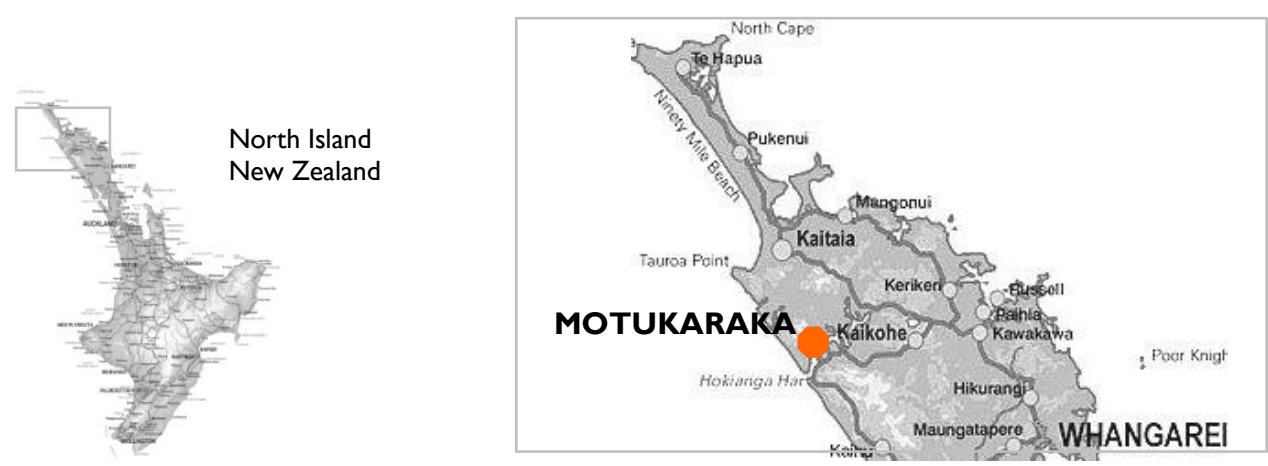

\section{Contextual background history of the Motukaraka community:}

Ngai Tupoto/Ngati Here hapu, part of Te Rarawa iwi, has a history of over twenty generations settlement in the rural Motukaraka region.

The hapu of Ngai Tupoto is centred around Motukaraka, Te Huahua and Tapuwae in the North Hokianga....Ngai Tupoto vigorously asserted mana whenua status when Pākehā settlement began... Ngai Tupoto people were granted title to the land at Tapuwae, Tautehere, Te Huahua, and Motukaraka. The majority of this land has been retained. 218

\footnotetext{
216 Ngai Tupoto Marae Trust, Retrieved 06.2006

217 Ngai Tupoto Marae Trust, Retrieved 06.2006

218 Ngai Tupoto Marae Trust, Retrieved 06.2006.
} 
The settlement's existing buildings consist of the several whare at Ngai Tupoto marae, several associated urupa (burial grounds), a catholic church on the hill above the marae named 'Our Lady of the Assumption' and approximately twenty rurally located houses. Both the marae and the church are located on marae reserve land owned by Ngai Tupoto ki Motukaraka.

The land was gifted for these purposes by tupuna [ancestor], Hone Parahoi Hare. The Church reflects the bicultural history, including the convergence of Māori and Pākehā religious identities. It is especially important to Ngai Tupoto, who built it and has consistently maintained it for nearly 100 years. ${ }^{219}$

As was the case for many rural areas of New Zealand, the large migration of Māori into the cities from the 1940's left many whanau permanently disconnected from their hapu and marae, "Large numbers of whanau moved to the cities from the late 1940's, but a trend of returning started from the late 1970's and today there are more than 200 hapu members living locally."220 The loss of local people had a large impact on the functioning of the marae and the wider community of Motukaraka, which is still being experienced today despite the gradual resurgence of returning hapu members. "A lot of people live around here, but many, many more live away."221

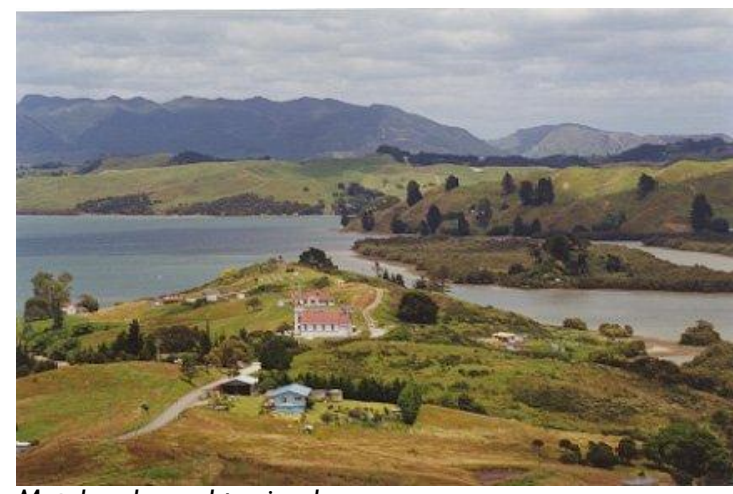

Motukaraka and peninsula

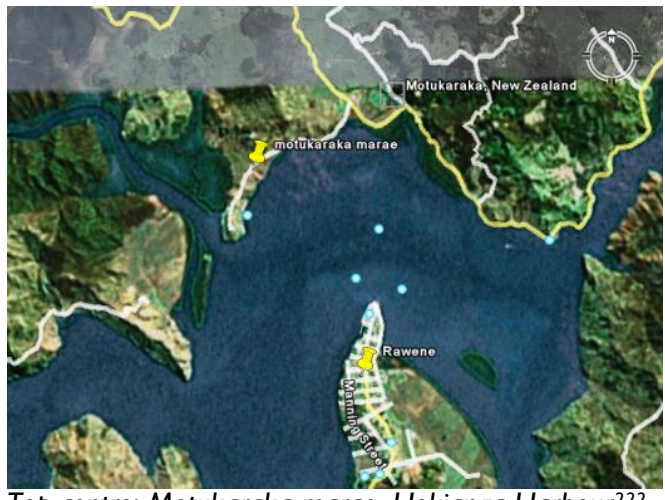

Top centre: Motukaraka marae, Hokianga Harbour 222

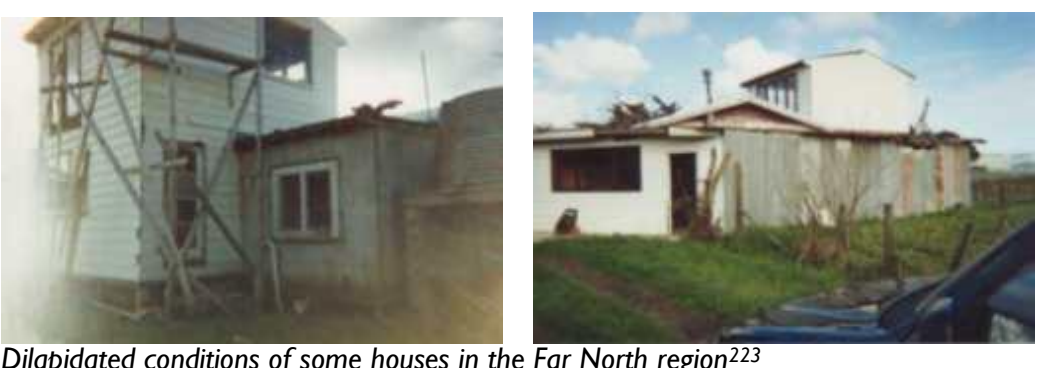

Dilapidated conditions of some houses in the Far North region 223

\footnotetext{
219 Ngai Tupoto/Ngati Here hapu, 2006.

220 Ngai Tupoto Marae Trust. Retrieved 06.2006.

221 White interview, November 2006.

222 Google Earth, Retrieved 28.02.08.

223 Ngai Tupoto Marae Trust, Retrieved 06.2006. [All images on this page]
} 


\section{Interviewees and project role}

The interviewee for this case study is Paul White, of Te Rarawa descent, Rawene resident (across the inlet from Motukaraka), member of Ngai Tupoto hapu and the secretary treasurer trustee of the papakāinga trust committee - Ngai Tupoto ki Motukaraka Trust. White's project role was to participate in the hapu planning process and facilitate the community planning process for the new marae based housing. Ngai Tupoto ki Motukaraka Trust, abbreviated in this study to 'Motukaraka Trust,' is responsible for Ngai Tupoto hapu communally owned land which consists of relatively small areas of land located between larger areas of multiple-owned land. Motukaraka Trust consists of six current trustees and is "owned by all hapu members and is responsible for four small blocks of land, Matatiaki I and 2 and Tokatorea at Motukaraka, and Te Rima Eka at Te Huahua."224 White explains that the appointed trustees operate in diverse roles throughout the community that seek to represent the breadth of the hapu.

...our trustee structure is mainly to reflect the diversity of our extended family... it's an attempt to tie in all the threads of our hapu development into this one trust. So those six people have a lot of involvement across a broad range of things that our hapu are doing, so we're trying to make sure it's all linked in. 225

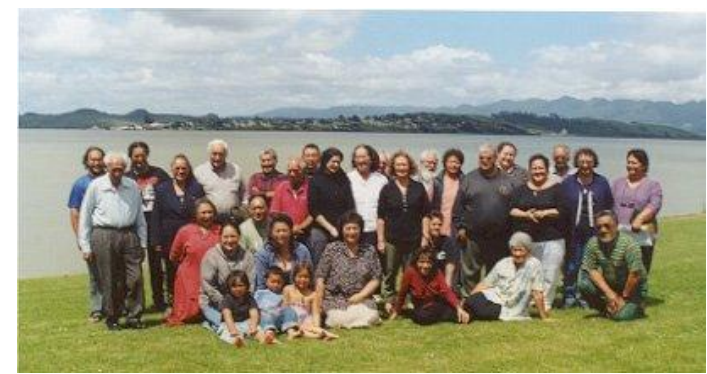

Members of Ngai Tupoto hapu226

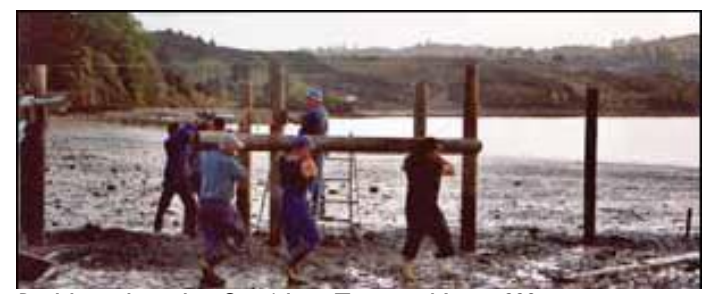

Building the wharf at Ngai Tupoto Marae 228

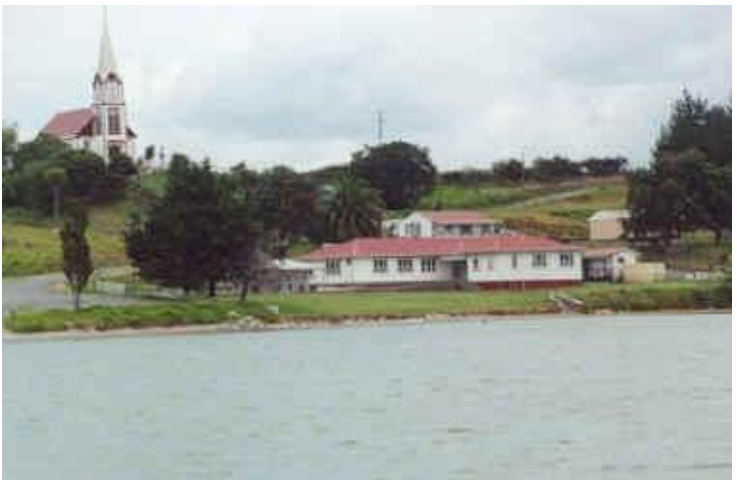

Ngai Tupoto marae \& Our Lady of the Assumption church 227

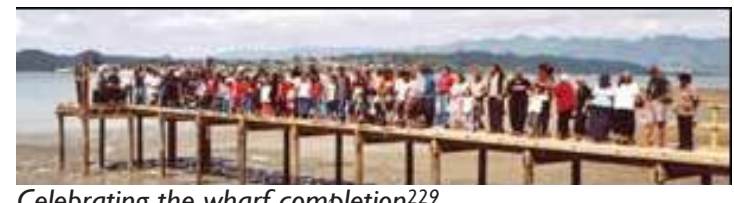

224 Ngai Tupoto Marae Trust, Retrieved 06.2006.

225 White interview, November 2006.

226 Ngai Tupoto Marae Trust, Retrieved 06.2006.

227 Ngai Tupoto Marae Trust, Retrieved 06.2006.

228 Te Rōpu Whāriki, 2005. 


\section{Case study findings \& interpretation}

\section{Profile of community participants in the project}

The members of Motukaraka marae community participated at different stages throughout the place-making project, from identifying solutions to planning and onto design decision making. The surveys were sent to various members of the marae community, which include the marae trustees and six members of the Motukaraka papakāinga trust. Survey forms were mailed to the seven contactable participants,' and six survey responses were received which gives an $86 \%$ response rate. All of the respondents' participated in most of the identified stages of the project; the parts of the project that most participated in were the community meetings, small group meetings, organising and directing the project, getting others involved in the project, making decisions about the project, presenting the project to others, designing buildings or areas and helping to build the initial project buildings and areas.

\section{Method of interpretation and presentation}

The interview information, additional material and survey responses are interpreted to provide evidence of the specific dimensions of community well being that were enhanced by the participatory process. The raw data from the survey is presented in tables to illustrate the accumulated findings. The category abbreviations are: strongly agree (SA), agree (A), neutral $(N)$, disagree $(D)$ and strongly disagree (SD).

229 Te Rōpu Whāriki, 2005. 


\section{Participatory processes \& community wellbeing findings}

\section{PROJECT INCEPTION PROCESSES:}

\section{Overview}

The community identified that both the limited numbers of hapu members who continued living in the area and lack of housing and marae facilities has impeded the community and cultural development of the hapu. One hapu member expresses the need for people who have the capacity to sustain the functioning of the marae and more on-site housing, which has successfully assisted in the past, for them to achieve this. The youth of the community questioned the existing representation of Motukaraka's existing marae buildings and how they could be enhanced to express the hapu identity.

\section{Community identifies impact of the lack of housing \& marae - $\quad .$.}

\section{Intentions}

The marae community embarked on a process of identifying the physical and cultural needs of the community.

...some years ago people started identifying housing as an ongoing need. We wanted to have more houses so we could have more people living closer to the marae, to support the functions of the marae... There's plenty of retired people living in cities all around the place who would like to move back. We've had some particularly good success over in other houses that we've got, where people have moved back from other areas and made a vast contribution to the marae... they couldn't make it living away. So that's our motivation really. 230

Wendy Henwood stated that the existing three rental houses that were produced as a papakāinga scheme a while ago have been very successful in housing three families that otherwise wouldn't have been there to functionally support the marae. ${ }^{231}$ The hapu plan adds:

There is considerable pressure on the few people who undertake the roles of kai korero [speakers] and kai powhiri [hosting and welcoming] on the marae. The pool of people needs to be grown. We also need to upskill the people to make sure that tikanga and kaupapa [cultural protocols] are maintained. ${ }^{232}$

230 White interview, November 2006.

231 Henwood telephone interview, 2006. 


\section{Findings}

Political, civil \& civic participation: Want to be involved in future decisions

SA $\quad A \quad N \quad D \quad S$

IIII II

Enhanced Sense of pride, belonging \& connectedness to community; Political, civil and civic participation \& commitment: Once the project is completed, one respondent hypothesises that the developments will influence hapu members to return home to participate at the marae and encourage the participation of the existing community members,

I believe this project will be great for the community when finished, as it will draw older people home and support and comfort the already decreasing population. Especially on our marae. People who have left the area decades ago no longer have homes to return to in the community; no doubt will greatly appreciate the opportunity to return. Providing they fit the criteria, they will again have a home to come back to.

White states that during the process the younger people of the marae community advocated for a larger and more flexible meeting house that would meet the needs of various hui and building features that would express the hapu identity, as there was no history of carved houses on the marae.

...[there were] younger people saying, 'well why haven't we got a carved meeting house?'. People in big tangi were starting to sleep in cars because there wasn't enough room. So it was just groups of younger people raising it. And then those younger people are getting older and there's more younger people coming on, so that's built up a bit of momentum. Some of the older ones [were] saying 'We haven't had carved meeting houses before, do we know what we're doing?'... And young people saying, 'Well this is more important'...to have carvings as an expression of our hapu tanga. 233

The respondents similarly agree and strongly agree that by being involved in the project, they want to be involved in future decisions that will affect their community.

232 Ngai Tupoto ki Motukaraka Trust, 2006. Ngai Tupoto ki Motukaraka Hapu Plan. p. 2

233 White interview, November 2006. 


\section{INITIAL PROJECT IMPLEMENTATION PROCESSES:}

\section{Overview}

After a decade of discussions around these concerns, the community commenced a 'redevelopment programme' five years ago and have done a large amount of work to address the issues above. Existing facilities, landscaping and services have been upgraded to provide for the long-term use of the marae and also the church centenary celebrations in 2010 where there are a large number of visitors expected to stay at the marae. The marae and wider community participated in rebuilding their wharf and marae entry areas which were part of a televised 'Hula Haka MitreI0 Marae D.I.Y.' project, which assisted in enhancing the momentum for the redevelopment.

\section{Community commence marae \& church redevelopment to meet}

\section{Intentions}

The marae renovation working bee intended to assemble as many members as possible to address the urgent physical needs of the facilities, in order to continue catering for the community and future celebrations to be held on site. The marae community also participated in a televised project in order to gain people and resources to rebuild the wharf and marae entry areas.

\section{Findings}

Reciprocity \& responsibility: Care more about what community thinks

Reciprocity \& responsibility: Benefit more from what happens in community

$\begin{array}{ccccc}\text { SA } & \text { A } & \text { N } & \text { D } & \text { S } \\ \text { II } & \text { I } & \text { I } & \text { I } & \text { I } \\ \text { III } & \text { II } & \text { I } & & \end{array}$

Enhanced Collective action: The community has experienced an enhanced collective ability by being heavily involved in physically constructing and renovating parts of the redevelopment. White expresses the magnitude of the work undertaken “...over the last five years we have done a huge amount of work." ${ }^{234}$ As the redevelopment programme came into effect five years ago, the community has worked together on building a sea retaining wall to counteract soil-erosion problems, upgraded the entire marae kitchen facilities, installed a new sewerage/drainage system and renovated the interior and exterior building facilities and landscaping.

234 White interview, November 2006. 
Enhanced Empowerment; Political, civil and civic participation \& commitment: White comments that the increased community involvement from usually non-participative community members was very encouraging and illustrated the community's aptitude.

...this marae DIY was a big boost to us to see what people power was, in terms of what we can do in short period of time, just mobilising our people and how many people got involved that hadn't been involved much in the past. [Their participation was] something to inspire a new generation. You often get people saying that every generation's got to leave its mark, and it's a chance for a new generation to leave their mark. ${ }^{235}$

Enhanced Reciprocity \& responsibility: Respondents' widely differ in their answers of strongly disagree, disagree, neutral, agree \& strongly agree that they cared more about what their community thought of their actions by being involved in the project, with one disagree comment of "I agree with and care for what the community will benefit." The respondents answered neutral, agree \& strongly agree about feeling they could benefit more from what happened in their community by being involved in the project, with the neutral comment of "Not personal benefit."

One respondent comment's that modelling good leadership and compassionate service of others within the community will be the best method of positive change, "Lead with example. Not wanting or expecting anything in return. Giving is better than receiving. Aroha nui [large amounts of love] always."

235 White interview, November 2006. 


\section{PROJECT BRIEFING PROCESSES:}

\section{Overview}

The timing of the redevelopment work coincided with Te Runanga O Te Rarawa, the Far North iwi authority, producing a hapu planning process concept and document in mid 2006. The marae community participated in the planning process for several weeks and identified the key long-term community priorities and responses to the social, environmental and economic issues occurring within the hapu and region. The plan's built development priorities were to propose an additional whare hui (meeting house) and the extension of the existing whare kai (dining hall) at the marae. The new housing scheme proposed four houses of two and three bedrooms located on two small blocks of land either side of the access road to the marae.

\section{Community engages in hapu planning to envision long-term goals}

\section{Intentions}

The marae community utilized the hapu planning process as it was the most relevant and appropriate planning framework for the population and region. The intention of the process was to gain the maximum participation from the hapu in deciding on some key overarching priorities and actions to enhance the long-term wellbeing of the region. White summaries, "trying to help hapu identify their priorities in a way that will lead to action." 236

\section{Findings}

Political, civil \& civic participation: Want to be involved in future decisions $\begin{array}{lllll}\text { SA } & \text { A } & N & D & S\end{array}$ Political, civil \& civic participation: More involved in local groups/activities Political, civil \& civic participation: More interest in decisions made by officials Sense of pride, belonging \& connectedness: More proud of community II III Sense of pride, belonging \& connectedness: Care about looks of community Collective action: More important to work together to improve conditions Collective action: Community works together to solve problems III I I II IIII II IIII I IIIIII

$\begin{array}{lll}\text { Empowerment: More willing to ask officials to meet needs of community } & \text { II III } \\ \text { Empowerment: Feel a more important part of community } & \text { III }\end{array}$

Enhanced Vision-making \& advocacy; Political, civil and civic participation \& commitment: For several weeks the marae community participated in the hapu planning process and

236 White interview, November 2006. 
developed a broad overview and key strategies to enhance the social, environmental and economic aspects of the community for the next five to ten years. White states that a unified and mobilising vision emerged for the hapu as the timing of the planning process coincided with the renovations of the marae and church.

So all these things were coming into sync. And the hapu planning process allowed us to bring all those things into the same context...by in large, out of the process there was a - 'Let's do it, let's do the whole thing together'...the housing can be tied in with it as well. So it's a really big push for us.237

The finalised priorities and goals articulated in the Ngai Tupoto ki Motukaraka Hapu Plan are paraphrased as follows,

To build the capacity of the people to carry out the roles of the Marae... to involve more whanau with the marae, to reinforce the identity of the hapu members, to make sure the people have access to good quality housing, to create employment in the Motukaraka area, to protect and enhance the environment and fulfil our kaitiakitanga [stewardship] responsibilities. 238

The respondents agree and strongly agree that they want to be involved in future decisions that will affect their community by being involved in this project, with an agree comment of, "The reason is much broader than having been involved in this project." The respondents agree and strongly agree about feeling more proud of their community by being involved in the project, with the agree comment of "I am proud for my community with this project. The respondents' involvement in local community groups and activities had stayed the same and increased by being involved in the project, with the stayed the same comments of, "I have always been involved with community groups, but this takes me home" and "Was already very involved." Similarly, the respondents answered neutral, agree and strongly agree that they had more interest in decisions being made by the local council and government, with one respondent's neutral comment of, "Already did this." By being involved in the project, the respondents answered neutral and strongly agree about caring more about what the community/area looks like, with a neutral comment of, "I always did care about it." One respondent gave no answer, but commented, "I care for the benefits that will be received by our people - not looks."

Enhanced Interpersonal \& organisational trust: White suggests that communal decision-making and interpersonal trust are some of the potential benefits for the whole community resulting from the project being located on 'true' communally owned land.

\footnotetext{
237 White interview, November 2006.

238 See Appendices for Ngai Tupoto ki Motukaraka Trust, 2006. Ngai Tupoto ki Motukaraka Hapu Plan. p. I
} 
...this is owned by all of us...And that's why it's easy to build something to the benefit of the whole community. And it has good proximity to the marae and to our urupa and to the harbour and the road and the power and all that sort of thing. ${ }^{239}$ Enhanced Collective action: All respondents agree that it was very important that people in their community worked together rather than alone to improve the conditions of the area, with additional comments of, "Marae/hapu development is always about the 'collective'," "United you stand, divided you fall?" and "Disapprovals and approvals [during decision making] with reasons are always helpful." Respondents agree and strongly agree that being involved in this project helped their community to work together to find ways to solve their problems, with the agree comment of "The project will not solve our problems but certainly address it" and the strongly agree comment of "It identified various hapu/marae members' strengths."

Enhanced Empowerment: The respondents' willingness to ask for what their community needed from local officials (like councils) had stayed the same and increased by being involved in the project; with a stayed the same comment of "Already did this." The respondents answered neutral and strongly agree that they felt a more important part of the community, by being involved in the project, with the neutral comment of, "Not 'more important' but more 'useful"' and a no answer comment of, "Importance is of little matter to me. Perhaps more appreciated and grateful for being involved."

239 White interview, November 2006. 


\section{PROJECT DESIGN PROCESSES:}

\section{Overview}

Motukaraka Trust was assigned with facilitating the housing scheme as they are responsible for the hapu communally owned land that the marae, church and future houses are located on. Motukaraka Trust approached the iwi housing services team to project manage the housing proposals as they had the appropriate expertise in local housing, and to engage in a tripartite partnership between the marae, the iwi and the future funders. The communitywide decision-making and resource availability enquiries for the housing proposals were held during five hui over a two year period to collect feedback from as many hapu members as possible. Six hundred people were sent written updates and oral reports were discussed at the iwi AGM.

\section{Trust members with development expertise assigned housing process}

\section{Intentions}

The Motukaraka Trust was assigned the detailed development work as they had the appropriate expertise, White explains:

In terms of the trustee group, because l've had a background in housing, they look to me for knowledge of process and that sort of thing. Amongst the extended whanau we've got other people with other types of expertise that we draw on. ${ }^{240}$

The intention of this process was for the trustees to work on the detailed planning and consult hapu regularly on the progress.

\section{Findings}

Effective leadership \& management: More trust in community leaders

$\begin{array}{ccccc}\text { SA } & A & \mathrm{~N} & D & S \\ \text { IIIII } & & \text { I } & \end{array}$

Enhanced Effective leadership \& management: Motukaraka Trust employed effective management methods and responsibility of the housing scheme's process through their thorough consultation forums with the community over the period of two years. The diversity of backgrounds and unique expertise of all trustee members ensured that a wide variety of needs were represented. By being involved in the project, the respondents' trust in community leaders that were a part of the project has stayed the same and increased.

240 White interview, November 2006. 


\section{Iwi housing services assist development process}

\section{Intentions}

Motukaraka Trust approached Te Runanga o Te Rarawa housing services team to partner and gain assistance with managing the housing proposals.

\section{Findings}

Social supports: More knowledge of local services

$\begin{array}{lllll}\text { SA } & \text { A } & \mathrm{N} & \mathrm{D} & \mathrm{S} \\ \text { IIII } & & \text { II } & & \end{array}$

Enhanced Social supports: Motukaraka Trust created effective support partnerships with iwi and government agency funders to accomplish the project. The respondents' knowledge of local services and facilities has stayed the same and increased by being involved in the project.

\section{Several regional hui to discuss housing \& development proposals}

\section{Intentions}

Motukaraka Trust utilised various community engagement strategies to gain maximum collaboration and feedback from the hapu members about the housing and marae developments. As the hapu members were widely dispersed geographically, the developments were discussed at general hui and updates were mailed out over the period of two years.

...we just talk about housing when we're having other meetings...Most of the families get picked up in our general consultations...So there's plenty of consultation. ${ }^{24}$

White explains how Motukaraka Trust utilised visualisation methods to communicate the new housing plans to members, such as drawing resemblances between the successful existing houses in the area and the proposed houses.

...most people find it difficult to conceptualise the plans... we've got some plans that we've built before around the area that we're probably going to reuse because they've been quite successful. So people will conceptualise and go 'Oh that will be similar to that house'... ${ }^{242}$

24I White interview, November 2006. 


\section{Findings}

Sense of pride, belonging \& connectedness: Talked to others in area more Sense of pride, belonging \& connectedness: More friendships in area

$\begin{array}{ccccc}\text { SA } & \text { A } & \text { N } & \text { D } & \text { S } \\ \text { IIII } & & \text { II } & & \\ \text { IIIIII } & & & & \\ \text { IIII } & & \text { II } & & \\ \text { II } & \text { II } & \text { I } & \text { I } & \\ \text { III } & \text { I } & & \text { I } & \end{array}$

Social supports: More knowledge of local services

Collective action: Want to volunteer more time

Equality \& tolerance: Community more accepting of different backgrounds

Enhanced Vision-making \& advocacy; Political, civil and civic participation \& commitment: White describes the community's understanding of the proposals by acknowledging the need for housing elderly members and support housing for people with mental health issues.

...the focus of people's needs....are definitely on older people. And some articulation of the need for support housing for people with mental health issues. ${ }^{243}$

Enhanced Sense of pride, belonging \& connectedness to community: By being involved in the project, the amount of times respondents' talked to others they saw around the area had stayed the same and increased, with a comment accompanying the neutral answer of, "Still early stages yet." Most of the respondents' friendships with people in the area had increased by being involved in the project with a comment of, "Probably more about relationships than friendship." One respondent answered that it had both increased and stayed the same with the comment, "The project is still in its negotiation stages - but I don't think it will change my relationship and friendship with people".

Enhanced Social supports: The respondents' knowledge of local services and facilities in the area had stayed the same and increased by being involved in the project.

Enhanced Collective action: By being involved in the project respondents disagree, are neutral, agree and strongly agree about wanting to volunteer more of their spare time to their community, with the neutral comment of "This project takes me back to my home community, not where I reside" and the disagree comment "I'm already involved to the max!"

Enhanced Equality \& tolerance: Respondents disagree, agree and strongly agree that their community was more accepting of people from different cultures and backgrounds by being involved in the project, with the disagree comment of, "Different cultures is not an issue with this project." One respondent gave no answer but commented, "Doesn't apply as the projects are for/by Māori”.

242 White interview, November 2006.

243 White interview, November 2006. 


\section{PROJECT IMPLEMENTATION PROCESSES:}

\section{Overview}

The 'Ngai Tupoto Marae whanau weekend' was held in late 2006 to plan and organise the completion of the new whare hui and extensions to the whare kai. 244 The participants' established working groups for reviewing and confirming plans, fundraising, building and creating artwork/carvings for the additions. White states that once the house plans have been finalised, a community hui will discuss the details and submit a resource consent application in anticipation of building the houses in 2007. A process of determining the future tenants out of the possible large number will be the next period of consultation with the community.

\section{Marae development weekend organises working groups}

\section{Intentions}

The intention of the Ngai Tupoto Marae whanau weekend was to gain participation from the community and establish working groups to plan, make decisions and implement the developments of the 'Project 2010'. There were also opportunities to help form artworks and carvings that expressed the hapu identity.

\section{Findings}

$\begin{array}{llllll}\text { Empowerment: More positive for future of community } & \text { SA } & \text { A } & N & D & S\end{array}$

Enhanced Empowerment: Most of the respondents strongly agree about feeling positive for the future of their community by being involved in the project, with a comment of, "It will again bring joy to those wanting to come home again." One respondent agreed with the comment of, "This is one aspect of 'feeling more positive about future"'. 


\section{CASE STUDY 4: Otara urban papakāinga complex}

The new buildings housing Te Kura Kaupapa Māori O Piripono are the first completed buildings of the planned urban papakāinga complex. The ecologically sustainable papakāinga is planned to feature several clusters of different functions; the thirty to sixty homes will cater for whanau housing, a youth 'at risk' residential unit, and kaumatua/kuia housing. There are spaces that will cater for small businesses and birthing centre/post-natal purposes. Four marae whare nui located in different areas of the papakāinga will provide different functions of hospitality, education, whare wairua for use by kaumatua and tangi, etc. In addition to the kura, kohanga reo buildings will be added to the educational area. Orchards, native plantings, streams and permaculture gardens will provide on-site food production, outdoor education and recreation.

Article from The New Zealand Herald:

A "sustainable urban village" that will test a new technique of flax-reinforced earth building is about to get under way in Otara. The first two buildings of a planned 30 to 60 home village will be built under the eyes of up to 20,000 visitors who are expected in the site for an "Eco Show" from February 25 to 29. Kōkiri Te Rahuitanga ki Otara, a training centre...aims to grow much of the food for the villagers and reuse all of their wastes on site.... ${ }^{245}$

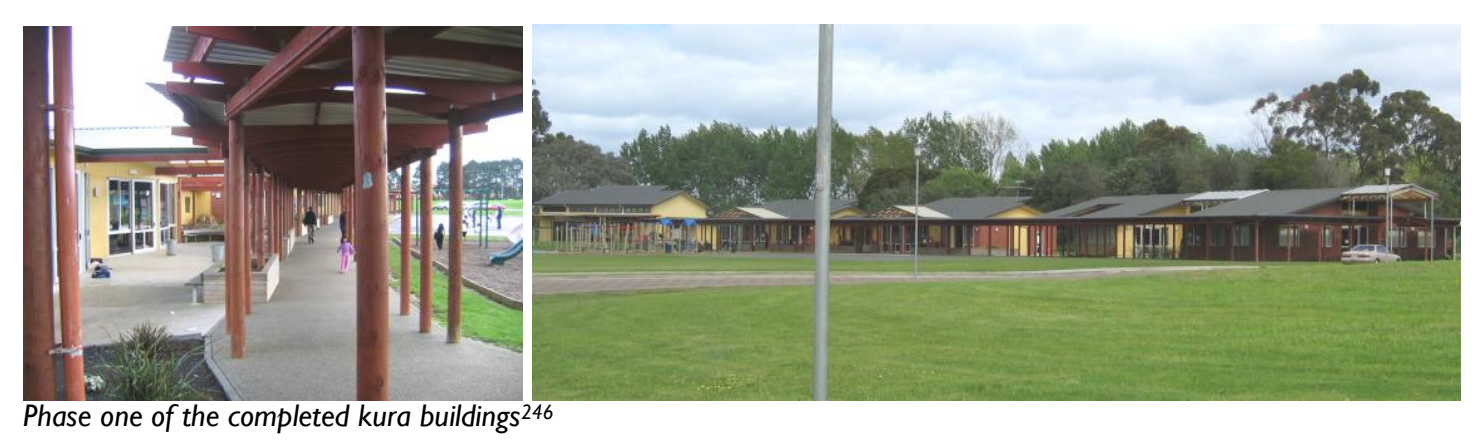

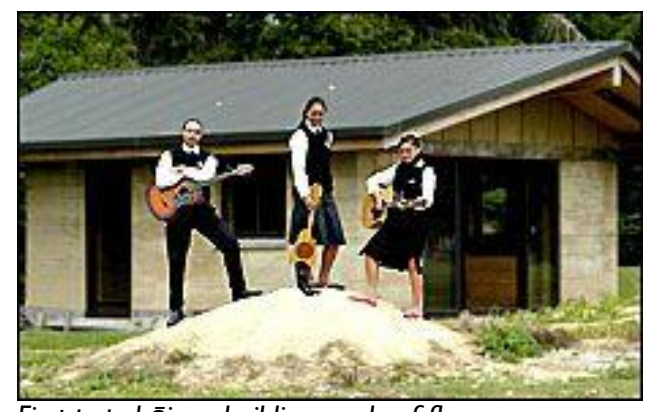

First papakāinga building made of flax fibre-reinforced rammed earth 248

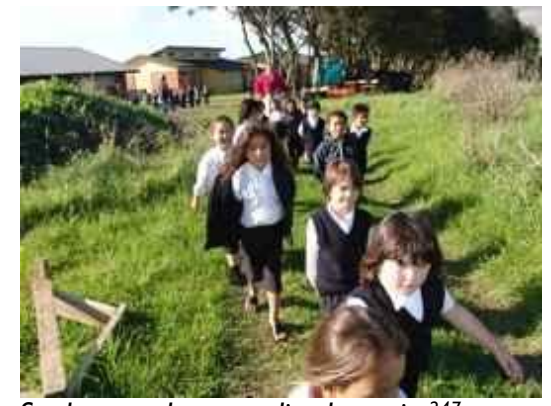

Students and surrounding kura site ${ }^{247}$

\footnotetext{
244 Ngai Tupoto Marae Trust, 2006.

245 Collins, II.1 0.2006

246 Te Kura Kaupapa Māori O Piripono Te Kura Whakahou ki Otara, Retrieved 10.2006.

247 Te Kura Kaupapa Māori O Piripono Te Kura Whakahou ki Otara, Retrieved 10.2006. Maramataka

248 Purcell, (photographer). 04.I I.2005.
} 


\section{Project location \& site description}

In 1979 Kōkiri Te Rahuitanga ki Otara Trust (Kōkiri Trust) established themselves on Alexander Crescent in suburban Otara by converting some old stable buildings and adding prefabs to provide a youth employment \& life skills training programme, youth 'at risk' residential care and kohanga reo (kaupapa Māori pre-school).

In 1997 Kōkiri Trust bought the whole largely vacant site to progress the papakāinga development. The site area of 28 acres, close to the main shopping area of Otara, spans both sides of Alexander Crescent and is surrounded by a mixture of residential private and state housing and educational facilities.
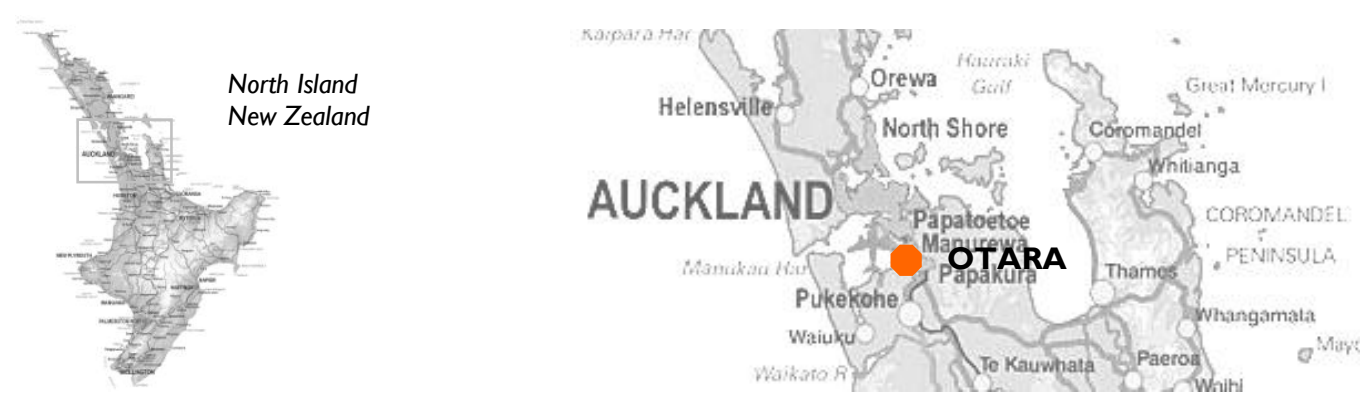

\section{Contextual history of Kōkiri Te Rahuitanga ki Otara Trust in the Otara community}

When the case study interviewee, Zena Tamanui, moved to Otara at age ten, the formerly known Department of Native Affairs, were implementing the new policy of a 'pepper potted' housing system, while condemning rural papakāinga houses and prohibiting Māori to build on their own land. Consequently, many Māori families moved to the cities for employment to send money back home. Tamanui states that many of her hapu ended up living in Otara.

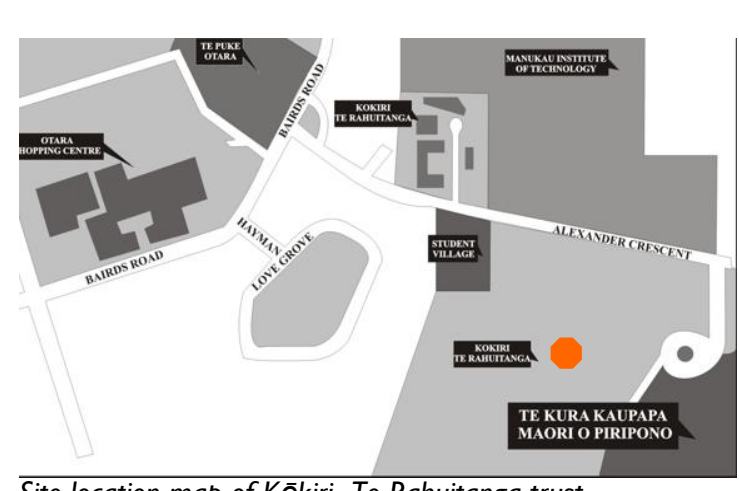

Site location map of Kōkiri Te Rahuitanga trust

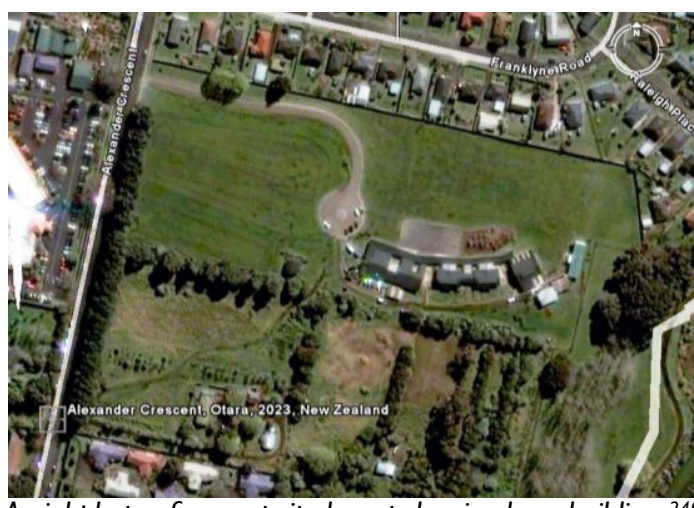
site complex with kura Piripono 250

249 Google Earth, Retrieved 28.02.08.

250 Te Kura Kaupapa Māori O Piripono Te Kura Whakahou ki Otara, Retrieved 10.2006. Location 


\section{Interviewee and project role}

Zena Tamanui is one of the founders and present chairwoman/C.E.O of Kōkiri Te Rahuitanga ki Otara Trust. She has resided in Otara for over forty years.

At the initial stage, Kōkiri Trust was made up of approximately ten people that had been members of a former youth group, family and local community members, and presently there are five main trustees and four to eight kaumatua.

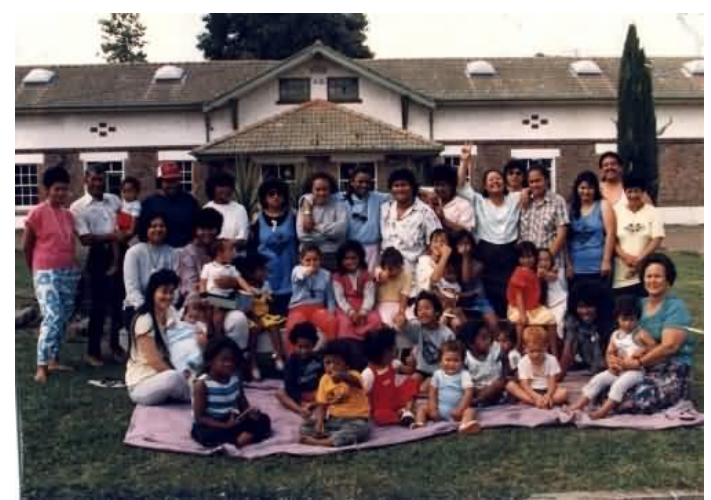

Te Rahuitanga kohanga reo 1986

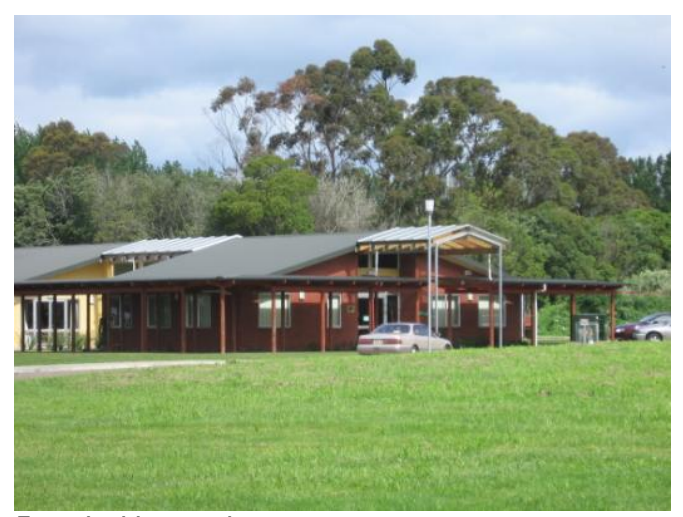

Entry buildings to kura

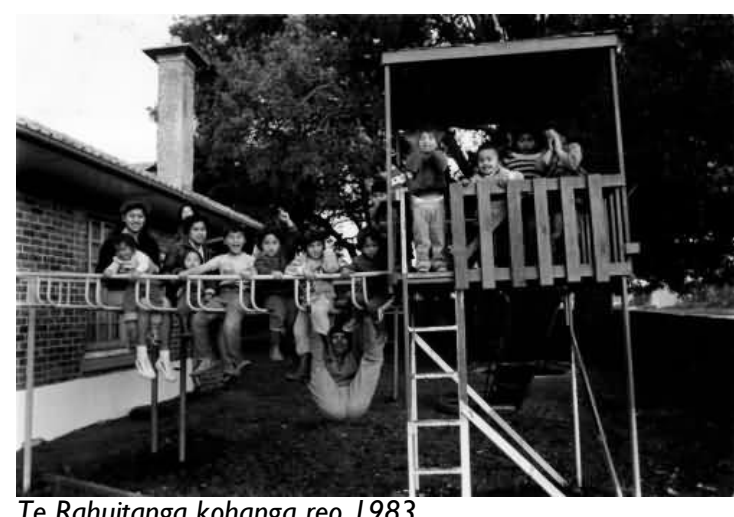

Te Rahuitanga kohanga reo 1983

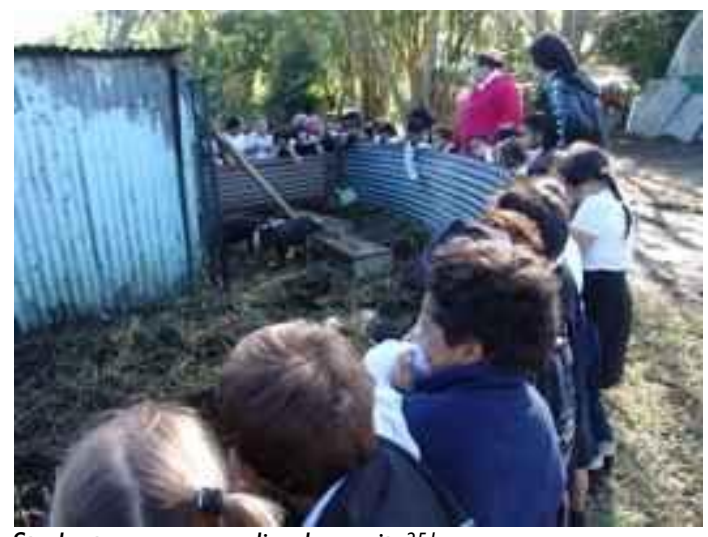

Students on surrounding kura site 251

25 I Te Kura Kaupapa Māori O Piripono Te Kura Whakahou ki Otara, Retrieved 10.2006. Maramataka 


\section{Case study findings \& interpretation}

\section{Profile of community participants in the place-making project}

The main community participants' of the papakāinga development are the Kōkiri Te Rahuitanga trust members who comprise of five main trustees and four to eight kaumatua. All have resided in the local community for at least a decade and are actively involved in community initiatives and employment. Most are employed or volunteer for both the Trust and the kura kaupapa/kohanga reo and participate in local committees and forums. Many local Otara community members have also participated in the development of the papakāinga concept through their involvement in the education initiatives and the consultation meetings at run at various local forums. The Kōkiri trustees and some teachers from the kura kaupapa that had participated over the development of the papakāinga concept, were discerned to be the most appropriate survey participants as they were the most consistently involved throughout the place-making project. Out of this group, survey forms were mailed to six contactable participants' and five survey responses were received which gives a $83 \%$ response rate. All of the respondents' participated in most of the identified stages of the project; the parts of the project that most participated in were the community meetings, small group meetings, organising and directing the project, getting others involved in the project, making decisions about the project, presenting the project to others, designing buildings or areas and helping to build the initial project buildings and areas.

\section{Method of interpretation and presentation}

The interview information, additional material and survey responses are interpreted to provide evidence of the specific dimensions of community well being that were enhanced by the participatory process. The raw data from the survey is presented in tables to illustrate the accumulated findings. The category abbreviations are: strongly agree (SA), agree (A), neutral $(\mathrm{N})$, disagree $(\mathrm{D})$ and strongly disagree $(\mathrm{SD})$. 


\section{Participatory processes \& community wellbeing findings}

\section{PROJECT INCEPTION PROCESSES:}

\section{Overview}

Tamanui and her fellow Otara Hillary College students formed a youth group, named

Whakahou, as a response to the rising negative behaviour caused by local youth in the Otara area. Whakahou became part of the activist movement and developed political \& social awareness tools through 'structural analysis' workshops that enabled the group to encourage and empower others in the community. Tamanui reflects that the concept and inspiration for the urban papakāinga came from the visions of many people over many years. The concept emerged from a combination of the visioning workshops that Tamanui ran at regional marae hui, positive lifestyle experiences of growing up in a rural papakāinga and being confronted with the needs of Otara families through involvement with Whakahou.

\section{Students form social group with local 'at risk' youth}

\section{Intentions}

Whakahou formed a youth group as a response to the negative behaviour of local youth in the Otara area with the intention of building positive group relationships and behaviour. Māori, Pacific Island and Pākehā students made up the group named 'Whakahou' (meaning resurgence or rebirth).

...we were all in our...17, 18, 19, 20's, and we'd all been together through college... and our friends and family were starting to get into trouble so we decided to form a youth group and try and do things so we would stay out of trouble. ${ }^{252}$

\section{Findings}

Enhanced Collective action; Empowerment: The members of Whakahou served the local youth that attended the group by providing positive social events and access to community resources such as food co-ops and relationship networking.

So we started running discos in '75, Wednesday, Thursday, Friday, holidays and then every Friday for almost eight years. So we did all that, meanwhile we did things like run food co-ops and stuff like that. ${ }^{253}$

252 Tamanui interview, December 2006

253 Tamanui interview, December 2006. 
Papakāinga idea emerges

from collective experiences

\& workshops

\section{Intentions}

While Tamanui was employed at a regional Runanga, she ran a series of regional marae hui with the intention of encouraging participants to discuss their visions for the future of their community and "what it is they dream for." 254

\section{Findings}

Enhanced Empowerment; Vision-making \& advocacy: At the various regional hui, the shared vision of a papakāinga arose as an ideal model for indigenous social, economic and environmental development.

I did a lot of workshop training in the social service area and vision workshops... running hui and talking about vision and what is it that they dream for, and basically the ideal papakāinga was their vision... So l'd like to believe that this is actually a collection of thousands of people's visions... 255

Enhanced Political, civil and civic participation \& commitment; Sense of pride, belonging \& connectedness to community: Tamanui stresses the importance of the papakāinga planning being carried out at relational community level as this is where the energy for change can start to build from.

...one of the things I discovered was that at a regional and at a local level unless you actually do it at a personal, whanau community level... that's actually where the energy is and that's the energy that's going to give life to the rest of the 'body'. ${ }^{256}$

One survey respondent comments on the large potential the papakāinga has to positively impact the future residents and surrounding community. They express that meaningful decisions and change happens when people actively participate and their thinking is open to being challenged with a willingness to look at alternative perspectives.

This has the potential to be a "slice of heaven" in the middle of suburbia. But it's a challenge to try to change the way people think, even those with power to make decisions like councils. The first and most important decisions start inside each individual's heads. Remove apathy, complacency and unwillingness to change, then you will see real and meaningful decisions being made.

\footnotetext{
254 Tamanui interview, December 2006.

255 Tamanui interview, December 2006.

256 Tamanui interview, December 2006.
} 


\section{Youth workers attend social}

analysis workshops

\section{Intentions}

Whakahou and Kōkiri Trust intended to build awareness of the effects that socio-political decisions have upon the community, in order to empower people to be more involved in decision-making. Tamanui states: "The individual changes the culture by their consciousness." 257

\section{Findings}

$\begin{array}{llllll}\text { Political, civil \& civic participation: More interest in decisions made by officials } & \text { SA } & \text { A } & \text { III } & \text { D } & \text { S } \\ & & \text { I }\end{array}$

Enhanced Empowerment; Vision-making \& advocacy: Tamanui recounts that Whakahou members' participation in the structural analysis workshops empowered them to perceive how the broad socio-political attitudes and decisions affected the struggles of their local community.

...we developed analysis tools that's not normally accessible at the community level...It was about using the tool of structural analysis in all those different areas to help people to have a look at a perspective, see the big picture. It was really choice. So you had an understanding of the micro and the macro...And also being able to link up with international people who had the same [concerns]... ${ }^{258}$

Enhanced Political, civil and civic participation \& commitment: The respondents strongly disagree, agree and strongly agree that they had more interest in decisions being made by the local council and government. 


\section{PROJECT BRIEFING AND DESIGN PROCESSES:}

\section{Overview}

Kōkiri Trust formed in 1979 to establish education training that aimed to provide employment and personal development skills for local youth in the areas of small business development, horticulture, information technology and multimedia.

Two other initiatives commenced; Kōkiri Trust's kohanga reo was one of the first developed in Auckland, and residential care was provided for children and teenagers that required alternative caregiving and accommodation to their family homes.

During Tamanui's participation in two conferences on indigenous development, she discovered many cultures exploring similar village concepts which encouraged the papakāinga concept to progress. Some Kōkiri trustees visited similar village communities in Australia to understand the processes and structures involved in managing this type of community model. After being disappointed by the attempts of seven architectural practices and students from a local university to develop the papakāinga concept, Kōkiri trustees decided undertake the master planning process themselves. An earth building architect and permaculture designer worked with Kōkiri Trust over a year to design the new public space in relationship with the existing natural resources and site.

\section{Kōkiri trust forms to \\ establish youth education \& caregiving initiatives}

\section{Intentions}

Kōkiri Trust formed to meet the identified needs of the local community. They intended to provide culturally appropriate education, employment alternatives to dependence on government benefits and residential foster care support for teenagers who were separated from their families.

\section{Findings}

$\begin{array}{llllll} & \text { SA } & A & N & D & S\end{array}$

Enhanced Empowerment; Vision-making \& advocacy: Tamanui states that the long-term training programmes offered local youth income alternatives to dependence of benefits. "We had a hundred and something trainees and we did a whole lot of different modules. We did that 
for a number of years..."259 Mentoring and residential care for teenagers still continues being based at the Trust's site.

Tamanui discusses the more culturally appropriate education that the parents at the kohanga reo instituted and how they addressed local issues such as racism.

... as young parents we wanted something better for our children because we had already come to an awareness that what they teach in schools was biased towards the northern hemisphere... the view of the southern hemisphere was that we're all uncivilised and we're still trying to catch up to this stuff... so we started having our own things and also we were very much aware of racism too. We did a program actually on that. 260

Enhanced Collective action: All respondents are unanimous that it was very important to them that people in their community worked together rather than alone to improve the conditions of the area.

\section{International \& local \\ research undertaken for \\ papakāinga model}

\section{Intentions}

Some of the trustees visited similar village communities in Australia to understand the decision-making processes and structures involved in managing a papakāinga. Tamanui participated in several international cultural forums to gain knowledge about cultural development.

\section{Findings}

Enhanced Vision-making \& advocacy; Collective action: Tamanui discovered that while Kōkiri Trust were developing their own village concept, many similar village models were being implemented internationally, which helped to encourage the papakāinga concept to progress.

...so at the same time as we're unravelling or rediscovering a lot of the things about what we want, I was fortunate to be in international circles where they were doing it as well. 261

I learnt personally that a lot of this exists in the world and every culture can go right back to its indigenous days when they all lived in villages or papakāinga so this is not new to any race in the world. ${ }^{262}$

\footnotetext{
259 Tamanui interview, December 2006.

260 Tamanui interview, December 2006.

261 Tamanui interview, December 2006.

262 Tamanui interview, December 2006.
} 


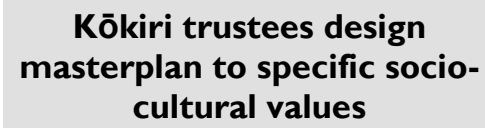

\section{Intentions}

After being disappointed by the attempts of several architects and student groups, Kōkiri Trust resorted to designing the masterplan for the papakāinga themselves. Their intention was to use their own knowledge gained from residing and working in Otara to design plans that embodied the socio-cultural values of the community.

So we went plan by plan and one of the things that we came up with was the fact that not only did we have to have housing plans but also social plans - where are people supposed to go, what's supposed to go where, how are we going to do it??263

Tamanui states that the community's vision of providing environments centred on developing individuals' thought processes is intended to enhance the wider community's educational development.

$\ldots$ in the end it's all about education to actually keep this going but also to contribute to the wider community and to the country - citizenship...Because our theory is about developing your processes of thinking... ${ }^{264}$

\section{Findings}

Empowerment: More positive for future of community

$\begin{array}{ccccc}\text { SA } & \text { A } & \text { N } & \text { D } & \text { S } \\ \text { IIIII } & & & & \\ \text { IIII } & & \text { I } & & \\ \text { II } & \text { III } & & & \\ \text { IIII } & \text { I } & & & \\ \text { IIIII } & & & & \end{array}$

Enhanced Vision-making \& advocacy; Empowerment; Collective action: Kōkiri Trust experienced a large learning curve in designing the arrangement and type of buildings that would express their values. Tamanui expresses the knowledge and empowerment the community gained through the members engaging in the detailed development of the papakāinga design and decision-making process.

...we started to figure out how to do all the stuff ourselves. So that's how we learnt what types of houses we were looking at and that we could actually get the houses we wanted, and [architectural consultants] tried to restrict us to budget and we said 'No, first of all, let's dream the dream, because if you dream a budget....265

\footnotetext{
263 Tamanui interview, December 2006.

264 Tamanui interview, December 2006.

265 Tamanui interview, December 2006.
} 
All of the respondents strongly agree about feeling positive for the future of their community by being involved in the project. One respondent expresses that there is significant community commitment to enhancing the empowerment, knowledge and quality of life of the community's members,

This community and the people (mixed ethnic groups) endeavour to enhance all aspects of awareness in religion, council matters, decision making, etc, that would increase the quality of life for children, parents, grandparents of Aotearoa...

Most respondents strongly agree that by being involved in the project that they want to be involved in future decisions that will affect their community, one respondent is neutral. All respondents either agree or strongly agree that being involved in this project helped their community to work together to find ways to solve their problems, with one respondent who strongly agreed adding "Specifically housing problems" to the question. The respondent further commented, "The way the question is worded puts too much emphasis on project" which in speculation, suggests that being involved in the project was only one method that their community worked together to solve their problems.

Enhanced Sense of pride, belonging \& connectedness to community: All respondents either agree or strongly agree about caring more about what the community/area looked like by being involved in the project, with a strongly agree comment of, "All the beauty has been scrapped away [from the existing area]." All respondents unanimously agreed that their knowledge of local services and facilities in the area had increased by being involved in the project.

\section{PROJECT PROMOTION PROCESSES:}

\section{Overview}

Kōkiri Trust organised a five day 'Ecoshow' expo to be held on the Alexander Crescent site and invited well-known national and international ecological design practitioners to facilitate workshops. This enabled the trustees to gain access to a large amount of information to enhance their future plans. The first two buildings of papakāinga were completed on site at the Ecoshow. 
'Ecoshow' expo - first papakāinga buildings built

\section{Intentions}

The hosting of the 'Ecoshow' was intended as a way to gather a large amount of expertise and knowledge to further develop the papakāinga. The first two buildings of the papakāinga were commenced at the show in order to launch and build momentum for the project.

\section{Findings}

Enhanced Political, civil and civic participation \& commitment: Hoskins comments on the effective process of involving the local community in the physical construction of the first papakāinga building.

We used local labour. We brought in some expertise. We used George Masina's [school principal] son, some of the guys and girls who were members of the residential unit came and helped. That was a very good process. We had to have a skilled earth builder on most of the time and a normal builder, but all the labour was donated by local people there. They made a huge difference. ${ }^{266}$

\section{PROJECT CO-ORDINATION PROCESSES:}

\section{Overview}

Kōkiri Trust formally communicates the progress of the papakāinga to local groups through forums such as the Otara Action Committee and the Otara Māori Forum. Much informal communication and feedback occurs through the trustees friendships and associations with local people as most have lived locally for over forty years. From the knowledge gained from residing and working in Otara and the research undertaken overseas, the trustees developed the village's organisational plans. Decisions were made on how the buildings would be best arranged to facilitate the educational, housing, health, religious, cultural, commercial and recreational needs of the resident and wider community. Governance of the papakāinga will be consensus managed by the residents, modelled on marae kaupapa and separate from the Kōkiri Trust who are the caretakers and vision holders for the land.

266 Hoskins interview, August 2006. 
Local community consulted

through forums \& existing

long-term networks

\section{Intentions}

Kōkiri trustees informally liaised with schools, neighbouring residents, training courses and employment involvements to gain the local community's support and participation in the papakāinga project. Kōkiri Trust formally communicates the progress of the papakāinga to through forums such as the Otara Action Committee and the Otara Māori Forum. The intention of consulting is to accurately represent the wider community's needs in the development process.

\section{Findings}

Collective action: Community works together to solve problems

$\begin{array}{ccccc}\text { SA } & \text { A } & \text { N } & \text { D } & \text { S } \\ \text { II } & \text { III } & & & \\ \text { II } & & \text { II } & & \\ \text { IIII } & & & & \text { I } \\ \text { IIII } & & & & \text { I } \\ \text { III } & \text { I } & & & \text { I } \\ & \text { III } & & & \\ & \text { I } & & & \\ \text { III } & & \text { I } & \text { I } \\ \text { III } & \text { I } & \text { I } & & \\ & \text { II } & \text { II } & \text { I } \\ \text { III } & \text { I } & & \text { I } \\ \text { III } & \text { I } & & & \text { I } \\ \text { IIII } & & \text { I } & \\ \text { IIII } & & & & \text { I }\end{array}$

Enhanced Interpersonal \& organisational trust; Effective leadership \& management: Tamanui states that all of the Trustees have resided long-term and been involved in many community forums in Otara which enables an accurate representation of community's needs to be reflected in the papakāinga design. Tamanui expresses that local's trust Kōkiri members as they recognise their consistent roles in encouraging positive change for the community.

We know the community 'cos we've lived here for forty years and so even though it's a transient type of community the majority here are actually founder families. So we all met in different circles and we're all involved in community stuff, so in terms of how does the community know about it, it's because we are the community or part of it. 267

And so either through education or social welfare or health or economics or educational, all of those forums we'll meet somehow and people know...People also

267 Tamanui interview, December 2006 
know that as Kōkiri, we've actually been building something or been actually doing something about something [making social changes]...268

Respondents agree and strongly agree that being involved in this project helped their community to work together to find ways to solve their problems. The respondents' trust in community leaders has stayed the same and increased by being involved in the project, with one respondent giving no answer and commenting "Not applicable - I am one".

Enhanced Vision-making \& advocacy: One respondent comments that the community members' vision for the papakāinga concept was conceived, guided and developed out of the community's unique history and experience.

We conceived the vision and have been continually evolving through our journey as a community organisation and community in our own right. Our vision and stance declares that any model must be founded on the premise of a lifestyle seeding from tangata whenua [indigenous people] of Aotearoa and Tauiwi [non-indigenous New Zealanders] and all their experiences that have been used to enhance and help grow these indigenous seeds, not replace/eliminate them.

Enhanced Collective action: Tamanui stresses the importance of developing the papakāinga by personally consulting at a community level as this is where the energy for change will build from.

Enhanced Sense of pride, belonging \& connectedness to community: Both questions of the amount of times the respondents' talked to others around the area and friendships with people in the area had mostly increased by being involved in the project. One respondent answered decrease for both questions and comments on the friendships with people in the area, "The development of values for the project limits," which suggests a limiting amount of time for developing friendships due to the development of the project values. Most respondents agree and strongly agree about feeling more proud of their community by being involved in the project, with one respondent strongly disagreeing and commenting, "Already feel this gives focus," perhaps, with speculation, thinking that this is inherent in their community's approach.

Enhanced Empowerment: Most of the respondents agree about feeling a more important part of the community by being involved in the project, with one respondent giving no answer and commenting, "Not applicable, it's because I am important to this community that the project has come about." Variance occurred where the respondents' willingness to ask for

268 Tamanui interview, December 2006 
what their community needed from local officials (like councils) had decreased, stayed the same and increased.

Enhanced Reciprocity \& responsibility: Respondents are neutral, agree and strongly agree that they cared more about what people in their community thought of their actions by being involved in the project, with the neutral comment of, "l'm part of this community/whanau." The respondents strongly disagree, are neutral and agree about wanting to volunteer more of their spare time to their community. Most respondents agree and strongly agree about feeling they could benefit more from what happened in their community by being involved in the project, with one strongly disagreeing with the comment of, "It's a two way process reciprocity."

Enhanced Equality \& tolerance: Respondents strongly disagree, agree and strongly agree that their community was more accepting of people from different cultures and backgrounds by being involved in the project, with the strongly disagree comment of, "Already have this view."

Enhanced Political, civil and civic participation \& commitment: Most respondents' involvement in local community groups \& activities had increased by being involved in the project with one answer that their involvement had decreased. Likewise, most respondents strongly agree that they wanted to be involved in future decisions that affected their community by being involved in the project, with one neutral answer.

\section{Resident coordination roles} $\&$ protocols planned

\section{Intentions}

Tamanui states that developing an organisational framework for the papakāinga is intended to sustain the residents and the vision.

Most people think well once you get a house it will be fine, but that's proven not to be right. The organisational structure has to be in place before this is all built, because if it's not then you've got people who come in with all their different lifestyles...There's nothing wrong with that, but people have to come in and actually share the best of each other's lifestyles with all of us. ${ }^{269}$

269 Tamanui interview, December 2006 


\section{Findings}

Enhanced Effective leadership \& management; Political, civil and civic participation \& commitment:

A vision of user-governance and user-management is planned for the papakāinga that aspires to encourage role responsibility and collaboration among the papakāinga residents.

We [Kōkiri Trust] don't want to be the governance of the village...because there's going to be a lot more people that will develop the role of the village rather than [us]...The governance of the village will be by the village. ${ }^{270}$

...they'll have roles in terms of what they need to do to be a part of the village and there'll be political roles in terms of decision making, there'll be economic roles in terms of money and there'll be social roles...You don't know which model will fit and so we've been developing our own form of infrastructure, governance, management and services...271

\section{PROJECT IMPLEMENTATION PROCESSES:}

\section{Overview}

The whole papakāinga process has taken between about eight years, with the first set of buildings currently featuring on site, the whare kura buildings, completed in 2002 . The last two years Kōkiri Trust has been concentrating on sourcing funding and forming the organisational infrastructure and management of the papakāinga community. Kōkiri Trust has invited other community groups, such as another Otara marae and local kaumatua, to join the papakāinga community.

\section{Trust source partnerships with local organisations \& funders}

\section{Intentions}

Kōkiri Trust has been sourcing funding to contribute to the ongoing developments. While the building work continues, Kōkiri Trust intends to source the labour from within the Otara community in order to generate income for the area. They have also invited other community groups, such as another Otara marae and local kaumatua, to join the papakāinga community to share in the benefits of the range of spaces that will be provided.

....Ngati Otara, we've invited them to shift to be a part of this...there's also an invitation to others to have some association. ${ }^{272}$

270 Tamanui interview, December 2006

271 Tamanui interview, December 2006

272 Tamanui interview, December 2006 


\section{Findings}

Social supports: More knowledge of local services

SA A $N$ D $S$

IIIII

Enhanced Interpersonal \& organisational trust: Currently a partnership team is formed with the Otara Economic Development Trust to explore commercial ventures, such as a cultural experience centre for tourists to experience the alternative models of education, cultural expression and village living of the existing and new Kōkiri facilities.

...we're in a partnership with Otara Economic Development Trust...We've been developing a project team on how we could best do that and the services here will actually come from the community and from this area. ${ }^{273}$

Enhanced Social supports: All of the respondents answered that their knowledge of local services and facilities in the area had increased by being involved in the project. Many collaborative partnerships and networks are formed with local community organisations that reciprocate support of each other. Local marae, trusts, social organisations, local builders and many individuals from the Otara community have collaborated to support the papakāinga development. 


\subsection{General case study trends \& findings}

\section{General process findings}

A common theme over all of the case studies is that the processes are not facilitated by typical "professionals," such as architects or government agencies. Some case studies do not even include professional services or authorities until the implementation phase. This observation illustrates that the participants employed a high level of Arnstein's termed 'citizen control', where the local people with expertise most relevant to addressing the local issues facilitated the process. The initiatives use participation in the place-making projects to facilitate and express improvements to the holistic wellbeing of the community.

\section{Participatory process summary}

Figure 3 groups the processes used in the case studies. Related processes of a similar type are grouped under relevant headings.

The individual processes are colour coded to indicate which case study they come from.

Key: Gisborne, Moerewa, Motukaraka, Otara

\section{Figure 3: Participatory process summary}
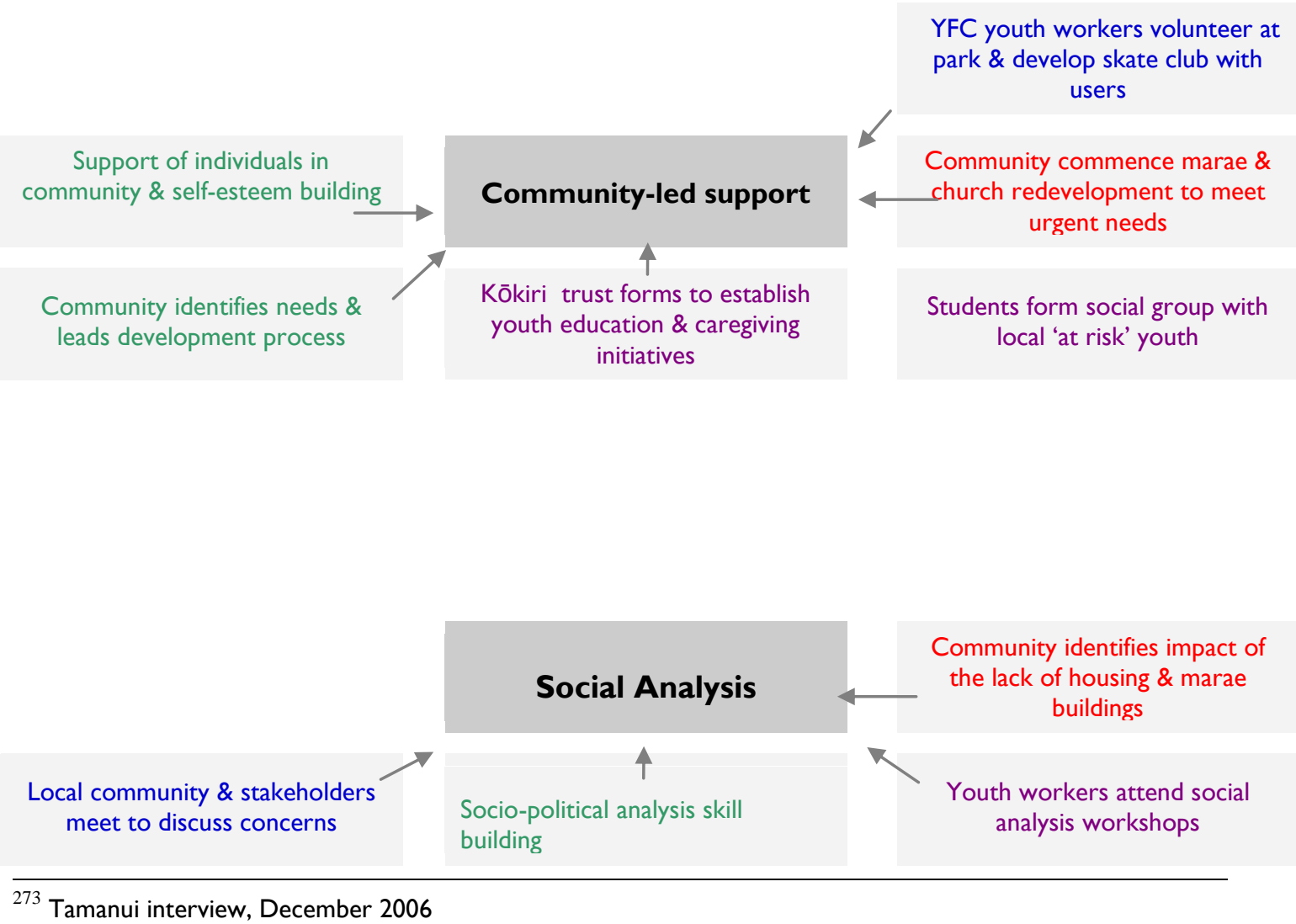
Township celebration event of past, present \& future

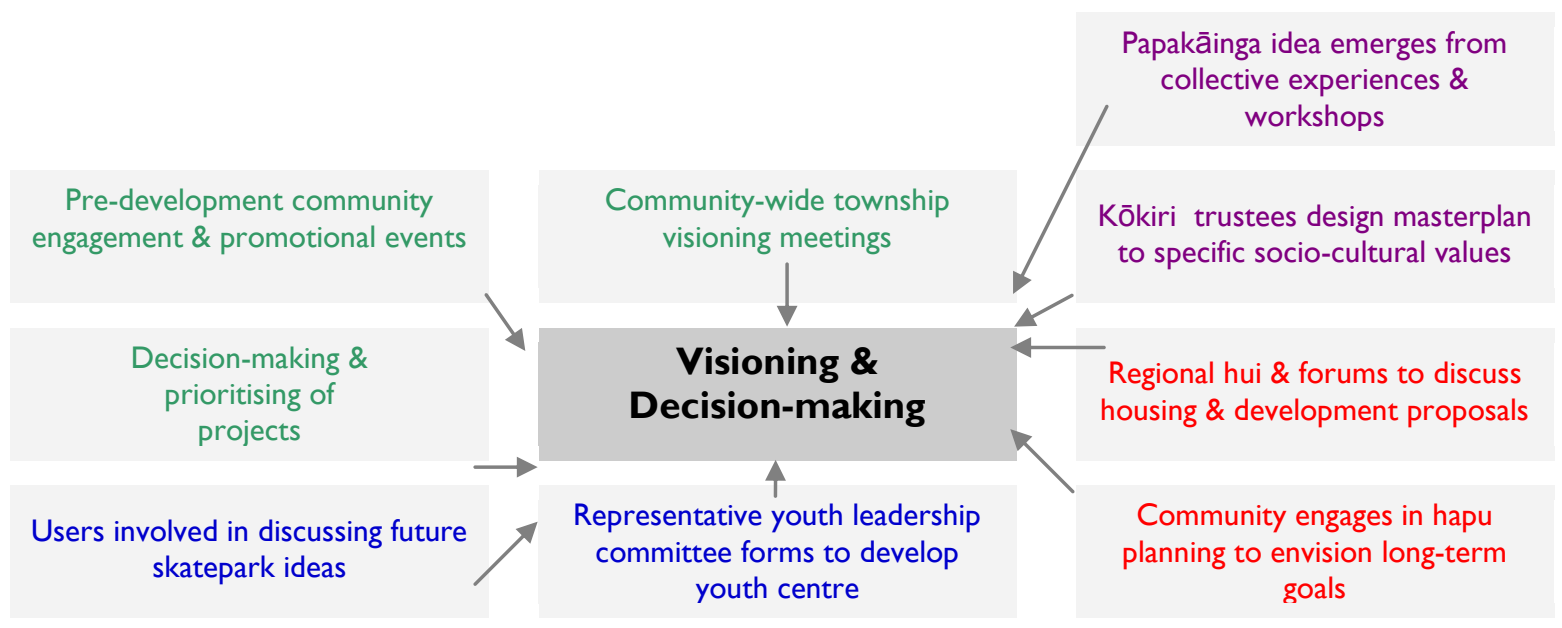

\begin{tabular}{|c|c|c|}
\hline $\begin{array}{l}\text { Working groups strategise \& } \\
\text { implement town centre projects }\end{array}$ & Collaboration & $\begin{array}{l}\text { Trust members with development } \\
\text { expertise assigned housing } \\
\text { process }\end{array}$ \\
\hline $\begin{array}{l}\text { International \& local research } \\
\text { undertaken for papakāinga model }\end{array}$ & $\begin{array}{l}\text { Community members \& youth } \\
\text { committee form project team }\end{array}$ & $\begin{array}{l}\text { Marae development weekend } \\
\text { organises working groups to } \\
\text { implement goals }\end{array}$ \\
\hline
\end{tabular}

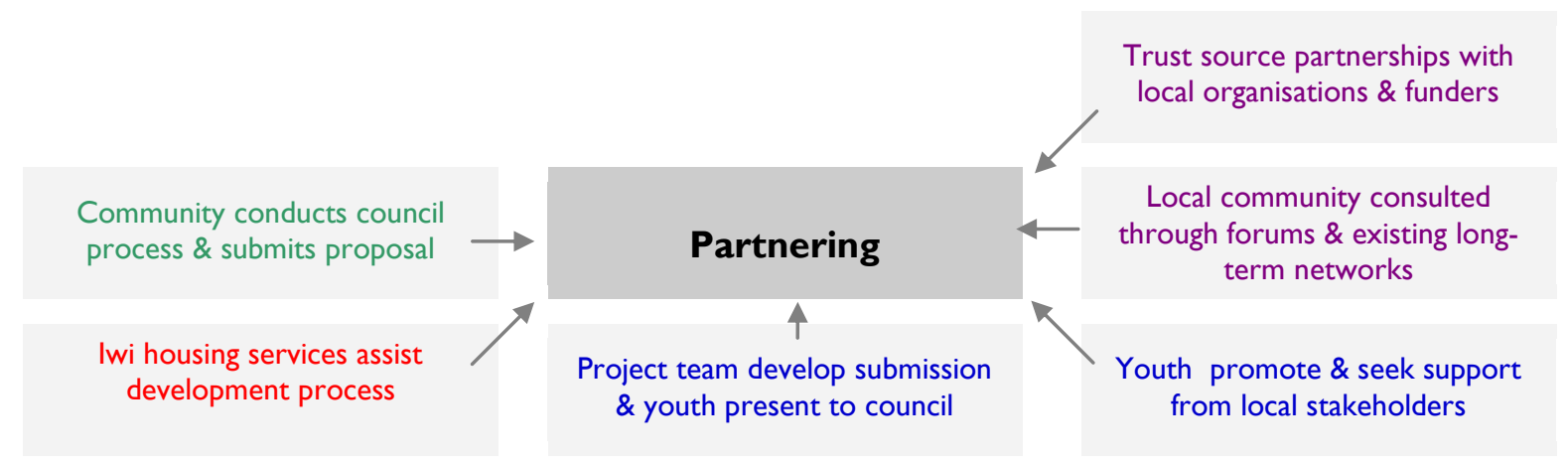


Ecoshow' expo - first papakāinga buildings built

\section{Implementation}

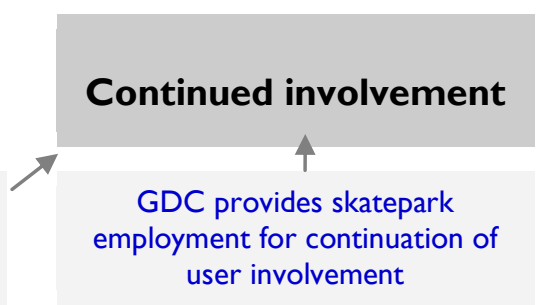

Project team presents opening of completed project building '
Resident co-ordination roles \& protocols planned
Consultants conduct focus groups to develop long-term plan

Community continue to develop initiatives \& seek support funding

\section{Survey trend findings}

An interpretation of the survey responses and the overall sample trend demonstrates that the majority of survey respondents strongly agree that community wellbeing has been enhanced across the range of dimensions. Refer Table 5 'Survey findings'. Within this strong leaning toward enhancement, particular dimensions are emphasised above others. Positive findings in both dimensions titled 'a desire to influence the future' and 'trust in leadership' show that local democracy and governance has been enhanced. Among dimensions of active citizenship, the findings of collective action and empowerment are heightened. Social capital is enhanced through an increase in equality and tolerance, a sense of pride, belonging and connectedness and social supports. In anecdotal support of this evidence, the overall comments from both the survey respondents and interviewees portray a very positive experience of their participation. One respondent seems to have misunderstood the survey's intention as they answered strongly disagree with many of the indicators, while providing reasons defending the high level of perceived community wellbeing present within their community. These answers have been included in the findings and used on basis of their reasons, which all reinforce the enhancement of community wellbeing. The highest praise for participation in place-making comes from a Gisborne survey respondent who reflected that in-depth participation in the project and ongoing developments empowered a change in life direction and helped to achieve their personal aspirations:

My involvement with the Alfred Cox Skatepark in Gisborne was very full on. I was around while the park was being shaped. Then later on when we put a building on it. I got so involved with this project that it helped change the course of my life. When I first got involved with YFC (Youth for Christ) I was unemployed, through my involvement they employed me part-time, then assisted me through a diploma in youth work. After completing the diploma I was hired as a Skatepark supervisor part-time. Also worked in Alternative Education which was established at the Skatepark. Then I moved on to train as a counsellor of which I am one paper away from a diploma... 


\section{Table 5: Survey findings}

Each mark represents the indicator that relates to each participants survey response answer. Colour key: Gisborne, Moerewa, Motukaraka, Otara

\begin{tabular}{|l|l|l|l|l|}
\hline $\begin{array}{c}\text { Strongly } \\
\text { agree } \\
\text { or } \\
\text { Increased }\end{array}$ & Agree & $\begin{array}{c}\text { Neutral } \\
\text { or } \\
\text { Stayed the } \\
\text { same }\end{array}$ & Disagree & $\begin{array}{c}\text { Strongly } \\
\text { disagree } \\
\text { or } \\
\text { Decreased }\end{array}$ \\
\hline
\end{tabular}

LOCAL DEMOCRACY AND GOVERNANCE

Vision-making and advocacy capability

Involved in future decisions

I III III แII - I II ||

III

Effective leadership \& management

III III IIIII II

III III

I

ACTIVE CITIZENSHIP

Political, Clvil and Civic Participation

Involved in future decisions

I III IIII III)

| II II III

III III III

III II

II II I

III

Interest in decisions made by officials

III IIIII IIIIII IIII!

Comm. work together (v.impt, sl.impt, undecd, n.impt) III II II

Volunteer more time

Help work together to solve problems

III

| IIIII |III ||

\section{IIII II II}

Reciprocity \& responsibility

Care about what comm. thought of actions

$\begin{array}{lll}\text { II II III } & \text { I II II } & \text { III II } \\ \text { II II } & \text { III II II } & \text { II I I II } \\ \text { I III II } & \text { II III II I } & \text { III }\end{array}$

Benefit more from what happened

I III III

II III II I

III III

Empowerment

More impt. part of comm.

Willingness to ask officials

\begin{tabular}{|c|c|}
\hline $\begin{array}{l}\text { I III } \\
\text { II IIII || III }\end{array}$ & III III IIII I II \\
\hline 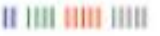 & II \\
\hline
\end{tabular}

Positive about future

II IIII HIIII IIIII

II

1

SOCIAL CAPITAL

Sense of pride, belonging and

connectedness to community

More proud of comm.

Better.area to live in/some to

Cared about what comm, look like

Amnt. of times talk to others

Knowledge of local services/facilities

Friendships in area

Interpersonal and Organisational Trust

Help work together to solve problems

Knew more geople to trust in crișis

Area safer

Equality/Tolerance

More accepting of diff cultures/bkgrds

Social Supports

Knowledge of local services/facilities

Is

| III III || || || || |

IIIII.II!.

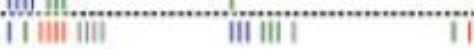

III IIII IIII IIII

IIII IIII IIII IIIII I I II

III III IIIIII IIII

IIII

$\mid 111$

1

।

î.....

III

int

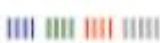

III

Key.

(underscore).................. (these questions were excluded from surveys for Motukaralca and Otara) 


\subsection{Case study summary findings}

Table 7 shows a summary of the integrated findings from the all of the case studies.

It demonstrates both that community wellbeing has been enhanced and the process by which it has been enhanced. The layout of the table shows the essential participatory processes and the guiding principles in the left column, the intentions of each process in the centre column and the community wellbeing findings in the right column. The individual principles are sourced from recommendations by the interviewees (footnoted), while the intentions for each process are interpreted from both the interview and supplementary case study material. The community wellbeing findings are sourced from both the case study interviews and survey responses. The findings are rated according to the level of support the case study participants' provided in their survey and interview answers. The ratings demonstrate the significance of the findings.

Refer to Table 6 in appendices for a condensed version of Table 7.

Community wellbeing evidence ratings:

*** Conclusive evidence of enhancement (three star rating) based on either:

a. All 4 case study interview findings strongly agree with the enhancement of community wellbeing OR

b. over $50 \%$ of the overall population of case study survey participants' strongly agree with the enhancement of community wellbeing

** Strong evidence of enhancement (two star rating) based on either:

c. 3 to 4 case study interview findings strongly agree with the enhancement of community wellbeing OR

d. over $50 \%$ of all the survey participants' of each case study strongly agree with the enhancement of community wellbeing

* Suggestive evidence of enhancement (one star rating) based on either:

a. I to 2 case study interview findings agree with the enhancement of community wellbeing OR

b. over $50 \%$ of all the survey participants' of each case study agree with the enhancement of community wellbeing

- Unaltered evidence of enhancement (one zero rating) based on either:

a. case study interview findings that anticipate, but have not yet experienced the enhancement of community wellbeing OR

b. over $50 \%$ of all the survey participants' of each case study are neutral with the enhancement of community wellbeing

There is no rating for inconclusive evidence where the individual responses vary widely. This is because the total is under $50 \%$ of all survey participants' that agree, are neutral or disagree with any one answer. 
Table 7: Case study summary findings

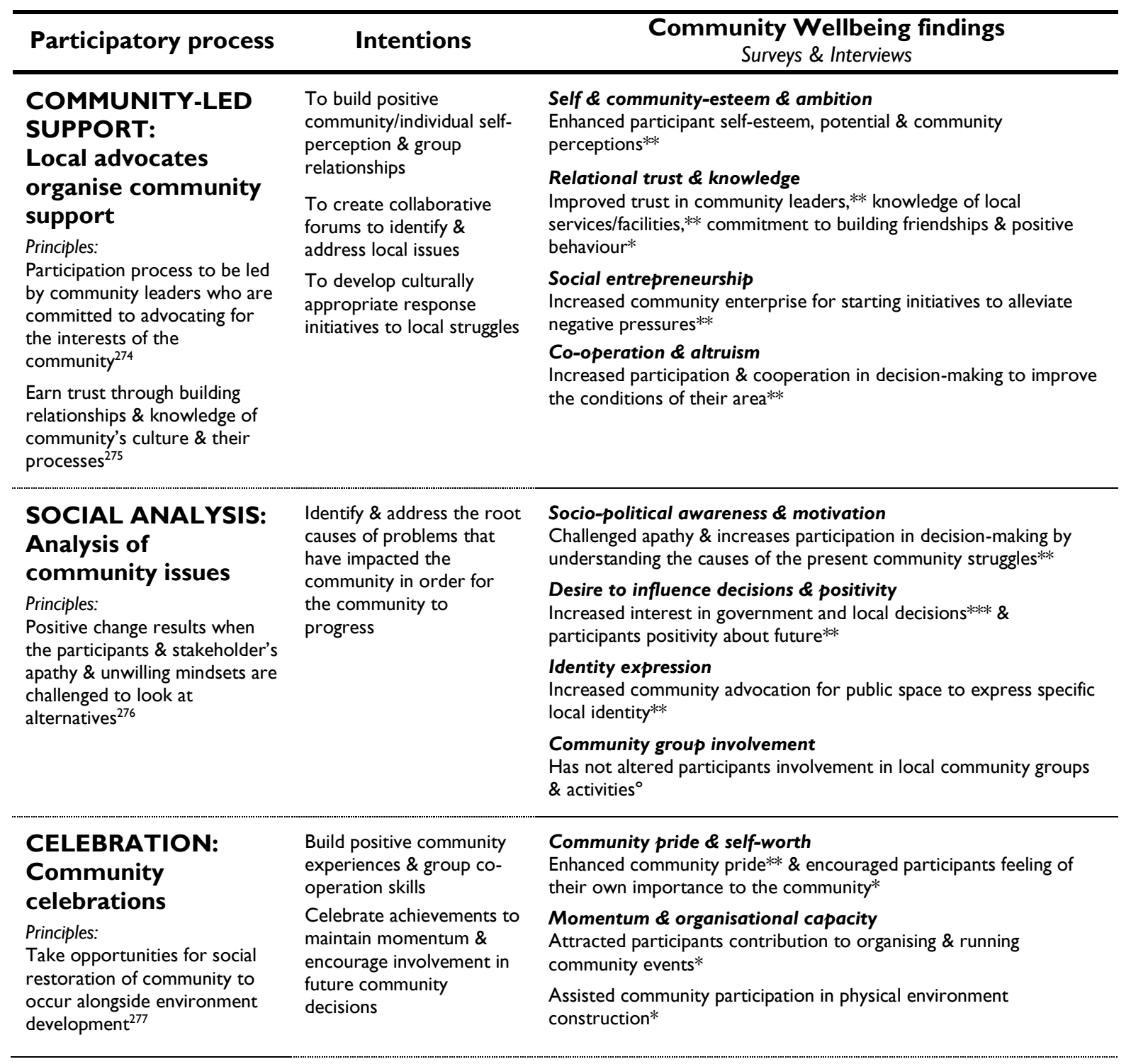

Table continued over next two pages...

\footnotetext{
${ }^{274}$ Hemi Toia interview, Community Employment Group, 2002.

275 Tims interview, August 2006; Recommendation from survey respondent, Motukaraka

276 Davis interview, August 2006; Tamanui interview, December 2006.

277 White interview, November 2006.
} 


\begin{tabular}{|c|c|c|}
\hline Participatory process & Intentions & $\begin{array}{l}\text { Community Wellbeing findings } \\
\text { Surveys \& Interviews }\end{array}$ \\
\hline \multirow{5}{*}{$\begin{array}{l}\text { VISIONING \& } \\
\text { DECISION MAKING: } \\
\text { Community visioning } \\
\text { \& decision-making } \\
\text { Principles: } \\
\text { User participation has been } \\
\text { successful when solutions to } \\
\text { community problems have } \\
\text { been sourced from the } \\
\text { community }\end{array}$} & \multirow{2}{*}{$\begin{array}{l}\text { Appropriately engage } \\
\text { participants in community } \\
\text { visioning process \& } \\
\text { present transparent } \\
\text { intentions of involvement }\end{array}$} & $\begin{array}{l}\text { Collective vision \& motivation } \\
\text { Inspired collective visions for community from participants \& } \\
\text { motivation for development }{ }^{* *}\end{array}$ \\
\hline & & \multirow{2}{*}{$\begin{array}{l}\text { Collaboration \& influence } \\
\text { Increased community collaboration to improve conditions of } \\
\text { area*** \& desire to be involved in future decisions } * * *\end{array}$} \\
\hline & \multirow{2}{*}{$\begin{array}{l}\text { Acknowledge and } \\
\text { incorporate community's } \\
\text { unique history \& } \\
\text { experience into visioning } \\
\text { process }\end{array}$} & \\
\hline & & $\begin{array}{l}\text { Capability \& knowledge } \\
\text { Increased commitment and capacity to implement projects** \& } \\
\text { knowledge of local services/facilities** }\end{array}$ \\
\hline & \multirow{2}{*}{$\begin{array}{l}\text { Communication and } \\
\text { discussion to enable } \\
\text { constructive input } \& \text { a } \\
\text { unified level of } \\
\text { understanding amongst } \\
\text { participants }\end{array}$} & $\begin{array}{l}\text { Trust in leaders } \\
\text { Enhanced trust in community leaders** }\end{array}$ \\
\hline $\begin{array}{l}\text { development process at the } \\
\text { personal/whanau level as these } \\
\text { groups have the motivation \& } \\
\text { necessity for change }{ }^{279}\end{array}$ & & $\begin{array}{l}\text { Promoting voiced needs \& fair decision-making } \\
\text { Promoted voiced needs \& priorities of specific community* \& } \\
\text { utilised fair democratic processes for decision-making between } \\
\text { participants* }\end{array}$ \\
\hline \multirow{2}{*}{$\begin{array}{l}\text { Use culturally inclusive } \\
\text { communication \& clear } \\
\text { processes to ensure there is a } \\
\text { unified level of understanding } \\
\text { between participants } \\
\text { be }\end{array}$} & \multirow{4}{*}{$\begin{array}{l}\text { Facilitate structured } \\
\text { community-wide } \\
\text { discussions, decision- } \\
\text { making process \& } \\
\text { representative results }\end{array}$} & $\begin{array}{l}\text { Cultural tolerance } \\
\text { Increased acceptance of people from different backgrounds** }\end{array}$ \\
\hline & & $\begin{array}{l}\text { Relational contact, self-worth \& pride } \\
\text { Increased community pride, }{ }^{*} \text { conversations with others in } \\
\text { area** \& their feelings of importance to the community** }^{* *}\end{array}$ \\
\hline $\begin{array}{l}\text { Visioning for the community } \\
\text { has to be conceived \& evolved } \\
\text { out of the community's own } \\
\text { history \& experience }{ }^{281}\end{array}$ & & $\begin{array}{l}\text { Enjoyment } \& \text { perception of area } \\
\text { Improved participants opinion of the area to live in }{ }^{* *} \& \text { cared } \\
\text { about what local area looks like** }\end{array}$ \\
\hline \multicolumn{2}{|l|}{$\begin{array}{l}\text { Architectural professionals role } \\
\text { is to draw out \& enable the } \\
\text { community's dreams to be } \\
\text { realised and translated into } \\
\text { built form }{ }^{279}\end{array}$} & \\
\hline \multirow{8}{*}{$\begin{array}{l}\text { COLLABORATION: } \\
\text { Form community } \\
\text { working groups } \\
\text { Principles: } \\
\text { Identify \& allocate appropriate } \\
\text { leadership roles to pre- } \\
\text { established respected people in } \\
\text { user group } \\
\text { Build community } \\
\text { empowerment through } \\
\text { participants initiative-taking \& } \\
\text { self-sufficiency }{ }^{283}\end{array}$} & \multirow{8}{*}{$\begin{array}{l}\text { Gain local collaboration \& } \\
\text { support } \\
\text { Utilise specific participant's } \\
\text { expertise to develop } \\
\text { project }\end{array}$} & $\begin{array}{l}\text { Responsive collaboration } \\
\text { Enhanced importance to participants that community to works } \\
\text { together to improve conditions** \& to solve their own } \\
\text { problems** }\end{array}$ \\
\hline & & $\begin{array}{l}\text { Teamwork capacity \& role-taking } \\
\text { Increased knowledge, commitment \& team work through group } \\
\text { engaging in project details** \& utilised participants specific } \\
\text { expertise in the process* }\end{array}$ \\
\hline & & $\begin{array}{l}\text { Relational understanding \& confidence } \\
\text { Increased relational trust, } * * \text { acknowledgement of others } \\
\text { circumstances, }{ }^{*} \text { community pride, } * \text { positivity about the future } * * * \\
\& \text { knowledge of local services and facilities** }\end{array}$ \\
\hline & & $\begin{array}{l}\text { Community reciprocity } \& \text { perceptions } \\
\text { Enhanced participants feeling of benefiting from what happened in } \\
\text { their community* \& cared about their community's appearance }{ }^{* *}\end{array}$ \\
\hline & & $\begin{array}{l}\text { Sustainable planning \& commitment } \\
\text { Increased the establishment of vision to sustain wider community } \\
\text { through new initiatives* \& increased participants desire to be } \\
\text { involved in future decisions } * *\end{array}$ \\
\hline & & $\begin{array}{l}\text { Community representation } \\
\text { Improved representation of community needs through relevant } \\
\text { consultation forums* }\end{array}$ \\
\hline & & $\begin{array}{l}\text { Youth commitment } \\
\text { Increased in-depth youth involvement in developing proposals* }\end{array}$ \\
\hline & & $\begin{array}{l}\text { Involvement in community-life } \\
\text { Has not altered participant involvement in local community } \\
\text { groups or activities }\end{array}$ \\
\hline
\end{tabular}

\footnotetext{
278 McMillan interview, August 2006; Davis interview, August 2006.

279 Tamanui interview, December 2006.

${ }^{280}$ Davis interview, August 2006.

${ }^{281}$ Recommendation from survey respondent, Otara

282 Tims interview, August 2006; Hemi Toia interview, Community Employment Group, 2002

${ }^{283}$ Tims interview, August 2006; Davis interview, August 2006.
} 


\begin{tabular}{|c|c|c|}
\hline Participatory process & Intentions & $\begin{array}{l}\text { Community Wellbeing findings } \\
\text { Surveys \& Interviews }\end{array}$ \\
\hline $\begin{array}{l}\text { PARTNERING: } \\
\text { Partner with } \\
\text { stakeholders }\end{array}$ & $\begin{array}{l}\text { Invite similarly interested } \\
\text { groups to utilise \& } \\
\text { participate in } \\
\text { developments }\end{array}$ & $\begin{array}{l}\text { Strong friendships, acceptance of others \& responsiveness } \\
\text { Increased friendships in area, } * * * \text { amount of conversations between } \\
\text { locals, } * * * \text { acceptance of different cultures \& backgrounds*** \& } \\
\text { participant's cared about what community thinks of their actions } * * *\end{array}$ \\
\hline \multirow{9}{*}{$\begin{array}{l}\text { Principles: } \\
\text { Creating and communicating a } \\
\text { written \& visual vision is crucial } \\
\text { to sustaining energy for the } \\
\text { duration of the project }^{279} \\
\text { All projects should proceed \& } \\
\text { correspond to the larger } \\
\text { community goals }\end{array}$} & \multirow{2}{*}{$\begin{array}{l}\text { Gain maximum support } \\
\text { from local authorities, } \\
\text { organisations, businesses } \\
\text { and residents }\end{array}$} & $\begin{array}{l}\text { Increased community pride, }{ }^{* *} \text { participant's care about what the } \\
\text { community thinks of their actions } * * \& \text { participants feel they benefit } \\
\text { more from what happens in their community** }\end{array}$ \\
\hline & & \multirow{3}{*}{$\begin{array}{l}\text { Representation, advocacy \& support } \\
\text { Increased participants willingness to ask local government for what } \\
\text { their community needs, }{ }^{* *} \text { increased their desire to be involved in } \\
\text { future decisions** \& interest in decisions made by local government }\end{array}$} \\
\hline & Seek professional & \\
\hline & $\begin{array}{l}\text { assistance to continue } \\
\text { developments }\end{array}$ & \\
\hline & \multirow{5}{*}{$\begin{array}{l}\text { Gain funding support \& } \\
\text { create continuity } \\
\text { processes for sustainable } \\
\text { long-term development }\end{array}$} & $\begin{array}{l}\text { Increased ability of participants to request support from } \\
\text { stakeholders and local authorities* \& increased their support* }\end{array}$ \\
\hline & & $\begin{array}{l}\text { Self-promotion \& communication } \\
\text { Enhanced trust \& recognition of community advocates, } * * * \text { improved } \\
\text { their effectiveness to appropriately consult with the wider } \\
\text { community* \& built support through collaborative relationships* }\end{array}$ \\
\hline & & $\begin{array}{l}\text { Local responsibility } \\
\text { Increased participants collaboration to solve their community } \\
\text { problems,* their feelings of importance to the community* \& } \\
\text { involvement in local groups \& activities** }\end{array}$ \\
\hline & & $\begin{array}{l}\text { Partnership \& reciprocal support } \\
\text { Increased partnerships* \& reciprocal support** between local } \\
\text { support organisations to develop initiatives \& increased knowledge } \\
\text { of local services and facilities** }\end{array}$ \\
\hline & & $\begin{array}{l}\text { Youth confidence } \\
\text { Increased youth participants confidence in articulating \& promoting } \\
\text { project to public* }\end{array}$ \\
\hline
\end{tabular}

IMPLEMENTATION: Mobilise the collective Implement physical improvements

effort of community own needs members to meet their

Gain maximum community Collaborative improvement of area

participation to implement Increased importance to participants about collaborating to achieve developments at their level goals* \& improve conditions of area**

of competency

Build community momentum for positive developments

Celebrate the completion with community, supporters and authorities

Increased friendships in area, $* *$ amount of conversations with others, ${ }^{* *}$ knowledge of local services \& facilities, ${ }^{*}$ enhanced perception that community is a better place to live in/come to**

Capability \& reciprocal benefits

Enhanced participants collective capacity to implement projects and inspire other initiatives* \& feeling they benefit from what happens in community*

\section{Altruism \& tolerance}

Encouraged volunteering*, relational trust* \& acceptance of people from different cultures and backgrounds*

\section{Positive relationships \& area satisfaction}

Positive community perception

Encouraged participants care of the community's appearance* \& what the community thinks about the participants actions*

Has not altered participant's care about what community thinks of their actions ${ }^{\circ}$

\section{CONTINUED} INVOLVEMENT: Continue participant opportunities

Principles:

Continue the existence of the group beyond the project ${ }^{285}$ Create multiple participant opportunities to undertake roles in development ${ }^{285}$
Provide regular structured Local enterprise

forums to discuss \& address ongoing matters

Continuation of relationships, partnerships \& involvement formed during process developments*
Increased establishment of new business \& education initiatives**

Strategy \& sustainability

Motivated strategising of long-term plans to sustain \& build new

\section{Personal accomplishment}

Cultivated the participant's achievements \& enhanced their circumstances through initial \& continued involvement in initiatives started during project*

Ongoing local support

Stimulated community support for participants to continue involvement in initiatives*

${ }^{284}$ Tamanui interview, December 2006; White interview, November 2006.

${ }^{285}$ Tims interview, August 2006; Davis interview, August 2006. 


\section{Discussion \& Conclusions}

\section{Overarching conclusions}

These overarching conclusions draw together the summary findings of the literature review, case study interviews and surveys. The answers to the thesis question, Does community participation in place-making enhance the wellbeing of marginalised communities? And if so, how? are addressed and concluded separately. Firstly, strong evidence is provided that confirms community participation in place-making does enhance the wellbeing of marginalised communities. Secondly, it concludes and demonstrates how this is effectively done. This is discussed throughout the conclusions two to four.

\section{The integrated research conclusions provide strong evidence that confirms community participation in place-making does enhance the wellbeing of marginalised communities}

The literature review summary initially contributes to confirming the link between participation and community wellbeing. The literature review summary findings demonstrate that empowerment \& group co-operation, citizen representation, self/community awareness and belonging were the community wellbeing dimensions most enhanced by participatory place-making. 286

The case study research investigated the enhancement of wellbeing in marginalised communities and has produced strong and more specific evidence of the link between participatory place-making and the enhancement of wellbeing in marginalised communities. This evidence is summarised in Table 7 'Case study summary findings.' While integrating these summaries, the findings that inter-related were grouped. From this process four community wellbeing dimensions became predominant as being most significantly enhanced by the participatory place-making process.

In demonstrating how these conclusions were made, the integrated summary findings are compiled in Table 8. Following the table there is a discussion under each predominant dimension that encapsulates the related findings and reinforces the significance of each predominant dimension.

286 Refer to Table I, p. 37 
Table 8: Integrated findings: Four predominant

community wellbeing enhancements

Key: Literature review summary findings

Case study summary findings

\begin{tabular}{|c|c|}
\hline Integrated summary findings: enhancements & $\begin{array}{l}\text { Predominant community } \\
\text { wellbeing enhancements }\end{array}$ \\
\hline $\begin{array}{l}\text { Social responsiveness } \\
\text { Self-awareness \& positive lifestyle changes } \\
\text { Self-awareness and esteem } \\
\text { Social responsibility } \\
\text { Socio-political awareness } \\
\text { Empowerment } \\
\text { Identity expression }\end{array}$ & Empowerment \\
\hline $\begin{array}{l}\text { Shared visions for local environment } \\
\text { Ability to influence } \\
\text { Citizen representation \& valuing of contribution } \\
\text { Shared community vision } \\
\text { Commitment \& sustainability to improve community's } \\
\text { circumstances } \\
\text { Representation and public presentation skills } \\
\text { Advocacy \& responsibility } \\
\text { Stimulates \& supports entrepreneurship } \\
\text { Develops long-term sustainability strategies }\end{array}$ & $\begin{array}{l}\text { Vision-making and } \\
\text { advocacy capability }\end{array}$ \\
\hline $\begin{array}{l}\text { Group cooperation \& implementation skills } \\
\text { Group co-operation } \\
\text { Group decision-making abilities } \\
\text { Trust in process \& facilitators } \\
\text { Teamwork and role-taking } \\
\text { Strong relationships, acceptance of others \& responsiveness } \\
\text { Wider networks \& partnership support }\end{array}$ & Collective action \\
\hline $\begin{array}{l}\text { Sense of belonging, collective consciousness \& identity with place } \\
\text { Satisfaction, positive perceptions \& safety of local environment } \\
\text { Pride \& collective momentum } \\
\text { Relationship building \& cultural tolerance } \\
\text { Pride in community \& area } \\
\text { Relational trust \& mutual benefits within community } \\
\text { Positive community perceptions \& representation } \\
\text { Positive relationships \& community perceptions } \\
\text { Collaborative capacity \& reciprocity } \\
\text { Altruism \& tolerance of others }\end{array}$ & $\begin{array}{l}\text { Sense of pride, belonging } \\
\text { and connectedness to } \\
\text { community }\end{array}$ \\
\hline
\end{tabular}




\section{The participants' empowerment is increased by participatory place-making}

The growth of participant empowerment is a major characteristic that underpins community participation. Community members participate because they are empowered through believing that their contribution will positively influence circumstances.

Positive changes to the participants' mindset and social outlook are the most significant empowerment aspects enhanced by participatory place-making. The integrated findings demonstrate that these aspects are critical to establishing the motivational basis and preparation for the participants' involvement in the visioning and decision-making processes. The personal development of participants is shown through the increase in self-esteem, a desire to express identity and positive lifestyle changes. The participants' societal outlook is also enhanced through an increased socio-political awareness and understanding of the consequences of decisions. This broad spectrum of personal and civic empowerment influences and thereby strengthens the development of many other community wellbeing aspects.

Active citizenship, which is one of the three overarching themes of community wellbeing, is enhanced by the predominance of empowerment that has resulted from the participatory place-making processes.

The participants' vision-making and advocacy capabilities are enhanced by participatory place-making

The integrated findings demonstrate that participatory place-making processes encourage participants to take initiative that increases their vision-making and advocacy capabilities. Processes that are inclusive, appropriately structured and transparent gain the interest and trust of the participants. This enables the group to identify, take responsibility and act to change local social issues. This direct action utilises the participants' specific local knowledge and leads to creating a shared vision for community spaces. Evidence from the integrated findings demonstrate that these collective solutions are the best methods for regenerating and sustaining community spaces. Advocacy develops in the participants when they publicly represent and promote the shared visions and causes on behalf of their community. Certain characteristics are cultivated throughout the process such as entrepreneurship and an increased commitment to sustain the long-term strategies.

The overarching theme of local democracy \& governance is enhanced by the predominance of vision-making and advocacy that has resulted from the participatory placemaking processes. 
The participant community's collective action is increased by participatory place-making

Collective action is increased through the participatory process. There are two different aspects to this change. One aspect is the enhanced teamwork that occurs when participants take on appropriate responsibility roles. The other is enhanced partnership between the participants and wider community networks.

The participants experience increased access and engagement in public decision making. This enhances their sense of competency in contributing to the process and has balanced the sharing of control between all project stakeholders. The co-operation process strengthens the connections between participants, builds a sense of group identity and increases the interpersonal and task-related skills of participants.

Supportive partnerships are increased through collaboration with the wider community networks and agencies. Involvement in participatory processes have increased trust in community leaders as well as moral and financial support for entrepreneurial initiatives.

Active citizenship is enhanced by the predominance of collective action that has resulted from the participatory place-making processes.

The participants' sense of pride, belonging and connectedness to the community is increased by participatory place-making

The integrated findings show that participatory place-making processes enhance a strong sense of pride, belonging and connection between the people of the community and to their physical environment. This establishes an increase in friendships, relational trust, cultural tolerance and reciprocity between community members. This is also shown to be linked with an increase in the community's connectedness to the physical environment through a enhanced identification with place, a sense of pride and community spirit. Positive perceptions and satisfaction with the physical environment has increased along with an increased altruism and feeling of safety within the public space.

Social capital is enhanced by the predominance of a sense of pride, belonging and connectedness to the community that has resulted from the participatory place-making processes.

As stated in the introduction to this research, community wellbeing is achieved when communities are capable of sustaining healthy levels of social, governmental, environmental and cultural development. All of these essential components have been represented in the integrated research. There is strong evidence that participatory place-making processes do increase local democracy and governance, active citizenship and social capital within marginalised communities. 


\section{A comprehensive range of participatory processes that engage the community in relevant ways is critical to an effective participatory project}

The literature review identifies many different approaches and intended outcomes of community participation. Some methods centre on advancing a quality environment, others community empowerment and some include the both with additional goals.

The case study research identifies the specific processes, including the principles and intentions, that are critical for engaging marginalised communities in place-making processes for their public spaces. ${ }^{287}$ Each participatory process demonstrates the specific aspects of community wellbeing that have been enhanced through these processes.

Community-led support initiatives are essential to meeting the participants' social needs in order to gain confidence and motivation to participate

Many different forms of community-led support have been provided to the participants of the case study communities. Youth workers and educators have volunteered to organise social youth groups and recreational events at the respective redevelopment project sites. They have built relationships among local youth, role-modelled positive behaviour and developed co-operation among the youth. Some community groups have extended this work to establishing on-site programmes that provide support in the forms of alternative education courses that are culturally appropriate and provide residential care-giving. Social support groups have been created by trusts and existing local services for the community to regain a positive community perception and confidence among the community members.

Trust organisations have also assembled community members to repair inadequate physical environments in urgent need.

Community-led support is crucial in building positive self/community perceptions and group relationships. Through these enhancements, participants gain an increased confidence and motivation for involvement in future visioning and decision-making processes. Seeking the most appropriate public space solution is achieved by starting with unifying the community members through the participation process.

The case study research concludes that through the provision of support networks, forums and services, the participants' community wellbeing is enhanced. This enhancement occurs in the areas of increased self-esteem, self-awareness, personal development, relationship networks and co-operation to respond to and initiate improvements in the community.

\footnotetext{
${ }^{287}$ Refer to the Case Study summary findings table. The left column identifies the processes and principles, the
} central column identifies the process intentions and the right column identifies the community wellbeing findings. 
The involvement of the community in analysing their own social issues is critical for empowering the participants to be involved in decision making

The case study participant's involvement in analysing the social issues of the community has largely been provided through forums and workshops. A range of organisations from social theorists to community development workers to local community trust members have arranged and facilitated these forums.

When community members participate in analysing the root causes of present social issues, participants gain perspective on the consequences of public decision-making and realise the value of their contribution. The intention of this process is to assist participants to recognise their ability to influence and that their involvement in community environment decisionmaking is meaningful and consequential for their community's progress.

The case study research concludes that participation in analysis processes enhances community wellbeing through an increase in the participants' socio-political awareness, personal empowerment and desire to express their community's identity.

Celebration events are the best way to build community pride \& collective momentum to participate

Celebrations are critical events where the population of the community gathers in one area to acknowledge and celebrate its strengths and achievements. The celebration events organised by the case study communities focused on different aspects; some celebrated the unique characteristics of the community, some used the event as a team-building exercise and most celebrated the completion of the physical development. Every celebration intended to build wider community cohesion and create positive community perceptions. The case study findings conclude that the celebrations increased the community's pride and collective momentum for participating in the subsequent stages of the project.

Effective visioning \& decision-making requires culturally appropriate engagement techniques \& constructive input methods

The previous stages have prepared the participants to meaningfully contribute to the visioning and decision-making processes. Across all of the case studies, this has been through mediums such as a series of community-wide meetings/hui or small group meetings for specific sectors or organisations of the community.

Culturally appropriate and transparent communication is required to engage participants with the visioning and decision-making process and to collaborate with fellow participants. The community's unique history and experience must be acknowledged and incorporated into visioning and decision making. Inspiring visioning techniques are required that encourage 
participants to articulate their aspirations for the future of the community. Discussions are to be structured in order to generate constructive participant input and maintain a unified level of understanding between participants. Decision-making methods must be clear and accessible for participant to use and result forums are to be representative of the collective outcomes.

The case study research concludes that community wellbeing has been enhanced through these processes by the participants building group co-operation skills and decision-making competency, collective visioning and trust in the process and the facilitators. They developed stronger relationships, cultural tolerance and pride in the community and its environment.

\section{Group collaboration must be fostered to utilise the participants' specific expertise and} encourage initiative-taking

Various types and sizes of project working groups formed from the case study communities. This included youth committees, large community groups divided into several task groups and trust member committees. The formation of participant working groups is required to utilise the participants' specific expertise and build co-operation in order to develop effective strategies for implementing the project. The intent of this process beyond the project is to encourage initiative-taking and self-sufficiency among participants.

The case study findings conclude that community wellbeing has been enhanced through the development of strong cohesive working relationships. Role-taking and teamwork has been enhanced, along with participants' increased trust in others and reciprocity between each other. An improved perception of the community occurs and participants represent the needs of the community increasingly. The participants also increase their commitment to establishing and sustaining long term community improvement strategies.

Partnerships between the participant group and other stakeholders increase the likelihood of successful implementation

The case study participant working groups sought partnerships with local authorities, businesses, community stakeholders, and specialist professional services in order to gain support, assistance and funding from the wider community. In seeking these partnerships, the working groups used a variety of approaches such as promoting their cause to community stakeholders, presenting submissions to local authorities, approaching local trust boards and consulting at local forums and among established networks. Some of the working groups also invited groups from similar communities to partner with them and share in utilising the developed public spaces. 
The case study findings conclude that the participants' responsiveness and advocacy has increased along with the ability of the participants to represent and promote the aspirations of the community. As a result, all of the organisations mentioned above have increased their assistance and support of the working groups. The process of building supportive partnerships has enhanced relationships and acceptance of others from different backgrounds while improving the community's pride and feeling of mutual benefits.

Involvement in implementation is critical to increasing the community's capabilities and building community momentum

The case study participant groups were involved in several different ways within the implementation process. Some were involved in the physical construction of the project at their level of competency, while others organised the opening celebrations of the physical completion of the project and invited the wider community, supporters and authorities. Both contributions intended to gain maximum collective effort and support from the participants in order to build momentum and positivity within the community.

The case study findings conclude that the participants' involvement in implementation has enhanced their collective capacity to improve the community's physical conditions and achieve their goals. In turn, this has inspired other initiatives, volunteering and feelings of mutual benefit. In addition, participants have an increased satisfaction and positive perception of their physical environment and care more for its appearance. Co-operating with others has also increased friendships, relational trust and an acceptance of people from different backgrounds.

\section{Continuing the participants' involvement beyond the project is essential to maintain the public space intentions and inspire community enterprise}

The case study communities continued the participants' involvement through actions such as organising participant employment at the site to maintain the environment, contracting professionals to consult with participants on long-term development strategies for the community, and planning organisational frameworks that will sustain the vision of the public spaces.

These processes provide regular structured forums to continue the existence of an effective participant group beyond the project. The also create ongoing opportunities that allow participants to continue contributing to the community using the skills they had developed throughout the process. Furthermore, it is intended to continue relationships and partnerships formed during the project and enable ongoing matters of concern to be 
addressed. This process also allows for future community members to contribute to the ongoing developments.

The case study research concludes that community wellbeing has been enhanced by increased local support and commitment. Furthermore, this has cultivated the participants' achievements and enhanced their personal circumstances. Entrepreneurship has increased along with the number of local enterprises and initiatives. The creation of long-term development strategies has similarly increased.

\section{Participant involvement in the initial preparation processes is critical to gaining community engagement in the participatory project and enhancing wellbeing}

Many of the participatory practices reviewed in this research, as well as those in common use, limit their focus of participatory place-making processes to those involving public collaboration and decision making. However, the conclusions from this research identify the significance of culturally appropriate engagement processes and the critical importance of preparing the participants for collaboration and decision making.

Appropriate methods of engaging participants in the process are crucial to initially gaining the community's trust and sustaining authentic participation from community members. All case study interviewees unanimously agree that in order to achieve this, relevant and culturally specific engagement approaches are to be utilised. Initially, this includes identifying the users and owners of the environment to be improved, building relationships with local community members and stakeholders, and developing knowledge of local cultures and their processes. ${ }^{288}$ When meeting with the community, the intentions of the process must be made clear and communication and facilitation need to be appropriate and inclusive to ensure there is unified a level of understanding amongst participants. ${ }^{289}$ Participants require a sense of trust that their needs will be fairly represented by the process and that appropriate opportunities will made for participants to collaborate on addressing their community's needs. ${ }^{289}$

The previous overarching conclusion identifies the two preparation processes of 'community-led support' and 'involvement in social analysis.' It outlines the aims of enhancing the participants' self-esteem, group co-operation and social analysis skills. This research previously mentioned Davis' concern about Moerewa community's long history of lacking

288 Tims interview, August 2006.

289 Davis interview, August 2006. 
access to participating in public decisions. He described the resultant apathy that had developed due to the participant's inexperience and perceived inability to exercise their public decision-making power. The case study research concludes that the two preparation processes of community-led support and social analysis enhance the empowerment, relational and social awareness skills of the participants. Furthermore, the evidence shows that these qualities need to be established first to prepare the participants for involvement in the visioning and decision-making process.

Upon reflection, perhaps the reason for typically omitting these processes from participatory place-making, is that these types are commonly entrusted to other disciplines such as social work and community development practice. The other participatory processes identified through the case studies also bear close resemblance to those used in community development projects. This is no surprise as some of the case study facilitation organisations are explicitly guided by community development principles. On the other hand, this evidence raises the potential applicability of community development principles to participatory design practice. Furthermore, some theories included in the literature review state that facilitation organisations that operate using community development principles are the most effective organisation for engaging the community in public space decisions. ${ }^{290}$ 


\section{Appointing community advocate(s) to plan and facilitate the participatory process is critical to gaining community engagement in the project and enhancing wellbeing}

Commonly community advocates 291 are consulted in conventional planning processes, but rarely involved in facilitating the process. Significant evidence from the research identifies the importance of engaging community advocates in planning and managing the participatory process.

One of the significant principles shown in the case study summary findings stress the importance of identifying community-based leaders who are committed to advocating for the interests of the community. ${ }^{292}$ As stated in the previous overarching conclusion, the community's trust of the facilitator and the process must be earned through building relationships and knowledge of community's culture in order for authentic community participation to occur. ${ }^{293}$ As the community advocate has pre-established the relational trust and knowledge through their usual community roles, their role in facilitating the process contrasts with conventional approaches. This benefits both the participants and project. These established relationships mean that the advocates have personal knowledge of the historical causes of the present community struggles. This knowledge informs appropriate community engagement techniques that assist in eliminating the community's initial suspicion of the project and increases their willingness to be involved. This is particularly beneficial where the facilitator organises forums for gathering the shared visions of the community. Other benefits identified are the advocates' existing relationships with influential community stakeholders to guide the process and the obvious time efficiencies due to the many advantages previously mentioned.

Overall, it seems that gaining trust from the community is the most valuable asset to achieving authentic participation. Community advocates are in the best position to build trust as they typically represent the community directly affected by the process outcomes and carry ongoing responsibilities beyond the project's completion. In every case study, the community's own experienced advocates (trustees, community leaders, youth leaders, etc.) facilitated participatory processes that enabled the collective dreams and visions of the community to be articulated and realised.

\footnotetext{
290 Wates \& Knevitt, 1987. p. 125

291 A community advocate (in this research the main interviewees of these case studies) is an individual or group that has a history paid or voluntary work for the common good of the community. They are motivated by the interests of the community above their own interests.

292 Hemi Toia interview, Community Employment Group, 2002.

293 Tims interview, August 2006; Davis interview, August 2006.
} 


\subsection{Significance of conclusions}

This research presents a challenge to the prevailing perceptions about the link between the design and social outcomes. Influenced by the past failure of environmental determinism, there is some scepticism of user participation design resulting in social outcomes. These results are perceived as 'soft' and a fortunate by-product to the main objective of design. This research shows that the design of public spaces can lead to enhanced social outcomes and that the process by which the design occurs is critical to achieving these. The evidence for this is robust, as it is supported by three methods of investigation. Additionally, while the survey sample is small, it is large in proportion to the population of project participants and relative to the population size of the geographical community.

These conclusions help inform the approach of several disciplines, particularly architectural and urban design practice and local government community planning. They identify a comprehensive range of participatory processes and intentions that are typically underutilised or not considered in conventional public consultation work. They also highlight the need for the mentioned disciplines to consider using the principles and methods employed by other disciplines such as community development, specifically when working on community space projects.

The research identifies processes that are critical to achieving effective public involvement and representation in community space decisions and to building community wellbeing. Furthermore, participatory processes that effectively engage participants from marginalised communities are demonstrated.

From another perspective, these findings could also assist disciplines that are involved in social, health, education, business and community development work. The potential is strong for these participatory public space projects to be vehicles for building the wellbeing and empowerment of marginalised communities. 


\section{References}

Arnstein, S. (1969). The ladder of citizen participation Journal of the Institute of American Planners, 34(4).

Bentley, Alcock, Murrain, McGlynn, \& Smith. (1985). Responsive environments: a manual for designers. Oxford : Butterworth Architecture.

Blundell Jones, P., Petrescu, D., \& Till, J. (2005). Architecture and Participation: Introduction. In P. Blundell Jones, D. Petrescu \& J. Till (Eds.), Architecture and Participation. New York: Spon Press.

Broome, J. (2005). Mass housing cannot be sustained. In P. Blundell Jones, D. Petrescu \& J. Till (Eds.), Architecture and Participation. New York : Spon Press.

Chavis, D. M. (2003). Sense of Community Index: Association for Study and Development of Community.

Chavis, D. M., \& Pretty, G. M. H. (1999). Sense of Community: Advances in measurement and application. Journal of Community Psychology, 27(6), pp. 635-642.

Chavis, D. M., \& Wandersman, A. (1990). Sense of Community in the Urban Environment: A Catalyst for Participation and Community Development. Amercian Journal of Community Psychology, I8(I), 55-8I.

Cheyne, C. (2006). Central Government and its Role in Community Planning. In Michelle Thompson-Fawcett \& Claire Freeman (Eds.), Living Together: Towards Inclusive Communities. Dunedin, N.Z. : Otago University Press.

Christchurch City Council NZ. (Retrieved II.04.06). Social Wellbeing Policy Report: Rationale from http://www.ccc.govt.nz/Publications/SocialWellbeingPolicy/Rationale.asp

Collins, S. (I I.10.2006). Eco-village to pioneer flax-mix earth building. The New Zealand Herald.

Comerio, M. C. (1984). Community Design: Idealism and entrepreneurship. In H. Sanoff (Ed.), Participatory Design, Theory and Techniques (1990). Raleigh, N.C. : Henry Sanoff (distributor)

Community Employment Group. (2001). Nobody, Somebody, Everybody. Employment Matters, I2(9), I-2.

Community Employment Group. (2002). Transcript of interviews with He Iwi Kotahi Tātou Trust in 'Journeys Together' video recording, from http://www.goodpracticeparticipate.govt.nz/resources/case-studies/moerewa.html

Creswell, J. W. (2003). Research Design: Qualitative, Quantitative and Mixed Method Approaches (2nd edition). Thousand Oaks, California : Sage Publications.

Davis, N. (Retrieved 17.05.2006). Background of the Trust, He Iwi Kotahi Tātou trust website from http://www.heiwi.co.nz/index.htm

Davis, N. (Retrieved 17.05.2006). Moerewa History, He Iwi Kotahi Tātou trust website from http://netlist.co.nz/communities/Moerewa/History.cfm 
de Carlo, G. (1992, 2005). Architecture's Public. In P. Blundell Jones, D. Petrescu \& J. Till (Eds.), Architecture and Participation. New York : Spon Press.

Design Tribe \& Executive Management Consultancy. (August 2002). Strategic Development Plan for Moerewa (pp. 23).

Draper, S. W. (Retrieved 15.02.08). The Hawthorne, pygmalion, placebo and other effects of expectation from www.psy.gla.ac.uk/ steve/hawth.html\#finding

Eketone, A., \& Shannon, P. (2006). Community Development and Empowerment. In Michelle Thompson-Fawcett \& Claire Freeman (Eds.), Living Together: Towards Inclusive Communities. Dunedin, N.Z. : Otago University Press.

Fishman, R. (1977). Urban Utopias in the Twentieth Century: Ebenezer Howard, Frank Lloyd Wright and Le Corbusier. New York : Basic Books.

Francis, M. (2003). Urban Open Space: Designing for User Needs. Washington, DC : Island Press.

Freeman, C. (2006). Introduction: Developing inclusive communities. In Michelle ThompsonFawcett \& Claire Freeman (Eds.), Living Together: Towards Inclusive Communities. Dunedin, N.Z. : Otago University Press.

Gatt, L., Reid, A., Anthony, J., Scott, F., Solomon, R., Brougham, M., et al. (2003). Quality of Life in New Zealand's Eight Largest Cities 2003. North Shore City, N.Z.

Gisborne Youth for Christ. (1999). Skate \& Youth Centre Proposal

Gisborne Youth for Christ. (1999). Skate Clubrooms Centre Resource Consent.

Gisborne Youth for Christ. (1999). Submission to Gisborne District Council Annual Plan.

Good Practice Participate. (2002). Transcript from Community Employment Group's video 'Journeys Together - Moerewa' from

http://www.goodpracticeparticipate.govt.nz/resources/case-studies/moerewa.html

Google Earth. (Retrieved 28.02.08). Aerial Maps.

Hawkes, J. (2003). The Fourth Pillar of Sustainability: Culture's essential role in public planning. Melbourne, Vic. Cultural Development Network. Common Ground

He Iwi Kotahi Tātou trust. (Retrieved 17.05.2006). He Iwi Kotahi Tātou trust website from http://netlist.co.nz/communities/Moerewa/

Henare, T. (Retrieved 17.05.2006). History of the town, He Iwi Kotahi Tātou trust website from http://netlist.co.nz/communities/Moerewa/History.cfm

Herndon, S. L., \& Kreps, G. L. (1995). Qualitative Research: Applications in Organisational Communication: Cresskill, N.J. : Hampton Press ; Annandale, Va. : Speech Communication Association.

International Association for Public Participation. (Retrieved 09.2006). 'IAP2' resources from www.iap2.org.au/usefulresources.htm

Jacobs, J. (196I). Death and Life of Great American Cities: New York: Vintage Books. 
Kruger, T. (Retrieved I I.2008). Māori economic development from http://www.maf.govt.nz/mafnet/rural-nz/people-and-their-issues/social-research-andwelfare/grassroots/grasrts-16.htm

Lochner, K., Kawachi, I., \& Kennedy, B. P. (1999). Social Capital: a guide to its measurement. Featuring theory titled Measurement of Community Competence: Summary of concepts used. Developed from L.S. Cottrell's (1976) Eight essential dimensions \& preconditions of a competent community with additions added by E. Eng \& E. Parker (1994). Health \& Place Journal, p. 268

Lynch, K. (198I). Good City Form. Cambridge, Mass.: MIT Press.

Lynch, K. (198I). A Theory of Good City Form: Cambridge, Mass. : MIT Press.

Mclndoe, G., Chapman, R., McDonald, C., Holden, G., Howden-Chapman, P., \& Sharpin, A. (2005). The Value of Urban Design: The economic, environmental and social benefits of urban design. Wellington, N.Z. : Ministry for the Environment.

McMillan, D. W., \& Chavis, D. M. (1986). Sense of community: A definition and theory. American Journal of Community Psychology, I4(I), 6-23.

Mead. B (photographer). (14.06.2003). Gisborne youngsters unstoppable article by J. Kirkland. The Gisborne Herald.

Ngai Tupoto ki Motukaraka Trust. (2006). Ngai Tupoto ki Motukaraka Hapu Plan.

Ngai Tupoto Marae Trust. (Retrieved 06.2006). History of the Hapu and Marae from http://www.terarawa.co.nz/marae/ngaitupoto

Ngai Tupoto Marae Trust. (Retrieved 06.2006). Redevelopment Programme from http://www.terarawa.co.nz/marae/ngaitupoto

Ngai Tupoto Marae Trust. (2006). Public notice: Whānau Weekend to kick off Ngai Tupoto Marae Project 2010.

Ngai Tupoto/Ngati Here hapu. (2006). The Church of Our Lady of Assumption brochure.

NZ Ministry for the Environment. (2007 second edition). Urban Design Toolkit. Wellington, N.Z. : Ministry for the Environment.

NZ Ministry of Social Policy. (August 2002). He Waka Kotuia, Joining Together on a Shared Journey: Report of the Community-Government Relationship Steering Group

Prilleltensky, I. (c. 2006). Justice and Well-being: Justice as a Determinant of Family and Community Well-Being: Peabody College of Vanderbilt University, Submitted to FamilyBased Community Development.

Purcell, D. (photographer). (04.I I.2005). 'Students earthed in music' article by Simon Collins. The New Zealand Herald.

Pyke, J., Wiseman, J., Heine, W., Langworthy, A., Raysmith, H., \& Salvaris, M. (2005). Measuring wellbeing, engaging communities: Sustainable strategies for the development of Community wellbeing indicators by Victorian local governments and their communities. Discussion Paper: Institute for Community Engagement and Policy Alternatives, Victoria University (Australia). 
Rapoport, A. (1973). The mutual interaction of people and their built environment : a cross-cultural perspective The Hague : Mouton ; Chicago : distributed in the USA and Canada by Aldine.

Rapoport, A. (1977). Human Aspects of Urban Form: Oxford ; New York : Pergamon Press.

Reis, A. (Spring 2000). Journal of Architectural and Planning Research I7(I).

Salvaris, M., \& Wiseman, J. (2004). Commonly used indicators of community progress and wellbeing. Featured in Mapping community wellbeing: Using community wellbeing indicators to choose goals and measure progress. Draft Scoping paper prepared for VicHealth.

Salvaris, M., \& Wiseman, J. (2004). Mapping community wellbeing: Using community wellbeing indicators to choose goals and measure progress. Draft Scoping paper prepared for VicHealth.

Sanoff, H. (1978). Designing with Community Participation Stroudsburg, Pa. : Dowden, Hutchinson \& Ross.

Sanoff, H. (1990). Participatory Design Theory \& Techniques: Raleigh, N.C. : Henry Sanoff (distributor).

Sanoff, H. (1992). Integrating Programming, Evaluation and Participation in Design, A Theory Z Approach. Aldershot, Hampshire : Avenbury.

Sarason, S. B. (1974). The psychological sense of community: Prospects for a community psychology. San Francisco : Jossey-Bass.

Schrader, B. (2005). We Call It Home: A History of State Housing in New Zealand: Auckland N.Z. : Reed.

Skatepark directory. (Retrieved 17.05.2006). Skatepark directory from http://www.018.co.nz/skatepark_view.php?listinglD=77

Te Kura Kaupapa Māori O Piripono Te Kura Whakahou ki Otara. (Retrieved I0.2006). Te Kura Kaupapa Māori O Piripono website from http://www.piripono.school.nz

Te Puni Kōkiri. (2002). Moerewa - a community triumphs. Kōkiri Paetae: A Celebration of Māori Achievements (40), 2-3.

Thorns, D. C. (2002). The Transformation of Cities, Urban Theory and Urban Life: Basingstoke ; New York : Palgrave.

Till, J. (2005). The Negotiation of Hope. In P. Blundell Jones, D. Petrescu \& J. Till (Eds.), Architecture and Participation: New York : Spon Press.

Towers, G. (1995). Building Democracy: community architecture in the inner cities: London : UCL Press.

Trochim, W. M. K. (Retrieved 20.06.06). The Research Methods Knowledge Base (2nd edition) from http://www.socialresearchmethods.net/kb/scallik.php

Wates, N., \& Knevitt, C. (1987). Community Architecture, How people are creating their own environment: London : Penguin.

Wills, J. (200I). Best practice benchmarking framework for the development of community indicators Measuring Community Well being - a framework for the development of 
community indicators, LGCSAA 8TH BIENNIAL NATIONAL CONFERENCE. Perth: Fellow centre for public policy, University of Melbourne.

Wills, J. (200I). Just, Vibrant \& Sustainable Communities: A framework for progressing \& measuring community wellbeing: Local Government Community Services Association of Australia.

Zeisel, J. (I98I). Inquiry by Design: Tools for environment-behaviour research: Monterey, Calif. : Brooks/Cole Pub. Co.

Zeisel, J. (1984). Inquiry By Design: Environment/Behaviour/Neuroscience in Architecture, Interiors, Landscape, and Planning: New York: W.W. Norton \& Company. 


\section{Appendices}

Table 2:

Case study overarching themes $\&$ dimensions derived from five theories

\begin{tabular}{|c|c|c|c|}
\hline & \multicolumn{3}{|c|}{ Dimensions from five theories } \\
\hline $\begin{array}{l}\text { THEORY I } \\
\text { Salvaris \& } \\
\text { Wiseman }\end{array}$ & $\begin{array}{l}\text { POLITICAL \& CIVIC } \\
\text { PARTICIPATION } \\
\text { Trust \& participation in democratic } \\
\text { processes }\end{array}$ & $\begin{array}{l}\text { SOCIAL INCLUSION } \\
\text { Sense of pride, belonging \& } \\
\text { connectedness } \\
\text { Safety } \\
\text { CULTURAL PARTICIPATION AND } \\
\text { CREATIVITY }\end{array}$ & $\begin{array}{l}\text { SOCIAL INCLUSION } \\
\text { Sense of pride, belonging \& } \\
\text { connectedness } \\
\text { Safety }\end{array}$ \\
\hline $\begin{array}{c}\text { THEORY } 2 \\
\text { Cottrell }\end{array}$ & $\begin{array}{l}\text { SELF-OTHER AWARENESS \& } \\
\text { CLARITY OF SITUATIONAL } \\
\text { DEFINITION } \\
\text { MANAGEMENT OF RELATIONS } \\
\text { WITH THE LARGER SOCIETY }\end{array}$ & $\begin{array}{l}\text { COMMITMENT } \\
\text { PARTICIPATION } \\
\text { ARTICULATENESS/EFFECTIVE } \\
\text { COMMUNICATION } \\
\text { CONFLICT CONTAINMENT \& } \\
\text { ACCOMMODATION } \\
\text { MACHINERY FOR FACILITATING } \\
\text { PARTICIPANT INTERACTION \& } \\
\text { DECISION MAKING }\end{array}$ & $\begin{array}{l}\text { MACHINERY FOR FACILITATING } \\
\text { PARTICIPANT INTERACTION \& } \\
\text { DECISION MAKING } \\
\text { SOCIAL SUPPORT } \\
\text { COMMITMENT }\end{array}$ \\
\hline $\begin{array}{l}\text { THEORY } 3 \\
\text { McMillan } \\
\text { \& Chavis }\end{array}$ & INFLUENCE & $\begin{array}{l}\text { MEMBERSHIP } \\
\text { INFLUENCE } \\
\text { SHARING OF VALUES \& } \\
\text { FULFILMENT OF NEEDS }\end{array}$ & $\begin{array}{l}\text { SHARED EMOTIONAL } \\
\text { CONNECTION } \\
\text { SHARING OF VALUES \& } \\
\text { FULFILMENT OF NEEDS }\end{array}$ \\
\hline $\begin{array}{c}\text { THEORY } 4 \\
\text { Wills }\end{array}$ & $\begin{array}{l}\text { DEMOCRATIC GOVERNANCE } \\
\text { Vision } \\
\text { Goals } \\
\text { Leadership } \\
\text { Policies }\end{array}$ & $\begin{array}{l}\text { ACTIVE CITIZENSHIP } \\
\text { SOCIAL JUSTICE } \\
\text { SOCIAL CAPITAL } \\
\text { CULTURAL VALUES }\end{array}$ & $\begin{array}{l}\text { SOCIAL CAPITAL } \\
\text { Interpersonal \& organisational trust } \\
\text { SENSE OF LOCAL PLACE \& } \\
\text { IDENTIFICATION WITH } \\
\text { COMMUNITY }\end{array}$ \\
\hline $\begin{array}{l}\text { THEORY } 5 \\
\text { Pyke, et al }\end{array}$ & DEMOCRACY \& CITIZENSHIP & $\begin{array}{l}\text { SOCIAL } \\
\text { Community connectedness \& sense } \\
\text { of community }\end{array}$ & $\begin{array}{l}\text { SOCIAL } \\
\text { Community connectedness \& sense } \\
\text { of community } \\
\text { Safety } \\
\text { Access \& availability of services } \\
\text { BUILT ENVIRONMENT } \\
\text { Open space }\end{array}$ \\
\hline $\begin{array}{l}\text { CASE } \\
\text { STUDY } \\
\text { FRAME } \\
\text { WORK }\end{array}$ & $\begin{array}{l}\text { LOCAL DEMOCRACY \& } \\
\text { GOVERNANCE } \\
\text { Vision-making \& advocacy } \\
\text { capability } \\
\text { Effective leadership \& } \\
\text { management }\end{array}$ & $\begin{array}{l}\text { ACTIVE CITIZENSHIP } \\
\text { Political, civil, civic } \\
\text { participation \& commitment } \\
\text { Collective action } \\
\text { Reciprocity \& responsibility } \\
\text { Empowerment }\end{array}$ & $\begin{array}{l}\text { SOCIAL CAPITAL } \\
\text { Sense of pride, belonging \& } \\
\text { connectedness to community } \\
\text { Interpersonal \& } \\
\text { organisational trust } \\
\text { Equality/tolerance } \\
\text { Social supports }\end{array}$ \\
\hline
\end{tabular}




\section{Table 3: Case study indicators derived from five theories}

\section{Local Democracy \& Governance}

\begin{tabular}{|c|c|c|}
\hline & $\begin{array}{l}\text { Dimensions from five } \\
\text { theories }\end{array}$ & Indicators from five theories \\
\hline $\begin{array}{l}\text { THEORY I } \\
\text { Salvaris \& } \\
\text { Wiseman }\end{array}$ & $\begin{array}{l}\text { POLITICAL \& CIVIC } \\
\text { PARTICIPATION }\end{array}$ & $\begin{array}{l}\text { Public trust and confidence in public institutions (contributes to Indicators 3, 4) } \\
\text { Public trust in political parties and government (contributes to Indicator 3) }\end{array}$ \\
\hline \multirow[b]{2}{*}{$\begin{array}{l}\text { THEORY } 2 \\
\text { Cottrell }\end{array}$} & $\begin{array}{l}\text { SELF-OTHER AWARENESS \& } \\
\text { CLARITY OF SITUATIONAL } \\
\text { DEFINITION }\end{array}$ & $\begin{array}{l}\text { Residents have strong opinions about way things are done (contributes to Indicator 2) } \\
\text { Compared with other towns, this town provides services to take care of most people's needs } \\
\text { (contributes to Indicator 3) }\end{array}$ \\
\hline & $\begin{array}{l}\text { MANAGEMENT OF RELATIONS } \\
\text { WITH THE LARGER SOCIETY }\end{array}$ & $\begin{array}{l}\text { People in this community try to influence what goes on in the larger surrounding areas } \\
\text { (contributes to Indicator I, 3) } \\
\text { Number of people who know about services/resources offered in larger society (contributes to } \\
\text { Indicator 3) }\end{array}$ \\
\hline $\begin{array}{l}\text { THEORY } 3 \\
\text { McMillan \& } \\
\text { Chavis }\end{array}$ & INFLUENCE & $\begin{array}{l}\text { Political efficacy, e.g., I feel I can contribute to local/city politics if I want to (contributes to } \\
\text { Indicators 3, 4) } \\
\text { Interested in knowing what goes on in the community (contributes to Indicator I) } \\
\text { Can trust community leaders (contributes to Indicators } 3,4 \text { ) }\end{array}$ \\
\hline $\begin{array}{l}\text { THEORY } 4 \\
\text { Wills }\end{array}$ & DEMOCRATIC GOVERNANCE & $\begin{array}{l}\text { Local governments deliver on good governance (contributes to Indicator 3) } \\
\text { Vision setting processes, e.g., strategic planning, advocacy, alliances, policies, guardianship of } \\
\text { community assets, funding and program design and implementation (contributes to Indicator 3) }\end{array}$ \\
\hline $\begin{array}{l}\text { THEORY } 5 \\
\text { Pyke, et al }\end{array}$ & DEMOCRACY \& CITIZENSHIP & $\begin{array}{l}\text { Percentage of people who think they have an opportunity to have a real say on issues important } \\
\text { to them (contributes to Indicators I, 2) } \\
\text { Percentage of people who feel encouraged to participate in decisions that affect them and their } \\
\text { community (contributes to Indicators I, 2, 3) }\end{array}$ \\
\hline \multicolumn{2}{|c|}{$\begin{array}{l}\text { Theory dimensions summarised into Case } \\
\text { Study dimensions } \\
\neg\end{array}$} & Theory indicators summarised into Case Study Indicators \\
\hline $\begin{array}{l}\text { CASE } \\
\text { STUDY } \\
\text { FRAME } \\
\text { WORK }\end{array}$ & $\begin{array}{l}\text { LOCAL DEMOCRACY \& } \\
\text { GOVERNANCE } \\
\text { Vision-making \& advocacy } \\
\text { capability } \\
\text { Effective leadership \& } \\
\text { management }\end{array}$ & $\begin{array}{l}\text { Indicator I. People in this community try to influence what happens in this } \\
\text { community } \\
\text { Indicator 2. Residents have strong opinions about way things are done } \\
\text { Indicator 3. Community leaders/town council are effective } \\
\text { Indicator 4. Can trust community leaders }\end{array}$ \\
\hline
\end{tabular}




\section{Active Citizenship}

\begin{tabular}{|c|c|c|}
\hline & $\begin{array}{l}\text { Dimensions from five } \\
\text { theories }\end{array}$ & Indicators from five theories \\
\hline \multirow{2}{*}{$\begin{array}{l}\text { THEORY I } \\
\text { Salvaris \& } \\
\text { Wiseman }\end{array}$} & SOCIAL INCLUSION & $\begin{array}{l}\text { Sense of optimism about the future of the community (contributes to Indicator 17) } \\
\text { Participation in social, political and community organisations (contributes to Indicator 5) } \\
\text { Participation in sporting and recreation activities (contributes to Indicator 6) } \\
\text { Percentage of people volunteering (contributes to Indicator 10) }\end{array}$ \\
\hline & $\begin{array}{l}\text { CULTURAL PARTICIPATION AND } \\
\text { CREATIVITY }\end{array}$ & $\begin{array}{l}\text { Levels of participation in cultural activities (contributes to Indicators 5, 6) } \\
\text { Usage of public arts and cultural facilities (contributes to Indicators 5, 6) }\end{array}$ \\
\hline \multirow{5}{*}{$\begin{array}{l}\text { THEORY } 2 \\
\text { Cottrell }\end{array}$} & COMMITMENT & $\begin{array}{l}\text { People feel they have an active role in making community function (contributes to Indicators 7, 8, } \\
\text { 3) } \\
\text { People volunteer for community activities (contributes to Indicator 10) } \\
\text { People engage in favours (contributes to Indicator I3) } \\
\text { People feel that what happens in community can affect them (contributes to Indicators 14, 12) }\end{array}$ \\
\hline & PARTICIPATION & $\begin{array}{l}\text { People belong to local service or civic clubs, fraternal organisations, church (contributes to } \\
\text { Indicator 5) }\end{array}$ \\
\hline & $\begin{array}{l}\text { ARTICULATENESS / EFFECTIVE } \\
\text { COMMUNICATION }\end{array}$ & $\begin{array}{l}\text { People are willing to stand before an outside group and state community needs (contributes to } \\
\text { Indicator 16) }\end{array}$ \\
\hline & $\begin{array}{l}\text { CONFLICT CONTAINMENT \& } \\
\text { ACCOMMODATION }\end{array}$ & $\begin{array}{l}\text { People speak out about differences and work together/find ways to solve differences (contributes } \\
\text { to Indicators } I I, 16 \text { ) }\end{array}$ \\
\hline & $\begin{array}{l}\text { MACHINERY FOR FACILITATING } \\
\text { PARTICIPANT INTERACTION \& } \\
\text { DECISION MAKING }\end{array}$ & $\begin{array}{l}\text { People in town try to influence what happens in this community (contributes to Indicators 7, 8) } \\
\text { People are willing to contact, e.g., phone, write a letter, to local officials (contributes to Indicator } \\
\text { 8) }\end{array}$ \\
\hline \multirow{3}{*}{$\begin{array}{l}\text { THEORY } 3 \\
\text { McMillan \& } \\
\text { Chavis }\end{array}$} & MEMBERSHIP & $\begin{array}{l}\text { Participation in churches or local organisations (e.g., PTA, youth groups, business/civic groups) } \\
\text { (contributes to Indicator 5) } \\
\text { Have a sense of civic duty (contributes to Indicators } 5,6,14,16 \text { ) } \\
\text { Desire for organisational participation (contributes to Indicators 5, 6, 9) } \\
\text { Feel that you belong/at home in community (contributes to Indicator 15) }\end{array}$ \\
\hline & INFLUENCE & $\begin{array}{l}\text { Involvement in political clubs/organisations or issue/action-orientated groups (contributes to } \\
\text { Indicators } 5,7, \mathrm{II} \text { ) } \\
\text { Feel that I am an important part of this community (contributes to Indicator I5) } \\
\text { Care about what my neighbours think of my actions (contributes to Indicator I2) }\end{array}$ \\
\hline & $\begin{array}{l}\text { SHARING OF VALUES \& } \\
\text { FULFILMENT OF NEEDS }\end{array}$ & $\begin{array}{l}\text { Perceptions of community's ability to solve problems, e.g., if there is a problem the community can } \\
\text { solve it (contributes to Indicators } 9,11 \text { ) } \\
\text { Have influence on improving what this community is like (contributes to Indicators } 7,9 \text { ) }\end{array}$ \\
\hline
\end{tabular}

Active Citizenship table continued on next page... 


\begin{tabular}{|c|c|c|}
\hline & $\begin{array}{c}\text { Dimensions from five } \\
\text { theories }\end{array}$ & Indicators from five theories \\
\hline $\begin{array}{l}\text { THEORY } 4 \\
\text { Wills }\end{array}$ & $\begin{array}{l}\text { ACTIVE CITIZENSHIP } \\
\text { SOCIAL JUSTICE } \\
\text { SOCIAL CAPITAL } \\
\text { CULTURAL VALUES }\end{array}$ & $\begin{array}{l}\text { Political, civil \& civic participation (contributes to Indicator 5) } \\
\text { Social supports (contributes to Indicator 9) } \\
\text { Empowerment (contributes to Indicator 16) } \\
\text { Reciprocity (contributes to Indicator 14) } \\
\text { Collective action (contributes to Indicator 9) } \\
\text { (contributes to Indicators 5,6) }\end{array}$ \\
\hline \multirow[t]{2}{*}{$\begin{array}{c}\text { THEORY } 5 \\
\text { Pyke, et al }\end{array}$} & SOCIAL & Volunteer rate (regular and occasional) (contributes to Indicator 10) \\
\hline & $\begin{array}{l}\text { Theory indicators } \\
\text { summarised into Case } \\
\text { Study indicators } \\
\square\end{array}$ & $\begin{array}{c}\text { Theory Indicators summarised into } \\
\text { Case Study Indicators } \\
\mathbb{Z}\end{array}$ \\
\hline $\begin{array}{l}\text { CASE } \\
\text { STUDY } \\
\text { FRAME } \\
\text { WORK }\end{array}$ & $\begin{array}{l}\text { ACTIVE CITIZENSHIP } \\
\text { Political, civil and civic } \\
\text { participation \& } \\
\text { commitment } \\
\text { Collective action }\end{array}$ & $\begin{array}{l}\text { Indicator 5. Participation in social, political and community organizations } \\
\text { Indicator 6. Participation in sporting and recreation activities } \\
\text { Indicator 7. People feel they have an active role in making community function } \\
\text { Indicator } 8 \text {. People are willing to contact e.g. phone, write a letter to local officials } \\
\text { Indicator } 9 \text {. Percentage of people believe its important to work together rather than } \\
\text { alone to improve the conditions of the area } \\
\text { Indicator 10. Percentage of people volunteering (regular and occasionally) } \\
\text { Indicator II. People speak out about differences and work together to find ways to } \\
\text { solve differences } \\
\text { Indicator 12. Care about what my neighbours think of my actions } \\
\text { Indicator 13. People engage in favours, e.g. Lending of goods } \\
\text { Indicator 14. People feel that what happens in community can } \\
\text { affect them } \\
\text { Indicator 15. Feel that I am an important part of this community } \\
\text { Indicator } 16 . \text { People are willing to stand before an outside group and state } \\
\text { community needs } \\
\text { Indicator } 17 \text {. Sense of optimism about the future of the community }\end{array}$ \\
\hline
\end{tabular}




\section{Social Capital}

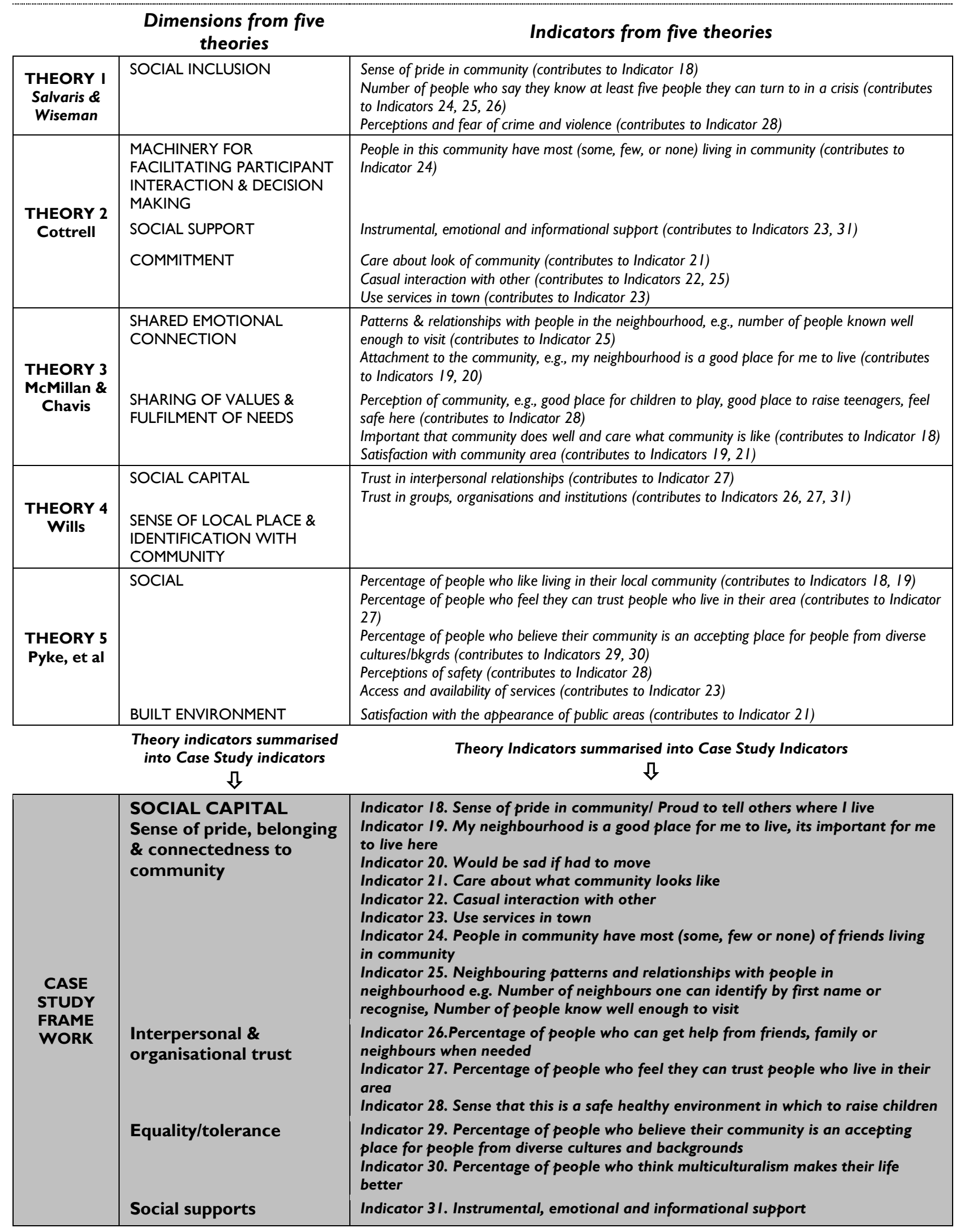


Table 6: Case study summary findings (condensed version)

\begin{tabular}{|c|c|}
\hline Participatory process & Community wellbeing enhancements \\
\hline $\begin{array}{l}\text { COMMUNITY-LED } \\
\text { SUPPORT }\end{array}$ & $\begin{array}{l}\text { Personal awareness and development } \\
\text { Group social response skills }\end{array}$ \\
\hline SOCIAL ANALYSIS & $\begin{array}{l}\text { Socio-political awareness } \\
\text { Empowerment } \\
\text { Self-determination }\end{array}$ \\
\hline CELEBRATE & Pride \& collective momentum \\
\hline $\begin{array}{l}\text { VISIONING \& } \\
\text { DECISION MAKING }\end{array}$ & $\begin{array}{l}\text { Collective visioning } \\
\text { Group co-operation } \\
\text { Contributive capacity for decisions } \\
\text { Trust in process \& facilitators } \\
\text { Relationship building \& cultural tolerance } \\
\text { Pride in community and area }\end{array}$ \\
\hline COLLABORATE & $\begin{array}{l}\text { Teamwork and role-taking } \\
\text { Relational trust \& mutual benefits } \\
\text { Commitment \& sustainability to improve community's } \\
\text { circumstances }\end{array}$ \\
\hline PARTNER & $\begin{array}{l}\text { Wider community networks, support and partnerships } \\
\text { Representation and public communication skills } \\
\text { Advocacy \& responsibility }\end{array}$ \\
\hline IMPLEMENT & $\begin{array}{l}\text { Positive relationships \& community perceptions } \\
\text { Collaborative capacity \& reciprocity } \\
\text { Altruism \& tolerance }\end{array}$ \\
\hline $\begin{array}{l}\text { CONTINUE } \\
\text { INVOLVEMENT }\end{array}$ & $\begin{array}{l}\text { Stimulates \& supports entrepreneurship } \\
\text { Developed long term sustainability strategies }\end{array}$ \\
\hline
\end{tabular}




\section{Community Place-making: Participatory Transformations of low income communities in Aotearoa/New Zealand}

\section{INTERVIEW QUESTIONS}

Interviewer: Andrea Ricketts

Interviewee: Dave Tims

Position \& Organisation: Youth For Christ Gisborne

Project: Alfred Cox Skatepark

Project Location: Gisborne

I am interested in the project you were involved in because I think it demonstrates that public participation in decisions about community places is successful in enhancing the community's well being.

\section{PERSONAL ROLE DESCRIPTION}

I. What was your role in this project?

2. How were you engaged in the project?

3. What personal skills and experience did you bring to the project?

\section{BEFORE THE PROJECT WAS THOUGHT OF}

\section{Context \& Situation of the community:}

4. How would you summarise the positive characteristics of the community before the project?

5. How would you summarise the negative characteristics of the community before the project?

\section{AT THE START OF THE PROJECT}

6. Who or what groups initiated the idea for the project?

7. What needs of the community was this project aiming to respond to?

8. Was there any influence for the idea from other similar projects?

9. What outcome was the project trying to reach?

\section{DURING THE PROJECT}

10. Please describe the process of the different stages of the project chronologically. (e.g., collective formed, public meetings, fundraising, local government \& consultant meetings, design, construction, etc)

II. What people and/or groups were involved in the process? (end users, community members, schools/students, consultants, trust members, local government, Iwi, NGO's, social services, construction contractors, community development workers)

12. What groups were involved in the project the whole way through (e.g., who were the groups that held the main responsibility?)

13. What influence did they have on decision making?

14. Did their influence help the process and how?

15. How do you think these groups benefited from the process?

16. Do you think participation from these groups was essential for achieving the goals that were set? 


\section{AFTER THE PROJECT}

Reflecting on and assessing the outcomes of the process

17. Did the project achieve the goals that were set?

18. To what extent did the participatory process contribute to achieving the goal of the project?

19. Do you think this participatory process has made a difference to community well being?

Future recommendations

20. If you had a chance to re-look at the project, what would you do to make the (a) process better and (b) the project better?

21 . For others doing similar projects, what would be the key things to include?

\section{DOCUMENTATION OF EACH STAGE OF THE PROJECT}

Before the project:

- Do you have documentation that outlines the goals at this period of the project?

- Do you have any documentation that describes this stage of the project? e.g., photos of existing conditions (conditions of street, park and surrounding areas, etc)

At the start of the Project:

- Do you have documentation that outlines the goals at this period of the project?

During the Project:

- Do you have any documentation that describes this stage of the project? e.g., photos of the development of the public space

After the Project:

- Do you have documentation that was produced at this period of the project? Photos of finished developments, etc. 


\section{Form 2: Survey form examples}

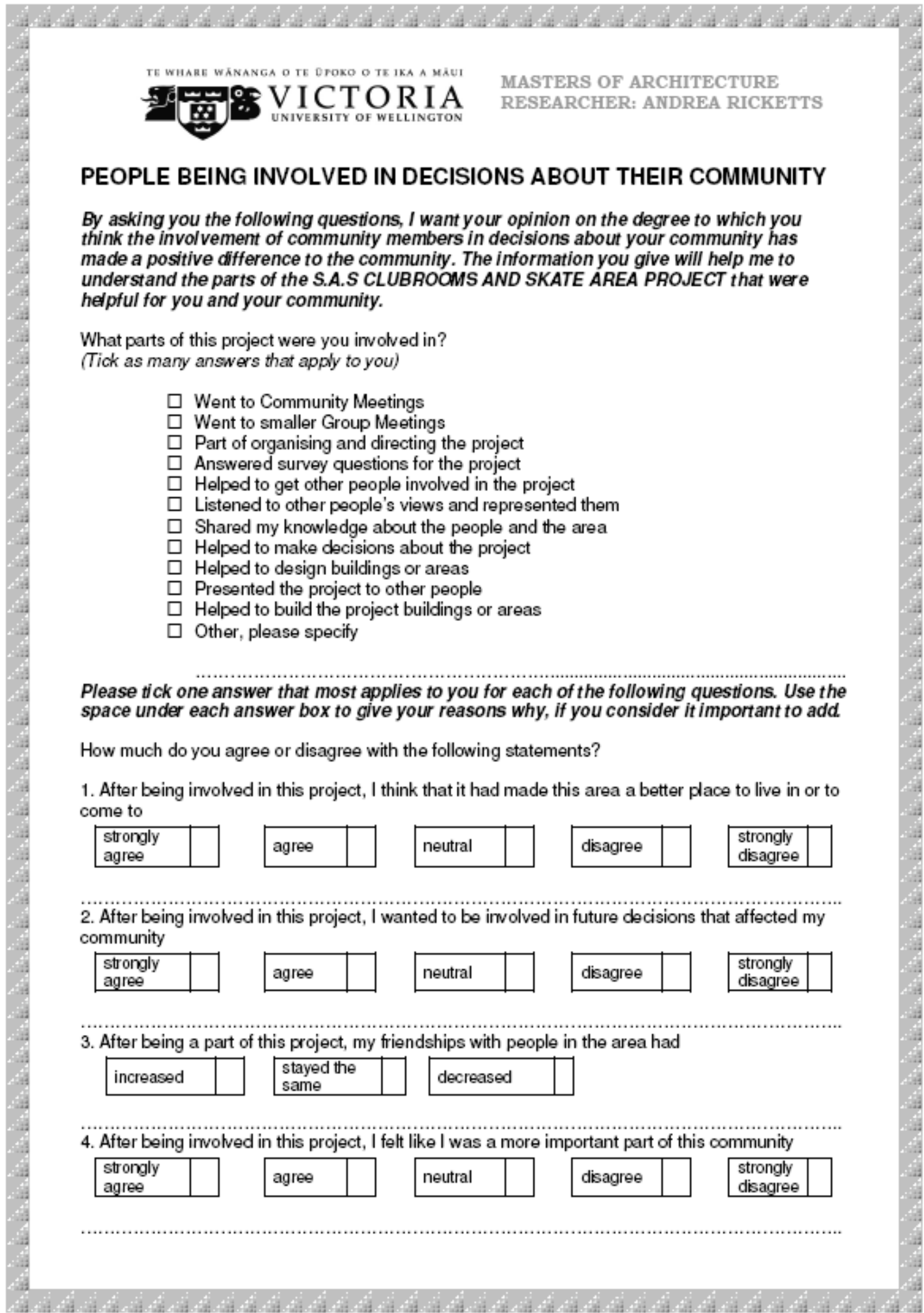


5. After being irvolved in this project, it had helped our community to work together to find ways to solve our problems

\begin{tabular}{|l|l|l|l|l|l|l|l|l|l|l|l|l|l|l|}
\hline $\begin{array}{l}\text { strongly } \\
\text { agree }\end{array}$ & agree & disagree & $\begin{array}{l}\text { strongly } \\
\text { disagree }\end{array}$ & \\
\hline
\end{tabular}

6. After being a part of this project, I felt more positive about the future of my community

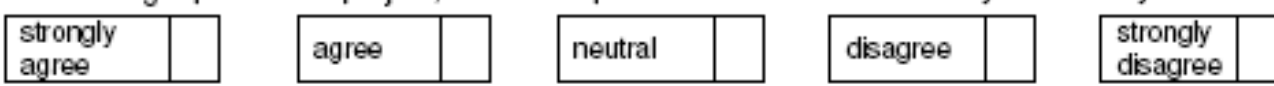

7. After being a part of this project, my imvolvement in local community groups and activities had

\begin{tabular}{|c|c|c|}
\hline increased & $\begin{array}{l}\text { stayed the } \\
\text { same }\end{array}$ & decreased \\
\hline
\end{tabular}

8. After being irvolved in this project, I wanted to volunteer more of my spare time to my community

\begin{tabular}{|l|l|l|l|l|l|l|l|l|l|l|l|l|l|l|l|}
\hline $\begin{array}{l}\text { strongly } \\
\text { agree }\end{array}$ & disagree & $\begin{array}{l}\text { strongly } \\
\text { disagree }\end{array}$ & \\
\hline
\end{tabular}

9. After being a part of this project, I felt more proud of my community

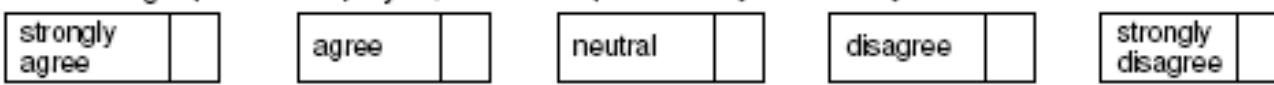

10. How important was it to you that people in your community worked together rather than alone to improve the conditions of the area?

\begin{tabular}{|c|c|c|c|}
\hline $\begin{array}{l}\text { very } \\
\text { important }\end{array}$ & $\begin{array}{l}\text { slightly } \\
\text { important }\end{array}$ & undecided & not important \\
\hline
\end{tabular}

11. After the community was involved in this project it had helped to make this area safer for people to be in

\begin{tabular}{|l|l|}
\hline $\begin{array}{l}\text { strongly } \\
\text { agree }\end{array}$ & \\
\hline
\end{tabular}
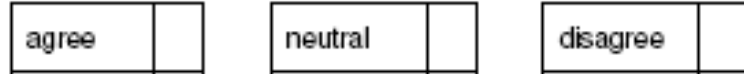

strongly disagree

12. After being a part of this project, I cared more about what the community/area looked like

\begin{tabular}{|c|c|c|c|c|}
\hline $\begin{array}{l}\text { strongly } \\
\text { agree }\end{array}$ & agree & neutral & disagree & \begin{tabular}{|l|} 
strongly \\
disagree
\end{tabular} \\
\hline
\end{tabular}

13. After being a part of this project, I cared more about what people in my community thought of my actions

\begin{tabular}{|c|c|c|c|c|}
\hline $\begin{array}{l}\text { strongly } \\
\text { agree }\end{array}$ & agree & neutral & disagree & $\begin{array}{l}\text { strongly } \\
\text { disagree }\end{array}$ \\
\hline
\end{tabular}


14. After being irvolved in this project, I felt I could benefit more from what happened in my community

\begin{tabular}{|c|c|c|c|c|}
\hline $\begin{array}{l}\text { strongly } \\
\text { agree }\end{array}$ & agree & neutral & disagree & $\begin{array}{l}\text { strongly } \\
\text { disagree }\end{array}$ \\
\hline
\end{tabular}

15. After being involved in this project, my trust in the community leaders that were a part of the project had

\begin{tabular}{|l|l|}
\hline increased &
\end{tabular}

\begin{tabular}{|l|l|}
\hline $\begin{array}{l}\text { stayed the } \\
\text { same }\end{array}$ & \\
\hline
\end{tabular}

decreased

16. After being a part of this project, my willingness to ask for what our community needs from local officials (like council) had

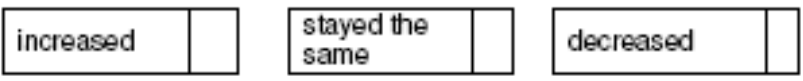

17. After being irvolved in this project, I knew more people that I could trust to help me if I was in a crisis situation

\begin{tabular}{|l|l|}
\hline $\begin{array}{l}\text { strongly } \\
\text { agree }\end{array}$ & \\
\hline
\end{tabular}

\begin{tabular}{|l|l|}
\hline agree & \\
\hline
\end{tabular}
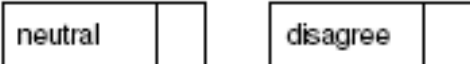

strongly disagree

18. After being involved in this project, I had more interest in decisions that were being made by the local council and govemment

\begin{tabular}{|l|l|l|l|l|l|l|l|l|l|l|l|}
\hline \begin{tabular}{|l|l|}
\hline strongly \\
agree
\end{tabular} & agree & $\begin{array}{l}\text { strongly } \\
\text { disagree }\end{array}$ & \\
\hline
\end{tabular}

19. After the community was involved in this project, I think that this place was more accepting of people from different cultures and backgrounds

\begin{tabular}{|c|c|c|c|c|}
\hline $\begin{array}{l}\text { strongly } \\
\text { agree }\end{array}$ & agree & neutral & disagree & $\begin{array}{l}\text { strongly } \\
\text { disagree }\end{array}$ \\
\hline
\end{tabular}

20. After being a part of this project, the amount of times I talked to others I saw around my area had

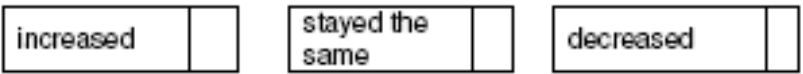

21. After being involved in this project, my knowledge of local services and facilities had

\begin{tabular}{|c|c|c|}
\hline increased & $\begin{array}{l}\text { stayed the } \\
\text { same }\end{array}$ & decreased \\
\hline
\end{tabular}

Please write any other thoughts about your involvement in this project that you would like to add, on the next page. 


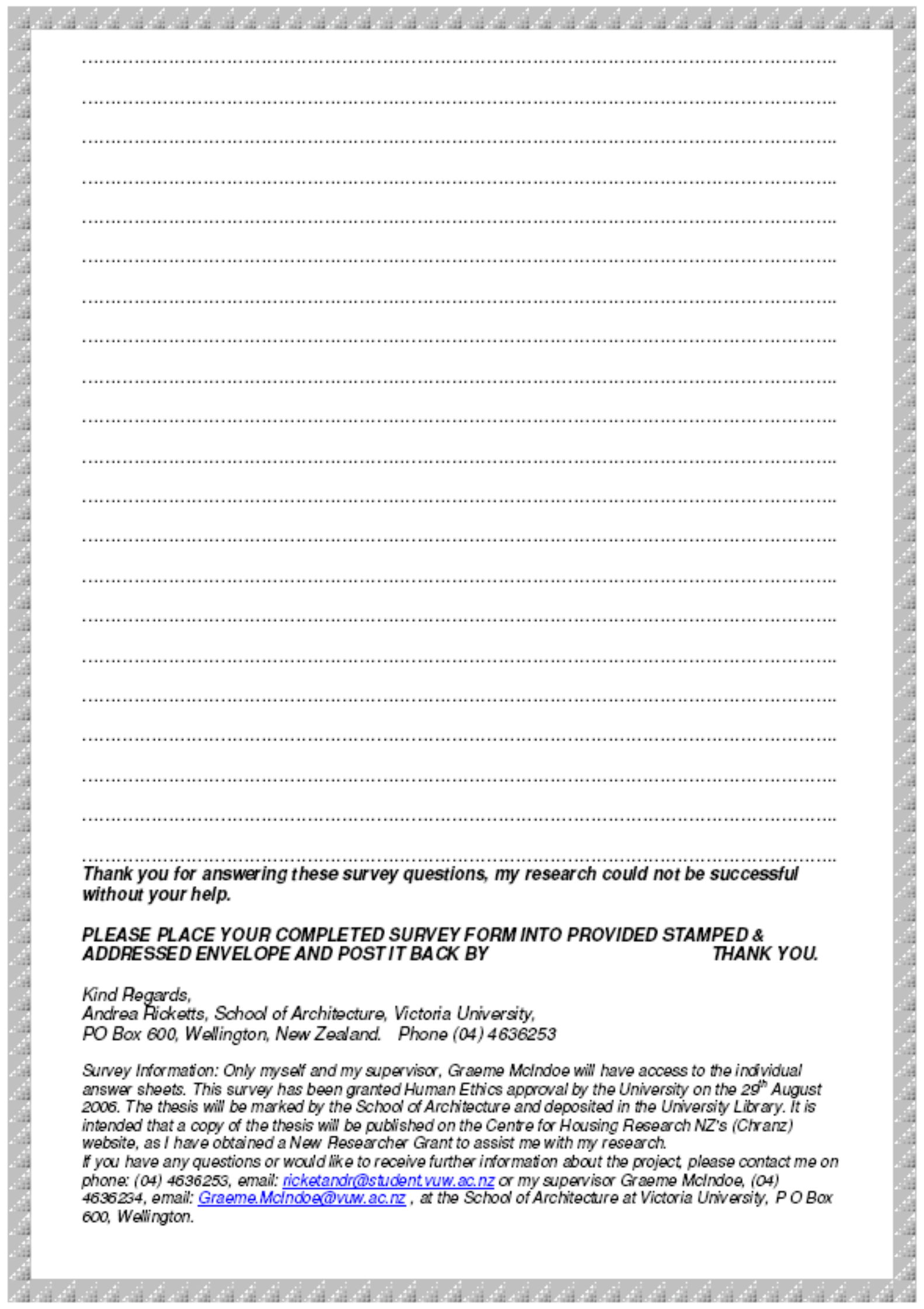




\section{Form 3: Survey information sheet}

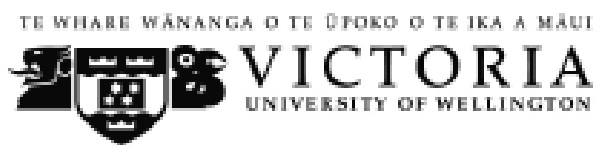

COMMUNITY DECISION MAKING SURVEY

MASTERS OF ARCHITECTURE

BY RESEARCHER: ANDREA RICKETTS

Thank you for agreeing to help me out with my research by answering the following questions about your involvement in your community project.

The topic of my research is about communities being irwolved in decisions about their environment.

The "community" and "project" that I am refering to in your case is the SETTING UP OF THE SURF AND SKATE (S.A.S) CL UBROOMS AND SKATE AREA USED BY THE SKATE COMMUNITY OF ALFRED COX SKATE PARK.

The answers you give will be anorymous and confidential, only grouped responses from all of the community participants will be included in my thesis. Please refer to the back page of the survey for further information and my contact details. Please let me know if you would like to receive a summary when it is completed.

Kind Regards, 
